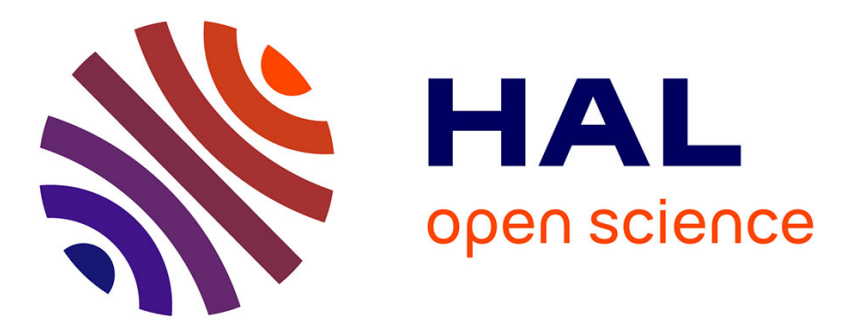

\title{
Prediction of thermodynamic properties of refrigerant fluids with a new three-parameter cubic equation of state
}

\author{
Christophe Coquelet, Céline Houriez, Jamal El Abbadi
}

\section{- To cite this version:}

Christophe Coquelet, Céline Houriez, Jamal El Abbadi. Prediction of thermodynamic properties of refrigerant fluids with a new three-parameter cubic equation of state. International Journal of Refrigeration, 2016, 69, pp.418-436. 10.1016/j.ijrefrig.2016.05.017 . hal-01344174

HAL Id: hal-01344174

https://hal-mines-paristech.archives-ouvertes.fr/hal-01344174

Submitted on 11 Jul 2016

HAL is a multi-disciplinary open access archive for the deposit and dissemination of scientific research documents, whether they are published or not. The documents may come from teaching and research institutions in France or abroad, or from public or private research centers.
L'archive ouverte pluridisciplinaire $\mathbf{H A L}$, est destinée au dépôt et à la diffusion de documents scientifiques de niveau recherche, publiés ou non, émanant des établissements d'enseignement et de recherche français ou étrangers, des laboratoires publics ou privés. 


\title{
Prediction of thermodynamic properties of refrigerant fluids with a new three- parameter cubic equation of state
}

\section{Prédiction des propriétés thermodynamiques des fluides frigorigènes avec une nouvelle équation d'état cubique à trois paramètres}

\author{
Christophe Coquelet ${ }^{1}$, Jamal El Abbadi, Céline Houriez \\ Mines ParisTech, PSL Research University, CTP - Centre Thermodynamique des Procédés, \\ 35 rue Saint Honoré, 77305 Fontainebleau Cedex, France
}

\begin{abstract}
To describe the thermodynamic properties of refrigerant fluids, it is important to use a reliable thermodynamic model able to predict accurate results for both pure compounds and mixtures. In this study, a new three-parameter cubic equation of state is presented, based on the modification of the well-known Patel-Teja equation of state. The new equation of state is associated with the Mathias-Copeman alpha function.

By only knowing the acentric factor $\omega$ and the experimental critical compressibility factor $Z_{c}$ of pure compounds, it is possible to predict thermodynamic properties for both pure compounds and mixtures by means of the new equation of state. No binary interaction parameter $\mathrm{k}_{\mathrm{ij}}$ is needed for the prediction of mixture properties.

The results obtained with the new equation of state show a good agreement with experimental data for vapor-liquid equilibrium and density properties. The obtained results are particularly satisfying for liquid density, and in the vicinity of the critical point, by comparison with the results obtained using the Peng-Robinson and the Patel-Teja equations of state.
\end{abstract}

Keywords: Equation of state, density, vapor-liquid equilibrium, refrigerant fluids, fluorinated compounds

Mots clés: Equation d'état, densités, équilibre liquide-vapeur, fluides réfrigérants, composés fluorés

\footnotetext{
1 Corresponding author. Email address: christophe.coquelet@mines-paristech.fr; Tel.: +33164694962 / +33164694963; Fax: +33164694968
} 
a

ARD

b

EoS

CEoS

$\mathrm{F}_{\text {obj }}$

$\mathrm{k}_{\mathrm{ij}}$

$\mathrm{m}_{\mathrm{n}}$

NEoS

$\mathrm{MC}$

$\mathrm{P}$

PR

PT

SRK

$\mathrm{R}$

$\mathrm{T}$

V

$\mathrm{X}$

y

Z

HFCs

HFOs

$\mathrm{HCFO}$

GWP

\section{Greek letters}

$\omega$

$\alpha$

$\Omega_{\mathrm{a}}, \Omega_{\mathrm{b}}, \Omega_{\mathrm{c}}$

$\rho$

\section{Subscripts}

\section{c}

cal
Cohesive energy parameter $\left(\mathrm{J} \mathrm{m}^{3} \mathrm{~mol}^{-2}\right)$

Average relative deviation

Covolume parameter $\left(\mathrm{m}^{3} \mathrm{~mol}^{-1}\right)$

Equation of state

Cubic equation of state

Objective function

Binary interaction parameter

Alpha function parameter

Our new equation of state

Mathias-Copeman

Pressure $(\mathrm{MPa}) / 1 \mathrm{MPa}=10^{6} \mathrm{~Pa}$

Peng-Robinson

Patel-Teja

Soave-Redlich-Kwong

Gas constant $\left(\mathrm{J} \mathrm{mol}^{-1} \mathrm{~K}^{-1}\right)$

Temperature (K)

Molar volume $\left(\mathrm{m}^{3} \mathrm{~mol}^{-1}\right)$

Liquid mole fraction

Vapor mole fraction

Compressibility factor

Hydrofluorocarbons

Hydrofluoroolefins

Hydrochlorofluoroolefins

Global warming potential

Acentric factor

Alpha function

Substance depending factors

Molar density ( $\mathrm{mol} \mathrm{m}^{-3}$ )

Critical property

Calculated property 


$\begin{array}{ll}\exp & \text { Experimental property } \\ \mathrm{i}, \mathrm{j} & \text { Molecular species } \\ \text { opt } & \text { Optimized property } \\ \mathrm{r} & \text { Reduced property }\end{array}$

\section{Superscripts}

V

$\mathrm{L}$
Vapor phase

Liquid phase

\section{Introduction}

For several years, new-generation refrigerants are proposed, in order to reduce the overall emission of greenhouse gases (Kyoto protocol, 1997) and to respect the environmental regulations issued by the European Union (F-gas regulations) [1]. In particular, due to their low global warming potential (GWP), hydrofluoroolefins (HFOs), such as the R-1234yf (2,3,3,3-tetrafluoropropene) and the R-1234ze (trans-1,3,3,3-tetrafluoropropene), arouse interest and have been proposed as replacements for some previous-generation fluids such as the 1,1,1,2-tetrafluoroethane (R-134a) [2]. However, the use of pure component fluid may not be suitable for some refrigeration applications, due to performance and safety concerns. Thus, blends of refrigerants are often considered, including for instance a HFO, a hydrofluorocarbon (HFC), and $\mathrm{CO}_{2}$, such as the R-445A blend.

The detailed knowledge of the thermodynamic properties of refrigerants, and particularly of their vapor-liquid equilibrium (VLE) behavior, is essential to design and optimize thermodynamic systems involving refrigerants, from the production and separation units to the refrigerant-based systems (such as air-conditioning systems, organic Rankine cycles, heat pumps etc.). In the field of refrigeration, there is a strong need for thermodynamic data of fluids, either to retrofit existing equipments with alternative refrigerants or to replace these equipments. In particular, when developing an alternative refrigerant, the list of possible mixtures is very large, and to obtain detailed experimental data for all the promising candidates can become rapidly time-consuming and expensive.

As a complement to experiment, equations of state (EOSs) are one of the most convenient tools to correlate, extrapolate and predict thermodynamic properties and phase behavior for pure fluids and mixtures. For instance, they can be very useful to screen possible fluid candidates for their suitability in a particular application. Since van der Waals introduced his famous EoS in 1873 [3], cubic EoSs (CEoSs) have been subject to active research and improvements, and were widely used in industrial process design and optimization, due to their accuracy, generality, simplicity and speed of computation [4], [5].

The Soave-Redlich-Kwong (SRK) and Peng-Robinson (PR) equations are among the most popular cubic EoSs and are used for many applications, in which thermodynamic and VLE properties are required.

Concerning the vapor pressures, the capacity of prediction of the cubic EoSs is related to the model chosen for the temperature-dependent alpha function, while the prediction of volumetric properties depends on the volume function [5]-[8]. For instance, in the PR-EoS, 
the modification of the volume dependency of attractive term represents an improvement upon SRK-EoS, and allows one to obtain better results for liquid densities and better representation of VLE for many mixtures [5], [6], [9].

One of the drawbacks of the two-parameter cubic EoSs is that they involve a critical compressibility factor $\mathrm{Z}_{\mathrm{c}}$ whose value is constant, regardless of the substance, providing saturated liquid densities and critical densities different from the experimental ones [7], [10].

A popular approach to improve molar volumes (and by consequence densities) is the volume translation method, introduced by Péneloux et al. [11]. Details concerning application of a Péneloux-type volume translation to an EoS can be find in a recent paper by Jaubert et al. [12] who discussed the effects of using such a volume translation on the different calculated thermodynamic properties,.

Another approach consists in developing van der Waals-type EoSs with three or more parameters, properly adjusted to correlate simultaneously the saturated densities and the vapor pressure of pure components [13].

In this work, we follow this latter approach, by using a substance-dependent critical parameter instead of a fixed value of $Z_{c}$ [14], to improve saturated liquid densities and critical densities. By doing so, we obtain a three-parameter equation of state. Note that it has been shown that the optimal value of the critical compressibility factor is generally different from the experimental one [14], [15].

One of the well-known three-parameter equation of state is the Patel-Teja (PT) EoS and its generalized form [16], [17], which has been successfully applied to correlate mixture VLE data [18].

The three-parameter cubic EoS proposed in this work (denoted by NEoS), which is a modification of the PT-EoS, is based on the use of an optimized substance-dependent critical compressibility factor, yielding better representation of liquid densities. The NEoS is associated with the Mathias-Copeman alpha function.

By applying the NEoS to pure compound refrigerants, we were able to develop correlations relating the alpha function parameters to the acentric factor, and the optimized critical compressibility factor to the experimental one. As a result, the NEoS can be used for a wide range of refrigerants for which no experimental data are available. Furthermore, in this work, we show that by only calculating for pure compounds the alpha function parameters and the optimized critical compressibility factor, from the correlations developed, we can extend the prediction to mixtures. This has been done without need of VLE experimental data, and with no adjustment of the binary interaction parameter $\mathrm{k}_{\mathrm{ij}}$ (as we worked with $\mathrm{k}_{\mathrm{ij}}=0$ ).

In this study, we present the results of prediction obtained with the NEoS for the pure compounds R-1234yf, R-1216 (hexafluoropropylene), $\mathrm{CO}_{2}$, and R-134a, for the binary mixtures R-421A (pentafluoroethane R-125 + R-134a), and R-508A (trifluoromethane R-23 + hexafluoroethane R-116), and for the ternary mixture R-404A (R-125 + 1,1,1-trifluoroethane $\mathrm{R}-143 \mathrm{a}+\mathrm{R}-134 \mathrm{a})$. The NEoS results are compared to those obtained using the PT and the PR EoSs.

\section{Model}

\subsection{Description of the NEoS}

In order to predict accurately the thermodynamic properties of refrigerants (both pure compounds and mixtures), a new EoS (denoted by NEoS) was developed, based on the modification of the well-known PT-EoS [16].

The NEoS is a three-parameter cubic EoS and is defined by the following relation: 


$$
P=\frac{R T}{v-b}-\frac{a(T)}{v^{2}+u b v+w b^{2}}
$$

where $\mathrm{P}$ is the pressure, $\mathrm{T}$ the temperature, $\mathrm{v}$ the volume, and $\mathrm{R}$ the universal constant for ideal gases. $b$ is the volumetric parameter and $a(T)$ the cohesive energy parameter.

$\mathrm{u}$ and $\mathrm{w}$ are two parameters defined in order to have: $\mathrm{u}+\mathrm{w}=0$, which was shown to be the optimal combination for liquid density calculations by cubic EoSs [10] - other authors such as Segura et al. [13] work on similar approaches, by the parameterization of $u$ and $w$, without fixing a relation between them.

Here, $\mathrm{u}$ and $\mathrm{w}$ are defined as follows:

$$
\begin{gathered}
u=1+\frac{c}{b} \\
w=-u
\end{gathered}
$$

While the PT-EoS [10], [16], [19] and the NEoS have the same definition for $\mathrm{u}$, a different definition for $\mathrm{w}$ is chosen in the NEoS in order to fulfil the conditions defined by $\mathrm{Ji}$ and Lempe [10], i.e. $\mathrm{u}+\mathrm{w}=0$ (note that in the case of the PT-EoS, $\mathrm{u}+\mathrm{w}=1$ ).

The cohesive energy parameter $\mathrm{a}(\mathrm{T})$ depends on the temperature and is defined as follows:

$$
a(T)=a_{c} \alpha(T)
$$

$\alpha(T)$ is the alpha function that will be defined below, and which depends on both the temperature and the substance.

The parameters $a_{c}, b$ and $c$ of Eq. (1)-(3) can conventionally be obtained from the thermodynamic conditions at the critical point, defined as follows:

$$
\left(\frac{\partial P}{\partial v}\right)_{T_{c}}=\left(\frac{\partial^{2} P}{\partial^{2} v}\right)_{T_{c}}=0
$$

Or from the mathematical constraint:

$$
\left(v-v_{c}\right)^{3}=v^{3}-3 v_{c} v^{2}+3 v_{c}^{2} v-v_{c}^{3}=0
$$

where $\mathrm{v}_{\mathrm{c}}$ is the optimized critical volume.

After rewriting Eq. (1), we obtain:

$$
v^{3}-\left[\frac{R T}{P}-(u-1) b\right] v^{2}+\left[\frac{R T}{P} u b-(w-u) b^{2}-\frac{a}{P}\right] v-\frac{R T}{P} w b^{2}+w b^{3}+\frac{a b}{P}=0
$$

The parameters $\mathrm{a}_{\mathrm{c}}, \mathrm{b}$ and $\mathrm{c}$ are calculated according to the relations: 


$$
\begin{aligned}
a_{c} & =\Omega_{a} \frac{R^{2} T_{c}{ }^{2}}{P_{c}} \\
b & =\Omega_{b} \frac{R T_{c}}{P_{c}} \\
c & =\Omega_{c} \frac{R T_{c}}{P_{c}}
\end{aligned}
$$

where $\Omega_{\mathrm{a}}, \Omega_{\mathrm{b}}$ and $\Omega_{\mathrm{c}}$ are factors depending on the substance [19], $\mathrm{T}_{\mathrm{c}}$ and $\mathrm{P}_{\mathrm{c}}$ are respectively the experimental critical temperature and pressure.

We set $\mathrm{T}=\mathrm{T}_{\mathrm{c}}$ and $\mathrm{P}=\mathrm{P}_{\mathrm{c}}$ in Eq. (6), then the comparison with Eq. (5) results in:

$$
\begin{gathered}
\Omega_{a}=1-3 Z_{C, o p t}\left(1-Z_{c, o p t}\right)+3\left(1-2 Z_{c, o p t}\right) \Omega_{b}+[2-(u+w)] \Omega_{b}{ }^{2} \\
\Omega_{b}{ }^{3}+\left[\left(1-3 Z_{c, o p t}\right)+(u+w)\right] \Omega_{b}{ }^{2}+3 Z_{c, o p t}^{2} \Omega_{b}-Z_{c, o p t}^{3}=0 \\
\Omega_{c}=1-3 Z_{c, o p t}
\end{gathered}
$$

$\mathrm{Z}_{\mathrm{c}, \text { opt }}$ is an apparent optimized critical compressibility factor. It is different from the experimental critical compressibility factor $Z_{c}$, and adjusted from the experimental VLE data [10], [20], in order to improve the prediction of liquid densities.

Here, as $u+w=0$, we can simplify Eq. (6) to obtain:

$$
\begin{gathered}
\Omega_{a}=1-3 Z_{C, \text { opt }}\left(1-Z_{c, \text { opt }}\right)+3\left(1-2 \mathrm{Z}_{\mathrm{c}, \mathrm{opt}}\right) \Omega_{b}+2 \Omega_{b}{ }^{2} \\
\Omega_{b}{ }^{3}+\left(1-3 Z_{c, \text { opt }}\right) \Omega_{b}{ }^{2}+3 Z_{c, \text { opt }}^{2} \Omega_{b}-Z_{c, \text { opt }}^{3}=0
\end{gathered}
$$

By including the critical compressibility factor in the calculations, better results can be obtained, even though the apparent critical compressibility factor $Z_{c, o p t}$ is larger than the experimental one, $\mathrm{Z}_{\mathrm{c}}$.

\subsection{Mathias-Copeman alpha function}

The NEoS is associated with the Mathias-Copeman (MC) alpha function [21], which is defined as follows: 


$$
\begin{gathered}
\alpha(T)=\left[1+m_{1}\left(1-\sqrt{\frac{T}{T_{c}}}\right)+m_{2}\left(1-\sqrt{\frac{T}{T_{c}}}\right)^{2}+m_{3}\left(1-\sqrt{\frac{T}{T_{c}}}\right)^{3}\right]^{2} ; \quad \text { if } T<T_{c} \\
\alpha(T)=\left[1+\mathrm{m}_{1}\left(1-\sqrt{\frac{T}{T_{c}}}\right)\right]^{2} ; \quad \text { if } T>T_{c}
\end{gathered}
$$

\subsection{Parameters adjustment}

To manage and treat the experimental data, we used an in-house software, allowing the adjustment and the calculations of the thermodynamic properties for pure components.

In order to predict the thermodynamic properties for different fluids, the parameters of the alpha function, $\mathrm{m}_{1}, \mathrm{~m}_{2}$, and $\mathrm{m}_{3}$, and the optimized critical compressibility factor $\mathrm{Z}_{\mathrm{c} \text {,opt }}$ were adjusted from data of 34 pure compounds obtained by using REFPROP 9.0 [22].

For the calculations, we used a modified simplex algorithm. The objective function (in the case of NEoS and PT-EoS) contains vapor pressures and liquid densities and is defined as follows:

$$
F_{o b j}=\frac{100}{N}\left[\sum_{1}^{N}\left(\frac{P_{e x p}-P_{c a l}}{P_{e x p}}\right)^{2}+\sum_{1}^{N}\left(\frac{\rho_{\text {exp }}^{L}-\rho_{c a l}^{L}}{\rho_{\text {exp }}^{L}}\right)^{2}\right]
$$

In the case of the PR-EoS, the objective function contains vapor pressures and is as follows:

$$
F_{o b j}=\frac{100}{N}\left[\sum_{1}^{N}\left(\frac{P_{e x p}-P_{c a l}}{P_{e x p}}\right)^{2}\right]
$$

$\mathrm{N}$ is the number of data points, $\mathrm{P}_{\text {exp }}$ is the experimental vapor pressure, $\mathrm{P}_{\text {cal }}$ the calculated vapor pressure, $\rho_{\text {exp }}^{\mathrm{L}}$ the experimental saturated liquid density and $\rho^{\mathrm{L}}$ cal the calculated saturated liquid density.

To estimate the parameters, we need the values of the critical pressure $P_{c}$, the critical temperature $T_{c}$, the experimental critical compressibility factor $Z_{c}$ (in the case of PR-EoS, $Z_{c}$ is fixed at 0.3074), and the acentric factor $\omega$. We need also the data of the vapor pressures $\mathrm{P}^{\text {sat }}$, as well as the saturated liquid densities $\rho^{\mathrm{L}}$ for different temperatures (for the NEoS and PTEoS; for PR-EoS, only the data of vapor pressures are required).

In this work, the temperatures range from the triple point temperature to the critical temperature $\left(\mathrm{T}_{\mathrm{c}}\right)$, with a step of $1 \mathrm{~K}$.

For the NEoS, PT-EoS, and PR-EoS, we estimate the alpha function parameter $\mathrm{m}_{1}$, while the parameters $m_{2}$ and $m_{3}$ were set to constant values. For the NEoS and PT-EoS, the optimized critical compressibility factor $Z_{c, \text { opt }}$ is also estimated, while the $Z_{c}$ value is 0.3074 for the PREoS. 
For the three CEoSs, we carried out the parameter determination by associating each EoS with the $\mathrm{MC}$ alpha function, leading to three different sets of parameters. Here, only the estimated parameters for the NEoS with the MC alpha function are presented (Cf. Table 1) and the parameters for both PT-EoS and PR-EoS are provided in Appendices A and B, respectively.

Based on these adjusted parameters, we established a correlation between the alpha function parameter $\mathrm{m}_{1}$ and the acentric factor $\omega$, as well as a correlation between the optimized critical compressibility factor $\mathrm{Z}_{\mathrm{c} \text {,opt }}$ and the experimental one $\mathrm{Z}_{\mathrm{c}}$.

In this way, we can calculate the alpha parameters and the optimized critical compressibility factor for other compounds, whose thermodynamic properties are not known experimentally, allowing us to predict their thermodynamic properties.

The correlations obtained with the NEoS are shown in Fig. 1 and given in Eq. (11).

From the graphical representations, we can see a correlation between the alpha function parameter $\mathrm{m}_{1}$ and the acentric factor $\omega$, and between the optimized critical compressibility factor $Z_{c, \text { opt }}$ and the experimental one $Z_{c}$. Based on our calculations, the parameters $m_{2}$ and $m_{3}$ are taken as constants.

$$
\begin{gathered}
m_{1}=2.7868 \omega^{2}-0.2376 \omega+0.3007 \\
m_{2}=0.47 \\
m_{3}=-0.08 \\
\mathrm{Z}_{\mathrm{c}, \mathrm{opt}}=-7.4737 \mathrm{Z}_{c}{ }^{2}+4.8824 \mathrm{Z}_{c}-0.4900
\end{gathered}
$$

The same work has been carried out for the other EoSs considered here, PT-EoS and PR-EoS, and the correlations developed for these EoSs are provided in Appendices A and B, respectively.

\section{Results and discussions}

\subsection{Pure compounds}

Based on the correlations developed, and using the parameters calculated from it, we predicted the thermodynamic properties of four pure compound refrigerant fluids: R-1234yf, $\mathrm{R}-1216, \mathrm{CO}_{2}$ and R-134a.

The results of the prediction were compared to the results obtained from REFPROP 9.0. The $\mathrm{P}-\rho$ diagram has been predicted at saturation and out of saturation.

\subsubsection{R-1234yf: Prediction at saturation}

The prediction at saturation was performed using the three EoSs, and were compared to the results from REFPROP 9.0, as well as to experimental data [23], [24]. The results were calculated from the triple point temperature to the critical temperature.

The parameters of the MC alpha functions and the critical compressibility factors were calculated from the correlations given in Eq. (11) (for the PR-EoS, the value of $Z_{c}$ is set to 0.30740). The values obtained for these parameters are reported in Table 2.

The graphical representation of the P- $\rho$ diagram at saturation is shown in Fig. 2. 
Based on the results of the prediction, we calculated the average relative deviation (ARD), the BIAS, and the relative deviation (RD) for each EoS considered here, compared to the results obtained from REFPROP 9.0. The ARD, the BIAS and the RD are defined by Eq. (14):

$$
\begin{gathered}
A R D(X) \%=\left|\frac{100}{N} \sum_{1}^{N} \frac{X_{\text {exp }}-X_{\text {cal }}}{X_{\text {exp }}}\right| \\
B I A S(X) \%=\frac{100}{N} \sum_{1}^{N} \frac{X_{\text {exp }}-X_{\text {cal }}}{X_{\text {exp }}} \\
R D X(\%)=100 * \frac{X_{\text {exp }}-X_{\text {cal }}}{X_{\text {exp }}}
\end{gathered}
$$

The ARD and the BIAS calculated using the parameters of the correlations are reported in Table 4.a, while the ARD and the BIAS calculated using the adjusted parameters are in Table 3.

From the results of the prediction represented in Fig. 2, we can see that the NEoS provides a better representation for the liquid density compared to PR-EoS and PT-EoS, especially at high temperature and in the vicinity of the critical point. We can also see that with the NEoS, it is possible to reproduce more accurately the location of the critical point, compared to the other two EoSs $\left[\rho_{\mathrm{c}}(\mathrm{NEoS})=3961 \mathrm{~mol} \mathrm{~m}^{-3} ; \rho_{\mathrm{c}}(\mathrm{PT}-\mathrm{EoS})=3573 \mathrm{~mol} \mathrm{~m}^{-3} ; \rho_{\mathrm{c}}(\mathrm{PR}-\mathrm{EoS})=3597\right.$ $\mathrm{mol} \mathrm{m}{ }^{-3} ; \rho_{\mathrm{c}}($ REFPROP $\left.)=4170 \mathrm{~mol} \mathrm{~m}^{-3}\right]$.

The vapor pressure and the vapor density appear to be well represented by the three EoSs, with the better results obtained with the PR-EoS for vapor density.

From Table 3, we can notice that by using the adjusted parameters instead of the parameters calculated from the correlations, the results are improved for the ARD and the BIAS.

Based on the results obtained, we represented the RD as a function of the temperature, using the NEoS (Cf. Fig. 3).

From the RD representation, we can see that the vapor pressure is overestimated at low temperature, and that the RD tends to 0 with increasing temperature.

The vapor density is overestimated at low and high temperatures and well represented at intermediate temperatures.

The liquid density is underestimated at low and high temperatures, and well represented at intermediate temperatures.

\subsubsection{R-1234yf: Prediction out of saturation}

For the prediction out of saturation (section 3.1.1), we used the same three EoSs as for the prediction at saturation. Four isotherms are considered here, for a reduced temperature $T_{r}$ of $0.7,0.9,1$, and 1.1. Note that the critical temperature of R-1234yf is $367.85 \mathrm{~K}$ [22].

The graphical representation of the P- $\rho$ diagram for the four isotherms out of saturation is shown in Fig. 2. 
From Fig. 2, we can see that the NEoS leads to better results for the liquid density than the PT-EoS and PR-EoS. Furthermore, with the NEoS it is possible to represent rather accurately the density at supercritical conditions, while the PT-EoS and PR-EoS show important deviations in this region, compared to the REFPROP results. Concerning the vapor density, it appears to be well represented by the three EoSs considered. 


\subsubsection{R-1216, $\mathrm{CO}_{2}$, and $\mathrm{R}-134 \mathrm{a}$ : Prediction at saturation}

The same study was carried out for the hexafluoropropylene (R-1216), the carbone dioxide $\left(\mathrm{CO}_{2}\right)$, and the 1,1,1,2-tetrafluoroethane (R-134a), using the three CEoSs. The results were predicted from the triple point temperature to the critical temperature (for R-1216, the results are for $\mathrm{T}_{\mathrm{r}}$ from 0.6 to 1 ).

The critical temperature of $\mathrm{R}-1216, \mathrm{CO}_{2}$, and $\mathrm{R}-134 \mathrm{a}$ are respectively $358.9 \mathrm{~K}$ [25], $304.13 \mathrm{~K}$ [22], and 374.21 K [22].

The parameters of the $\mathrm{MC}$ alpha functions and the critical compressibility factor were calculated from the correlations established. The values of these parameters are reported in Table 2.

The graphical representations of the P- $\rho$ diagram at saturation, using the three CEoSs associated with the MC alpha function, are shown in Fig. 4, 5, and 6. The results are compared to REFPROP and experimental data [25], [26].

The ARD and the BIAS were calculated for the results obtained with the EoSs, compared to the results of REFPROP 9.0 (experimental results in the case of R-1216). The values obtained for the ARD and the BIAS are reported in Table 4.a.

From Fig. 4 to 6 and Table 4.a, the same conclusions as for R-1234yf can be drawn in the case of R-1216, $\mathrm{CO}_{2}$, and R-134a. For these three compounds, the NEoS provides a better representation of the saturated liquid density in general, and especially in the critical region. The PT-EoS and PR-EoS show deviations, relative to experiment and REFPROP, in representing the saturated liquid density, particularly in the case of the R-1216.

The saturated vapor density and the vapor pressure are well represented by all the three EoSs, with better results when using PR-EoS.

\subsubsection{R-1216, $\mathrm{CO}_{2}$, and R-134a: Prediction out of saturation}

As for R-1234yf, the prediction out of saturation for $\mathrm{R}-1216, \mathrm{CO}_{2}$, and $\mathrm{R}-134 \mathrm{a}$ was performed for four isotherms, with $\mathrm{T}_{\mathrm{r}}=0.73,0.9,1$, and 1.01 in the case of $\mathrm{R}-1216, \mathrm{~T}_{\mathrm{r}}=0.8,0.9,1$, and 1.1 in the case of $\mathrm{CO}_{2}$, and $\mathrm{T}_{\mathrm{r}}=0.7,0.9,1$, and 1.1 in the case of R-134a.

The graphical representation of the P- $\rho$ diagram for the four isotherms studied out of saturation is shown in Fig. 4, 5, and 6.

From the Fig. 4 to 6 , the NEoS provides a better representation of the liquid density than the PT-EoS and PR-EoS. In addition, with the NEoS it is possible to represent accurately the density at supercritical conditions.

In the case of the R-1216, we can see that the PT-EoS and PR-EoS lead to important deviations in the prediction of the liquid density, relative to the experimental data, while the NEoS results are close to experiment.

For the $\mathrm{CO}_{2}$ and $\mathrm{R}-134 \mathrm{a}$, the representation of the liquid density at $\mathrm{T}_{\mathrm{r}}=0.9$ obtained by using the NEoS is not in very good agreement with the REFPROP results, however, the PT-EoS and PR-EoS fail also to reproduce these results.

The vapor phase is in overall well represented by the three EoSs for all the isotherms considered. 


\subsection{Mixtures}

For the mixtures, the classical van der Waals mixing and combining rules [27] have been used for the calculations:

$$
\begin{gathered}
a=\sum_{i=1}^{N} \sum_{j=1}^{N} x_{i} x_{j} a_{i j} \\
a_{i j}=\left(1-k_{i j}\right) \sqrt{a_{i} a_{j}} \quad, \quad i=1,2 \ldots . N, j=1,2 \ldots . N \\
b=\sum_{i=1}^{N} x_{i} b_{i} \\
c=\sum_{i=1}^{N} x_{i} c_{i}
\end{gathered}
$$

where $x_{i}$ is the mole fraction of the component $i, a_{i}$ is the energy parameter, and $b_{i}$ and $c_{i}$ are the covolume parameters of the component $\mathrm{i}$, and $\mathrm{k}_{\mathrm{ij}}$ is the binary interaction parameter. $\mathrm{N}$ is the number of components of the system.

\subsubsection{VLE (Vapor-liquid equilibrium) calculation}

The VLE calculation was performed for 12 different binary mixtures of refrigerants by using the NEoS, and the obtained results were compared to experiment. The experimental data used were collected from the literature [28]-[38]. The results of the calculation are shown in Fig. 7 to 18 .

For some systems, the binary interaction parameter $\mathrm{k}_{\mathrm{ij}}$ was set to 0 , and we obtained accurate results compared to the experimental ones (Fig. 9 to 12). For the systems more delicate to model, like the azeotropic ones, we noticed that with $\mathrm{k}_{\mathrm{ij}}$ set to 0 , it is not possible to represent the azeotropic behavior. An adjusted $\mathrm{k}_{\mathrm{ij}}$ parameter is thus needed in this case (Fig. 13 to 18). We can also note that for supercritical temperatures, an adjusted $\mathrm{k}_{\mathrm{ij}}$ parameter leads to more accurate results than a $\mathrm{k}_{\mathrm{ij}}$ set to 0 .

In addition, the ARD and the BIAS of the pressure and the vapor composition were calculated for the binary mixtures studied in this section. The ARD and the BIAS were calculated comparing to the experimental data collected from the literature. The results are reported in Table 4.b.

The $\mathrm{k}_{\mathrm{ij}}$ values were adjusted for each isotherm by using the NEoS. For the sake of comparison, we give also the values of $\mathrm{k}_{\mathrm{ij}}$ fitted by using the PR-EoS. The $\mathrm{k}_{\mathrm{ij}}$ values used for the azeotropic and supercritical systems studied are reported in Table C.1 (Table C.1 is provided as supplementary content).

From the Table C.1, we can note that lower $\mathrm{k}_{\mathrm{ij}}$ values are generally obtained when using the NEoS compared to the PR-EoS. These $k_{i j}$ values are represented as a function of temperature in Fig. C.1 to C.6, for the six systems for which an adjusted $\mathrm{k}_{\mathrm{ij}}$ value was used (Fig. C.1 to C.6 are provided as supplementary content). From these latter figures, we can note a correlation between $\mathrm{k}_{\mathrm{ij}}$ and the temperature, with the NEoS and PR-EoS, for the different binary systems 
considered here. For the systems whose one component has its critical temperature in the range considered (Fig. C.1 and C.2), we can see a discontinuity of the $\mathrm{k}_{\mathrm{ij}}(\mathrm{T})$ function: two correlations have thus been employed for these latter systems, depending on if we are below or above the critical temperature. For the $\mathrm{CO}_{2}+\mathrm{R}-32$ system (Fig. C.1), we note that the correlation between $\mathrm{k}_{\mathrm{ij}}$ and the temperature is not very strong above the critical temperature of $\mathrm{CO}_{2}$ with NEoS, while it is better with the PR-EoS (coefficients of determination respectively equal to 0.58 and 0.99 ).

For the $\mathrm{SO}_{2}+\mathrm{R}-32$ system (Fig. C.2), in the case of the NEoS, there is a strong correlation between $\mathrm{k}_{\mathrm{ij}}$ and the temperature, both below and above the critical temperature of $\mathrm{CO}_{2}$ (both coefficients of determination around 0.96), while with the PR-EoS, the correlation is weaker (coefficients of determination equal to 0.51 and 0.78 , respectively below and above the critical temperature).

From Fig. 13 to 18 , we can clearly see that considering an adjusted binary interaction parameter $\mathrm{k}_{\mathrm{ij}}$ is necessary to model accurately the VLE behavior of some systems. Indeed, a $\mathrm{k}_{\mathrm{ij}}$ parameter is needed for systems including asymmetric components (in terms of molecular size, and nature and strength of intermolecular interactions, such as the quadrupolar ones, for instance).

It would be interesting to assess the effect of using mixing rules more complex than the van der Waals ones, such as $\mathrm{g}^{\mathrm{E}}$-mixing rules, and of adding a polar term to the NEoS, to take into account the polarity of refrigerants.

Inspired from the work of Jaubert and coworkers [39]-[43], an additional path that could be interesting to investigate is to apply a group contribution method to the NEoS, allowing the use of the van der Waals mixing rules, and to calculate a predictive $\mathrm{k}_{\mathrm{ij}}$. 


\subsubsection{Binary mixtures: $R-421 A$ and $R-508 A$}

Based on the correlations and the parameters calculated for the pure compounds, we studied the two binary systems:

- R-421A, which is a mixture at fixed composition of R-125 (58 wt\%) and R-134a (42 wt\%);

- R-508A which is a mixture at fixed composition of R-23 (39 wt\%) and R-116 (61 wt \%).

The prediction was performed using the three above-mentioned EoSs, associated with the MC alpha function. The MC alpha function parameters and the critical compressibility factor were calculated from the correlations established in section 2.3 and their values are reported in Table 2.

The predicted pressure-density diagrams are shown in Fig. 19 and 20, together with the results obtained from REFPROP 9.0. The prediction out of saturation was performed for four isotherms: $\mathrm{T}_{\mathrm{r}}=0.7,0.9,1.0,1.1$. The critical temperatures are $355.93 \mathrm{~K}$ for $\mathrm{R}-421 \mathrm{~A}$ and 283.34 K for R-508A [22].

From Fig. 19 and 20, we can see that the NEoS provides a better representation for the liquid density, both at saturation and out of saturation, especially at low $\left(\mathrm{T}_{\mathrm{r}}=0.7\right)$ and critical temperatures, for the two systems R-421A and R-508A. Note that the PR-EoS and PT-EoS fail to represent accurately the liquid densities of the two systems considered here at saturation, and at $\mathrm{T}_{\mathrm{r}}=0.7$ and $\mathrm{T}_{\mathrm{r}}=1.0$, while the vapor densities out of saturation appear to be well represented by the three EoSs.

However, for the vapor density at saturation, we can see from Table 4.a that the deviations to the REFPROP results are quite large for the R-421A. For the R-508A, the deviations are smaller, and we obtain the best results with the NEoS, compared to the PR-EoS and PT-EoS.

For the R-421A, for $\mathrm{T}_{\mathrm{r}}=1.0$, the results predicted by the three EoSs don't match very well the REFPROP results when increasing pressure, however, the best agreement is obtained with the NEoS, relative to PR-EoS and PT-EoS. For the R-508A, for $T_{r}=0.9$, the PR-EoS and PT-EoS provide results in slightly better agreement with the REFPROP results, compared to the NEoS.

\subsubsection{Ternary mixture: $\mathbf{R}-404 \mathrm{~A}$}

In this section, we study the ternary system R-404A, which is a mixture of R-125 (44 wt\%), $\mathrm{R}-134 \mathrm{a}$ (4 wt\%), and R-143a (52 wt\%). The same work as described in section 3.2.2 for the binary mixtures was carried out for the R-404A system.

The prediction was performed using the three EoSs presented above, associated with the MC alpha function. The MC alpha function parameters and the critical compressibility factor were calculated with the correlations established (Cf. Table 2).

The results of the prediction for the pressure-density diagram were compared to the results obtained from REFPROP 9.0. (Cf. Fig. 27). The prediction out of saturation was performed for four isotherms: $\mathrm{T}_{\mathrm{r}}=0.7,0.9,1.0,1.1$. The critical temperature of the R-404A is estimated to be $\mathrm{T}_{\mathrm{c}}=345.2 \mathrm{~K}[22]$.

For the ternary mixture R-404A, and as we can see from Fig. 27, the NEoS gives a good representation of the density at the critical and supercritical temperatures, compared to the PT-EoS and PR-EoS, but the NEoS results are less satisfactory at subcritical temperatures for 
liquid density. However, the saturation liquid density is well represented by using the NEoS, relative to the other two EoSs.

For $\mathrm{T}_{\mathrm{r}}=0.7$, the PT-EoS provides results in better agreement with REFPROP results, compared to the PR-EoS and NEoS.

For $T_{r}=0.9$, the three EoSs fail to represent accurately the liquid density. The vapor density appears to be well represented by the three EoSs for all the isotherms considered.

However, for the vapor density at saturation, and as we can see from Table 4.a, the deviations to REFPROP are quite large with the three EoSs.

\section{Conclusion}

In this paper, we introduced a new three-parameter cubic equation of state based on the principle of corresponding states.

This EoS was used for the study of refrigerant fluids including pure component, binary, and ternary fluids: R-1234yf, R-1216, $\mathrm{CO}_{2}, \mathrm{R}-134 \mathrm{a}, \mathrm{R}-421 \mathrm{~A}, \mathrm{R}-508 \mathrm{~A}$, and R-404A. The NEoS was used to predict the thermodynamic properties of these fluids, such as the pressure- $x-y$ and pressure-density diagrams, and the results obtained were compared to the PT-EoS and PREoS ones.

The three EoSs considered in this paper were associated with the MC alpha function. The parameters of this alpha function, as well as the optimized critical compressibility factor (for the NEoS and the PT-EoS), were calculated based on the correlations established in the present work.

For the binary and ternary systems, the binary interaction parameters $\mathrm{k}_{\mathrm{ij}}$ was set to 0 , without any fitting to experimental data. However, for some systems, such as the azeotropic ones, it has been necessary to consider a $\mathrm{k}_{\mathrm{ij}}$ parameter to accurately represent the VLE behavior of the systems. Indeed, for instance, the refrigerant compounds are characterized by a large heterogeneity in terms of molecular properties, as some compounds possess strong dipole and/or quadrupole moments and other compounds only weak multipole moments. This may be why a $\mathrm{k}_{\mathrm{ij}}$ parameter is needed to model some of the binary systems considered.

It would also be interesting to test other mixing rules than the van der Waals ones, such as $\mathrm{g}^{\mathrm{E}}$ -mixing rules, or to add a polar term in the NEoS to take into account the polarity of some refrigerant compounds.

An additional path that could be interesting to investigate is the combination of the NEoS with a group contribution method to calculate the $\mathrm{k}_{\mathrm{ij}}$ of van der Waals mixing rules, as it is done successfully with the PPR78 model [39]-[43].

Together, the results of the predictions for the pure compounds and for the binary and ternary mixtures show that the NEoS provides a better representation of the liquid density at saturation and out of saturation, compared to the results obtained with the PT-EoS and PREoS. The results are also better for the density in the critical region. However, the NEoS prediction concerning the ternary mixture could be improved for the subcritical temperatures.

The density in the critical region is well represented by using the NEoS, compared to the other EoSs considered in this work. However, this prediction could be better by combining the NEoS with a renormalization group theory [44], [45], using a crossover approach [46], [47] or the White's recursive method [48]. Such a study will be carried out in a future work. 
In overall, the NEoS provides a better representation of the densities, which are essential for the prediction of transport properties (viscosity, thermal conductivity...), and it would be particularly interesting to couple the NEoS with the TRAPP method [49], [50], for instance.

The prediction ability of VLE (without $\mathrm{k}_{\mathrm{ij}}$ ) for complex systems with the NEoS is limited, however, from the results presented in this paper concerning refrigerants, the NEoS shows better density prediction potentialities (without $\mathrm{k}_{\mathrm{ij}}$ ) than the PR-EoS and PT-EoS, and this EoS deserves thus to be tested in process simulators for industrial purpose. 


\section{Appendices}

\section{A. Patel-Teja EoS}

In Table A-1 are reported the alpha function parameters and the critical compressibility factor adjusted from vapor pressure and saturated liquid density of pure compounds, obtained using PT-EoS associated with the MC alpha function.

Based on this adjustment, correlations were established, relating the alpha function parameters to the acentric factor $\omega$, and the optimized critical compressibility factor to the experimental one. The results are reported in Eq. (A.1).

$$
\begin{gathered}
m_{1}=3.6410 \omega^{2}-0.5673 \omega+0.6142 \\
m_{2}=-0.01 \\
m_{3}=0.4 \\
\mathrm{Z}_{\mathrm{c}, \mathrm{opt}}=-11.356 \mathrm{Z}_{c}{ }^{2}+6.8984 \mathrm{Z}_{c}-0.7266
\end{gathered}
$$

In Fig. A. 1 are shown the correlations relating the alpha function parameter $m_{1}$ to the acentric factor $\omega$, and the optimized critical compressibility factor to the experimental one.

\section{B. Peng-Robinson EoS}

In Table B-1 are reported the alpha function parameters adjusted from vapor pressure of pure compounds, obtained using PR-EoS associated with the MC alpha function.

Based on this adjustment, a correlation was established, relating the alpha function parameters to the acentric factor $\omega$. The results are reported in Eq. (B.1).

$$
\begin{gathered}
m_{1}=-0.0944 \omega^{2}+1.5012 \omega+0.3417 \\
m_{2}=0 \\
m_{3}=0.49
\end{gathered}
$$

In Fig. B. 1 is displayed the correlation relating the alpha function parameter $m_{1}$ to the acentric factor $\omega$.

\section{Supplementary content}

Supplementary content related to this article can be found in the attached word file. 


\section{References}

[1] V. Lasserre, F. Heyndrickx, R. Rivoallon, and L. Guegan, "le règlement F-Gas, objectifs et impacts," Rev. Générale du Froid du Cond. d'Air, 2014.

[2] B. Minor and M. Spatz, "HFO-1234yf Low GWP Refrigerant Update," International Refrigeration and Air Conditioning Conference. 2008.

[3] J. D. Waals, Over de continuiteit van den gas- en vloeistoftoestand. A. W. Sijthoff, 1873.

[4] J. V. Sengers, R. F. Kayser, C. J. Peters, and H. J. White, Equations of State for Fluids and Fluid Mixtures. Elsevier, 2000.

[5] J. O. Valderrama, "The State of the Cubic Equations of State," Ind. Eng. Chem. Res., vol. 42, no. 8, pp. 1603-1618, Apr. 2003.

[6] Y. S. Wei and R. J. Sadus, "Equations of state for the calculation of fluid-phase equilibria," AIChE J., vol. 46, no. 1, pp. 169-196, Jan. 2000.

[7] C. H. Twu, J. E. Coon, and J. R. Cunningham, "A new cubic equation of state," Fluid Phase Equilib., vol. 75, pp. 65-79, Aug. 1992.

[8] C. H. Twu, D. Bluck, J. R. Cunningham, and J. E. Coon, "A cubic equation of state with a new alpha function and a new mixing rule," Fluid Phase Equilib., vol. 69, pp. 33-50, Dec. 1991.

[9] H. Orbey and S. I. Sandler, Modeling Vapor-Liquid Equilibria: Cubic Equations of State and Their Mixing Rules, Volume 1. Cambridge University Press, 1998.

[10] W.-R. Ji and D. A. Lempe, "A systematic study of cubic three-parameter equations of state for deriving a structurally optimized PVT relation," Fluid Phase Equilib., vol. 147, no. 1-2, pp. 85-103, Jun. 1998.

[11] A. Péneloux, E. Rauzy, and R. Fréze, "A consistent correction for Redlich-KwongSoave volumes,” Fluid Phase Equilib., vol. 8, no. 1, pp. 7-23, Jan. 1982.

[12] J.-N. Jaubert, R. Privat, Y. L. E. Guennec, and L. Coniglio, "Note on the properties altered by application of a Péneloux-type volume translation to an equation of state," Fluid Phase Equilib., vol. 419, pp. 88-95, Mar. 2016.

[13] H. Segura, D. Seiltgens, A. Mejía, F. Llovell, and L. F. Vega, "An accurate direct technique for parameterizing cubic equations of state," Fluid Phase Equilib., vol. 265, no. 1-2, pp. 155-172, Mar. 2008.

[14] M. M. Abbott, "Cubic equations of state," AIChE J., vol. 19, no. 3, pp. 596-601, May 1973.

[15] G. Schmidt and H. Wenzel, "A modified van der Waals type equation of state," Chem. Eng. Sci., vol. 35, no. 7, pp. 1503-1512, Jan. 1980.

[16] N. C. Patel and A. S. Teja, "A new cubic equation of state for fluids and fluid mixtures," Chem. Eng. Sci., vol. 37, no. 3, pp. 463-473, 1982.

[17] J. O. Valderrama, "A generalized Patel-Teja equation of state for polar and nonpolar fluids and their mixtures.," J. Chem. Eng. JAPAN, vol. 23, no. 1, pp. 87-91, Mar. 1990.

[18] A. Danesh, D.-H. Xu, and A. C. Todd, "Comparative study of cubic equations of state for predicting phase behaviour and volumetric properties of injection gas-reservoir oil systems," Fluid Phase Equilib., vol. 63, no. 3, pp. 259-278, 1991.

[19] L. A. Forero G. and J. A. Velásquez J., "The Patel-Teja and the Peng-Robinson EoSs performance when Soave alpha function is replaced by an exponential function," Fluid Phase Equilib., vol. 332, pp. 55-76, Oct. 2012.

[20] W.-R. Ji, E. Stiebing, G. Hradetzky, and D. A. Lempe, "Extrapolation of VLE data and simultaneous representation of caloric and volumetric properties by means of a cubic 3parameter equation of state," Fluid Phase Equilib., vol. 260, no. 1, pp. 113-125, Oct. 2007. 
[21] P. M. Mathias and T. W. Copeman, "Extension of the Peng-Robinson equation of state to complex mixtures: Evaluation of the various forms of the local composition concept," Fluid Phase Equilib., vol. 13, pp. 91-108, Jan. 1983.

[22] E. W. Lemmon, M. L. Huber, and M. O. McLinden, "REFPROP, Reference Fluid Thermodynamic and Transport Properties.” 2010.

[23] A. Valtz, H. Madani, C. Coquelet, and D. Richon, "Arkema Confidential Report," 2008.

[24] K. Tanaka and Y. Higashi, "Thermodynamic properties of HFO-1234yf (2,3,3,3tetrafluoropropene)," Int. J. Refrig., vol. 33, no. 3, pp. 474-479, 2010.

[25] C. Coquelet, D. Ramjugernath, H. Madani, A. Valtz, P. Naidoo, and A. H. Meniai, "Experimental Measurement of Vapor Pressures and Densities of Pure Hexafluoropropylene,” J. Chem. Eng. Data, vol. 55, no. 6, pp. 2093-2099, Jun. 2010.

[26] V. G. Niesen, L. J. Van Poolen, S. L. Outcalt, and C. D. Holcomb, "Coexisting densities and vapor pressures of refrigerants R-22, R-134a, and R-124 at 300-395 K," Fluid Phase Equilib., vol. 97, pp. 81-95, Jun. 1994.

[27] T. Y. Kwak and G. A. Mansoori, "Van der waals mixing rules for cubic equations of state. Applications for supercritical fluid extraction modelling," Chem. Eng. Sci., vol. 41, no. 5, pp. 1303-1309, Jan. 1986.

[28] C.-N. Kim and Y.-M. Park, "Vapor-Liquid Equilibrium of HFC-32/134a And HFC125/134a Systems," Int. J. Thermophys., vol. 20, no. 2, pp. 519-530.

[29] J. S. Lim, J.-Y. Park, B.-G. Lee, and Y.-W. Lee, "Phase equilibria of 1,1,1trifluoroethane (HFC-143a) + 1,1,1,2-tetrafluoroethane (HFC-134a), and + 1,1difluoroethane (HFC-152a) at 273.15, 293.15, 303.15, and 313.15 K," Fluid Phase Equilib., vol. 193, no. 1-2, pp. 29-39, Jan. 2002.

[30] Y. Higashi, "Vapor-Liquid Equilibrium, Coexistence Curve, and Critical Locus for Pentafluoroethane + 1,1,1-Trifluoroethane (R125/R143a)," J. Chem. Eng. Data, vol. 44, no. 2, pp. 333-337, Mar. 1999.

[31] C. Coquelet, D. Nguyen Hong, A. Chareton, A. Baba-Ahmed, and D. Richon, "Vapour-liquid equilibrium data for the difluoromethane+1,1,1,2,3,3,3heptafluoropropane system at temperatures from 283.20 to $343.38 \mathrm{~K}$ and pressures up to 4.5 MPa," Int. J. Refrig., vol. 26, no. 5, pp. 559-565, Aug. 2003.

[32] E.-Y. Chung and M. S. Kim, "Vapor-Liquid Equilibria for the Difluoromethane (HFC32) + 1,1,1,2-Tetrafluoroethane (HFC-134a) System," J. Chem. Eng. Data, vol. 42, no. 6, pp. 1126-1128, Nov. 1997.

[33] P. Hu, L. X. Chen, and Z. S. Chen, "Vapor-liquid equilibria for the 1,1,1,2tetrafluoroethane (HFC-134a)+1,1,1,2,3,3,3-heptafluoropropane (HFC-227ea) and 1,1,1-trifluoroethane (HFC-143a)+2,3,3,3-tetrafluoroprop-1-ene (HFO-1234yf) systems," Fluid Phase Equilib., vol. 360, pp. 293-297, 2013.

[34] A. Valtz, C. Coquelet, and D. Richon, "Vapor-Liquid Equilibrium Data for the Sulfur Dioxide (SO 2) + Difluoromethane (R32) System at Temperatures from 288.07 to 403.16 K and at Pressures up to 7.31 MPa," Int. J. Thermophys., vol. 25, no. 6, pp. 1695-1711, Nov. 2004.

[35] F. Rivollet, A. Chapoy, C. Coquelet, and D. Richon, "Vapor-liquid equilibrium data for the carbon dioxide (CO2) + difluoromethane (R32) system at temperatures from 283.12 to $343.25 \mathrm{~K}$ and pressures up to $7.46 \mathrm{MPa}$," Fluid Phase Equilib., vol. 218, no. 1, pp. 95-101, Apr. 2004.

[36] Y. Zhang, M. Gong, and J. Wu, "Vapor-liquid equilibrium measurement and correlation for R23 + R116 system," J. Chem. Ind. Eng., vol. 59, pp. 269-275, 2008.

[37] E. El Ahmar, A. Valtz, P. Paricaud, C. Coquelet, L. Abbas, and W. Rached, "Vapourliquid equilibrium of binary systems containing pentafluorochemicals from 363 to 
413 K: Measurement and modelling with Peng-Robinson and three SAFT-like equations of states," Int. J. Refrig., vol. 35, no. 8, pp. 2297-2310, Dec. 2012.

[38] M. Ju, Y. Yun, M. S. Shin, and H. Kim, "(Vapour+liquid) equilibria of the \{trifluoromethane (HFC-23)+propane $\}$ and \{trifluoromethane (HFC-23)+n-butane systems," J. Chem. Thermodyn., vol. 41, no. 12, pp. 1339-1342, Dec. 2009.

[39] J.-N. Jaubert and F. Mutelet, "VLE predictions with the Peng-Robinson equation of state and temperature dependent kij calculated through a group contribution method," Fluid Phase Equilib., vol. 224, no. 2, pp. 285-304, Oct. 2004.

[40] J.-N. Jaubert, S. Vitu, F. Mutelet, and J.-P. Corriou, "Extension of the PPR78 model (predictive 1978, Peng-Robinson EOS with temperature dependent kij calculated through a group contribution method) to systems containing aromatic compounds," Fluid Phase Equilib., vol. 237, no. 1-2, pp. 193-211, Oct. 2005.

[41] R. Privat, J.-N. Jaubert, and F. Mutelet, "Use of the PPR78 Model To Predict New Equilibrium Data of Binary Systems Involving Hydrocarbons and Nitrogen. Comparison with Other GCEOS," Ind. Eng. Chem. Res., vol. 47, no. 19, pp. 74837489, Oct. 2008.

[42] S. Vitu, R. Privat, J.-N. Jaubert, and F. Mutelet, "Predicting the phase equilibria of CO2+hydrocarbon systems with the PPR78 model (PR EOS and kij calculated through a group contribution method)," J. Supercrit. Fluids, vol. 45, no. 1, pp. 1-26, May 2008.

[43] J.-N. Jaubert, R. Privat, and F. Mutelet, "Predicting the phase equilibria of synthetic petroleum fluids with the PPR78 approach," AIChE J., vol. 56, no. 12, pp. 3225-3235, Dec. 2010.

[44] K. Wilson, "Renormalization Group and Critical Phenomena. II. Phase-Space Cell Analysis of Critical Behavior," Phys. Rev. B, vol. 4, no. 9, pp. 3184-3205, Nov. 1971.

[45] K. Wilson and M. Fisher, "Critical Exponents in 3.99 Dimensions," Phys. Rev. Lett., vol. 28, no. 4, pp. 240-243, Jan. 1972.

[46] M. Dicko and C. Coquelet, "Application of a new crossover treatment to a generalized cubic equation of state," Fluid Phase Equilib., vol. 302, no. 1-2, pp. 241-248, Mar. 2011.

[47] J. Janeček, P. Paricaud, M. Dicko, and C. Coquelet, "A generalized Kiselev crossover approach applied to Soave-Redlich-Kwong equation of state," Fluid Phase Equilib., vol. 401, pp. 16-26, Sep. 2015.

[48] J. Cai and J. M. Prausnitz, "Thermodynamics for fluid mixtures near to and far from the vapor-liquid critical point," Fluid Phase Equilib., vol. 219, no. 2, pp. 205-217, May 2004.

[49] M. L. Huber, D. G. Friend, and J. F. Ely, "Prediction of the thermal conductivity of refrigerants and refrigerant mixtures," Fluid Phase Equilib., vol. 80, pp. 249-261, Nov. 1992.

[50] S. . Klein, M. . McLinden, and A. Laesecke, “An improved extended corresponding states method for estimation of viscosity of pure refrigerants and mixtures," Int. J. Refrig., vol. 20, no. 3, pp. 208-217, May 1997. 


\section{List of tables}

Table 1 - Experimental and NEoS adjusted parameters for several refrigerant families (with $\mathrm{m}_{2}=0.47$ and $m_{3}=\mathbf{- 0 . 0 8}$ ). $\omega$ is the acentric factor, $m_{1}$ the alpha function parameter, and $Z_{c, o p t}$ and $Z_{c}$ the optimized and the experimental critical compressibility factors, respectively.

Table 2 - Calculated parameters for the R-1234yf, R-1216, CO2, R-125, R-134a, R-143a, R23 and R-116 ( $m_{2}$ and $m_{3}$ are set to fixed values).

Table 3 - ARD and BIAS for R-1234yf using the adjusted parameters for EoSs

Table 4.a - ARD and BIAS for the pure compounds R-1234yf, R-1216, CO2, R-134a, the binary mixtures R-421A, R-508A, and the ternary mixture R-404A, using the calculated parameters for EoSs.

Table 4.b - ARD and BIAS of the pressure and vapor composition for the VLE calculation

Table A.1 - Experimental and PT-EoS adjusted parameters for several refrigerant families $\left(\mathbf{w i t h}_{\mathbf{2}} \mathrm{m}_{2}=\right.$ 0.01 and $\left.m_{3}=0.4\right)$. $\omega$ is the acentric factor, $m_{1}$ the alpha function parameter, and $Z_{c, o p t}$ and $Z_{c}$ the optimized and the experimental critical compressibility factors, respectively.

Table B.1 - Experimental and PR-EoS adjusted parameters for several refrigerant families $\left(\right.$ with $\mathbf{m}_{2}=0$ and $\left.m_{3}=0.49\right)$. $\omega$ is the acentric factor, $m_{1}$ the alpha function parameter, and $Z_{c, o p t}$ and $Z_{c}$ the optimized and the experimental critical compressibility factors, respectively.

Table C.1 - $k_{\mathrm{ij}}$ values used with the NEoS and PR-EoS, for the azeotropic and supercritical systems.

\section{List of figures}

Fig. 1 - Correlations obtained with the NEoS. (a): the $m_{1}$ parameter as a function of the acentric factor $\omega$ (coefficient of determination $R^{2}=0.82$ ); (b): the optimized critical compressibility factor $Z_{c, o p t}$ as a function of the experimental critical compressibility factor $Z_{c}\left(\right.$ coefficient of determination $\left.R^{2}=0.89\right)$.

Fig. 2 - Relative deviation (RD) as a function of the temperature for R-1234yf with NEoS, using the calculated parameters. $(\circ)$ RD of vapor pressure; $(\Delta)$ RD of saturated liquid density; ( $\square$ ) RD of saturated vapor density.

Fig. 3 - P-p diagram for R-1234yf. ( $\Delta$ ) Experimental data [24]; ( $\Delta$ ) Experimental data [23]; (-) REFPROP; $(\times)$ Critical Point: REFPROP ( $\left.T_{c}=367.85 K\right)$; (- - - ) NEoS; (.....) PT-EoS; (- - $)$ PR-EoS. Out of saturation: $T_{r}=0.7,0.9,1.0,1.1$.

Fig. 4 - P-p diagram for R-1216. $(\Delta)$ Experimental data [25]; $(x)$ Critical Point: Experimental $\left(\mathbf{T}_{c}=358.9\right.$ K) [25]; (- - -) NEoS; (.....) PT-EoS; (-- -) PR-EoS. Out of saturation: $T_{r}=0.73,0.9,1.0$, and 1.01 .

Fig. 5 - P-p diagram for $\mathrm{CO}_{2} \cdot(-)$ REFPROP; $(\times)$ Critical Point: REFPROP $\left(\mathrm{T}_{\mathrm{c}}=304.13 \mathrm{~K}\right)$; (- - - -) NEoS; (......) PT-EoS; $(---)$ PR-EoS. Out of saturation: $T_{r}=0.8,0.9,1.0$, and 1.1

Fig. 6 - P-p diagram for R-134a. $(\Delta)$ Experimental data [26]; (-) REFPROP; ( $\times$ ) Critical Point: REFPROP $\left(T_{c}=374.21 K\right) ;(---)$ NEoS; (.....) PT-EoS; $(---)$ PR-EoS. Out of saturation: $T_{r}=0.7,0.9$, 1.0, and 1

Fig. 7 - VLE prediction for R-125 (1) + R-134a (2). Experimental data [28]: (•) 263.15 K; ( $\Delta$ ) 273.15 K; (×) 283.15 K; ( $\triangle)$ 293.15 K; ( $\square)$ 303.15 K. NEoS: $(-) k_{i j}=0$. 
Fig. 8 - VLE prediction for R-143a (1) + R-134a (2). Experimental data [29]: (•) 273.15K; ( $\Delta$ ) 293.15K; $(\times)$ 303.15 K; ( $\Delta)$ 313.15 K. NEoS: $(-) \mathrm{k}_{\mathrm{ij}}=0$.

Fig. 9 - VLE prediction for R-125 (1) + R-143a (2). Experimental data [30]: (•) 273.15 K; ( 1 ) 293.15 K; (×) 313.15 K. NEoS: $(-) k_{i j}=0$.

Fig. 10 - VLE prediction for R-32 (1) + R-227ea (2). Experimental data [31]: (•) $283.20 \mathrm{~K}$; ( $\Delta$ ) $303.21 \mathrm{~K}$; $(\times)$ 323.21 K; ( $\Delta)$ 343.38 K. NEoS: $(\longrightarrow) k_{i j}=0$.

Fig. 11 - VLE prediction for R-32 (1) + R-134a (2). Experimental data [32]: (•) 263.15 K; ( $\Delta$ ) 273.15 K; ( $\times$ ) 283.15 K; ( $\triangle$ ) 293.15 K; (口) 303.15 K; ( ( ) 313.15 K; (+) 323.15 K. NEoS: $(-) k_{i j}=0$

Fig. 12 - VLE prediction for R-143a (1) + R-1234yf (2). Experimental data [33]: (•) $283.15 \mathrm{~K}$; ( $\triangle$ ) 293.15 K; (×) 303.15 K; ( $\Delta$ ) 313.15 K; ( $\square)$ 323.15 K. NEoS: (一) $\mathbf{k}_{\mathrm{ij}}=0$.

Fig. 13 - VLE prediction for $\mathrm{SO}_{2}(1)+\mathrm{R}-32$ (2). Experimental data [34]: (•) $288.07 \mathrm{~K}$; ( $(\Delta)$ ) $303.16 \mathrm{~K}$; (x) 323.15 K; ( $\Delta$ ) 343.15 K; (口) 353.15 K; ( () 363.15 K; (+) 383.18 K; (ロ) 403.16 K. NEoS: (一) $k_{\mathrm{ij}}=0$; (- - - -) $\mathbf{k}_{\mathrm{ij}}$ adjusted.

Fig. 14 - VLE prediction for $\mathrm{CO}_{2}(1)+\mathrm{R}-32$ (2). Experimental data [35]: (•) $283.12 \mathrm{~K}$; ( $(\Delta) 293.11 \mathrm{~K}$; ( $\times$ ) 303.13 K; ( $\Delta$ ) 305.15 K; (口) 313.30 K; ( () 323.34 K; (+) 333.33 K; (ロ) 343.23 K. NEoS: (一) $\mathrm{k}_{\mathrm{ij}}=0$; (- - - -) $\mathbf{k}_{\mathrm{ij}}$ adjusted.

Fig. 15 - VLE prediction for R-23 (1) + R-116 (2). Experimental data [36]: (•) 194.33 K; ( (4) 199.71 K; (×) 214.19 K; ( $\triangle$ ) 229.63 K; (口) 244.94 K. NEoS: (-) $k_{\mathrm{ij}}=0$; ( - - - -) $k_{\mathrm{ij}}$ adjusted.

Fig. 16 - VLE prediction for isopentane (1) + R-365mfc (2). Experimental data [37]: (•) 363.12 K; ( $\Delta$ ) 373.20 K; (×) 393.22 K; ( $\Delta)$ 413.09 K. NEoS: $(-) k_{\mathrm{ij}}=0$; (- - - -) $\mathrm{k}_{\mathrm{ij}}$ adjusted.

Fig. 17 - VLE prediction for R-23 (1) + butane (2). Experimental data [38]: (•) 283.15 K; ( $\Delta$ ) 293.15 K; $(\times) 303.15 \mathrm{~K}$; ( $\Delta) 313.15 \mathrm{~K}$. NEoS: $(-) \mathrm{k}_{\mathrm{ij}}=0$; (- - - ) $\mathrm{k}_{\mathrm{ij}}$ adjusted.

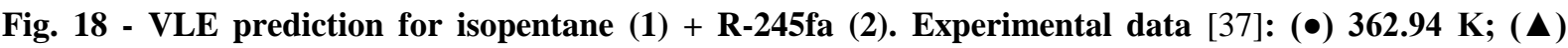
373.17 K; ( $\times)$ 392.87 K; ( $\Delta)$ 412.91 K. NEoS: $(-) k_{i j}=0$; ( - - - $) k_{i j}$ adjusted.

Fig. 19 - P-p diagram for R-421A. (-) REFPROP; $(\times)$ Critical Point: REFPROP $\left(T_{c}=355.93\right.$ K); (- - - -) NEoS; (......) PT-EoS; (-- PR-EoS. Out of saturation: $T_{r}=0.7,0.9,1.0,1.1$.

Fig. 20 - P-p diagram for R-508A. (-) REFPROP; $(\times)$ Critical Point: REFPROP $\left(T_{c}=283.34 K\right)$; (- - - ) NEoS; (......) PT-EoS; (-- ) PR-EoS. Out of saturation: $T_{r}=0.7,0.9,1.0,1.1$.

Fig. 21 - P-p diagram for R-404A. (-) REFPROP; $(\times)$ Critical Point: REFPROP $\left(T_{c}=345.2 ~ K\right)$; (- - - -) NEoS; (......) PT-EoS; (-- P) PR-EoS. Out of saturation: $T_{r}=0.7,0.9,1.0,1.1$.

Fig. A.1 - Correlations obtained with the PT-EoS. (a): the $m_{1}$ parameter as a function of the acentric factor $\omega$ (coefficient of determination $R^{2}=0.83$ ). (b): the optimized critical compressibility factor $Z_{c, o p t}$ as a function of the experimental critical compressibility factor $Z_{c}\left(\right.$ coefficient of determination $\left.R^{2}=0.92\right)$.

Fig. B.1 - Correlation obtained with the PR-EoS: $m_{1}$ parameter as a function of the acentric factor $\omega$ (coefficient of determination $\mathrm{R}^{2}=\mathbf{0 . 9 8}$ ).

Fig. C.1 - $\mathrm{k}_{\mathrm{ij}}$ as a function of temperature: $\mathrm{CO}_{2}+\mathrm{R}-32$. (•) NEoS; ( $\triangle$ ) PR-EoS;(- - - -) $\mathrm{CO}_{2}$ critical temperature $\left(T_{c}=304.13 \mathrm{~K}\right)$.

Fig. C.2- $\mathrm{k}_{\mathrm{ij}}$ as a function of temperature: $\mathrm{SO}_{2}+\mathrm{R}-32$. (•) NEoS; ( $\triangle$ ) PR-EoS;(- - -) R-32 critical temperature $\left(T_{c}=351.26 \mathrm{~K}\right)$.

Fig. C.3 - $k_{i j}$ as a function of temperature: isopentane + R-365mfc. ( $\left.\bullet\right)$ NEoS; ( $\triangle$ ) PR-EoS. 
Fig. C.4- $k_{\mathrm{ij}}$ as a function of temperature: R-23 + R-116. (•) NEoS; ( $\triangle$ ) PR-EoS.

Fig. C.5 - $k_{i j}$ as a function of temperature: isopentane + R-245fa. (•) NEoS; ( $\triangle$ ) PR-EoS.

Fig. C.6 - $k_{\mathrm{ij}}$ as a function of temperature: R-23 + butane. (•) NEoS; ( $\triangle$ ) PR-EoS.

Fig. C.7 - Enthalpies of saturated phases. (०) REFPROP. (- - - -) NEoS.

Fig. C.8 - Enthalpies of vaporization. (०) REFPROP. (- - - -) NEoS.

Fig. C.9 - Isobaric heat capacities of saturated phases. (○) Liquid. (•) Vapor - REFPROP. (- - - -) NEoS.

Fig. C.10 - Isobaric heat capacities at P = 5 MPa. ( $\circ)$ REFPROP. (- - - -) NEoS. 
Table 5 - Experimental and NEoS adjusted parameters for several refrigerant families (with $\mathbf{m}_{2}=0.47$ and $\left.m_{3}=\mathbf{- 0 . 0 8}\right)$. $\omega$ is the acentric factor, $m_{1}$ the alpha function parameter, and $Z_{c, o p t}$ and $Z_{c}$ the optimized and the experimental critical compressibility factors, respectively.

\begin{tabular}{|c|c|c|c|c|c|}
\hline Families & Compounds & $\omega$ & $\mathbf{m}_{1}$ & $\mathbf{Z}_{\mathrm{c}, \mathrm{opt}}$ & $\mathbf{Z}_{\mathrm{c}}$ \\
\hline \multirow{4}{*}{ PFC } & R-C318 & 0.35530 & 0.60916 & 0.29152 & 0.27751 \\
\hline & R-14 & 0.17850 & 0.39304 & 0.29695 & 0.27883 \\
\hline & $\mathrm{R}-116$ & 0.25660 & 0.49092 & 0.29399 & 0.28151 \\
\hline & $\mathrm{R}-218$ & 0.31720 & 0.53351 & 0.28765 & 0.27553 \\
\hline \multirow{6}{*}{ CFC } & R-11 & 0.18875 & 0.36197 & 0.28744 & 0.27901 \\
\hline & R-12 & 0.17948 & 0.34391 & 0.28682 & 0.27643 \\
\hline & R-13 & 0.17230 & 0.34292 & 0.28839 & 0.27685 \\
\hline & R-113 & 0.25253 & 0.45677 & 0.28711 & 0.28019 \\
\hline & R-114 & 0.25230 & 0.47429 & 0.29044 & 0.27563 \\
\hline & R-115 & 0.25000 & 0.45928 & 0.29007 & 0.26779 \\
\hline \multirow{6}{*}{ HCFC } & $\mathrm{R}-21$ & 0.20610 & 0.38831 & 0.28473 & 0.27006 \\
\hline & $\mathrm{R}-22$ & 0.22082 & 0.37537 & 0.27902 & 0.26825 \\
\hline & $\mathrm{R}-123$ & 0.28192 & 0.46712 & 0.28022 & 0.26806 \\
\hline & R-124 & 0.28810 & 0.47540 & 0.28121 & 0.26865 \\
\hline & R-141b & 0.21950 & 0.39624 & 0.28235 & 0.27057 \\
\hline & $\mathrm{R}-142 \mathrm{~b}$ & 0.23210 & 0.39073 & 0.27830 & 0.26786 \\
\hline \multirow{14}{*}{ HFC } & $\mathrm{R}-125$ & 0.30520 & 0.51102 & 0.28365 & 0.26844 \\
\hline & R-134a & 0.32684 & 0.49929 & 0.27428 & 0.26004 \\
\hline & R-143a & 0.26150 & 0.39374 & 0.26895 & 0.25502 \\
\hline & R-152a & 0.27521 & 0.38981 & 0.26439 & 0.25233 \\
\hline & $\mathrm{R}-161$ & 0.21700 & 0.33583 & 0.26915 & 0.25979 \\
\hline & R-227ea & 0.35700 & 0.57089 & 0.28239 & 0.26849 \\
\hline & R-23 & 0.26300 & 0.39189 & 0.26924 & 0.25821 \\
\hline & R-236ea & 0.37940 & 0.62687 & 0.28904 & 0.27578 \\
\hline & R-236fa & 0.37721 & 0.59681 & 0.28170 & 0.26664 \\
\hline & $\mathrm{R}-245 \mathrm{ca}$ & 0.35360 & 0.57228 & 0.28505 & 0.27003 \\
\hline & $\mathrm{R}-245 \mathrm{fa}$ & 0.37760 & 0.59424 & 0.28041 & 0.26702 \\
\hline & R-32 & 0.27690 & 0.34346 & 0.25255 & 0.24291 \\
\hline & $\mathrm{R}-365 \mathrm{mfc}$ & 0.38000 & 0.60464 & 0.28564 & 0.26686 \\
\hline & R-41 & 0.20040 & 0.25742 & 0.25587 & 0.24036 \\
\hline \multirow{2}{*}{ HFO } & R-1234yf & 0.27600 & 0.46360 & 0.28085 & 0.26519 \\
\hline & $\mathrm{R}-1234 \mathrm{ze}(\mathrm{E})$ & 0.31300 & 0.50226 & 0.28049 & 0.26651 \\
\hline HCFO & R-1233zd(E) & 0.34137 & 0.51623 & 0.28252 & 0.27884 \\
\hline $\begin{array}{l}\text { NATURAL } \\
\text { FLUIDS }\end{array}$ & $\mathrm{CO}_{2}$ & 0.22394 & 0.42919 & 0.28868 & 0.27458 \\
\hline
\end{tabular}


Table 6 - Calculated parameters for the R-1234yf, R-1216, CO2, R-125, R-134a, R-143a, R23 and R-116 ( $m_{2}$ and $m_{3}$ are set to fixed values).

\begin{tabular}{|c|c|c|c|c|c|}
\hline CEoS & Compound & $\mathbf{m}_{1}$ & $\mathbf{m}_{2}$ & $\mathbf{m}_{\mathbf{3}}$ & $\mathrm{Z}_{\mathrm{c}, \mathrm{opt}}$ \\
\hline \multirow{8}{*}{ NEoS } & R-1234yf & 0.44741 & 0.47 & -0.08 & 0.27917 \\
\hline & $\mathrm{R}-1216$ & 0.56391 & 0.47 & -0.08 & 0.28529 \\
\hline & $\mathrm{CO}_{2}$ & 0.38725 & 0.47 & -0.08 & 0.28714 \\
\hline & $\mathrm{R}-125$ & 0.48777 & 0.47 & -0.08 & 0.28208 \\
\hline & R-134a & 0.52074 & 0.47 & -0.08 & 0.27424 \\
\hline & R-143a & 0.42914 & 0.47 & -0.08 & 0.26906 \\
\hline & R-23 & 0.43097 & 0.47 & -0.08 & 0.27239 \\
\hline & $\mathrm{R}-116$ & 0.42322 & 0.47 & -0.08 & 0.29217 \\
\hline \multirow{8}{*}{ PT-EoS } & R-1234yf & 0.73498 & -0.01 & 0.4 & 0.30417 \\
\hline & R-1216 & 0.86744 & -0.01 & 0.4 & 0.30979 \\
\hline & $\mathrm{CO}_{2}$ & 0.66975 & -0.01 & 0.4 & 0.31139 \\
\hline & $\mathrm{R}-125$ & 0.78021 & -0.01 & 0.4 & 0.30689 \\
\hline & R-134a & 0.81773 & -0.01 & 0.4 & 0.29936 \\
\hline & R-143a & 0.71483 & -0.01 & 0.4 & 0.29409 \\
\hline & $\mathrm{R}-23$ & 0.71684 & -0.01 & 0.4 & 0.29750 \\
\hline & $\mathrm{R}-116$ & 0.70837 & -0.01 & 0.4 & 0.31543 \\
\hline \multirow{8}{*}{ PR-EoS } & R-1234yf & 0.74884 & 0 & 0.49 & $0.30740^{\mathrm{a}}$ \\
\hline & R-1216 & 0.85972 & 0 & 0.49 & 0.30740 \\
\hline & $\mathrm{CO}_{2}$ & 0.67314 & 0 & 0.49 & 0.30740 \\
\hline & $\mathrm{R}-125$ & 0.79107 & 0 & 0.49 & 0.30740 \\
\hline & R-134a & 0.82227 & 0 & 0.49 & 0.30740 \\
\hline & R-143a & 0.72781 & 0 & 0.49 & 0.30740 \\
\hline & R-23 & 0.72999 & 0 & 0.49 & 0.30740 \\
\hline & R-116 & 0.72069 & 0 & 0.49 & 0.30740 \\
\hline
\end{tabular}

${ }^{\mathrm{a}}$ For the PR-EoS, the value of $\mathrm{Z}_{\mathrm{c}}$ is set to 0.30740 . 
Table 7 - ARD and BIAS for R-1234yf using the adjusted parameters for EoSs

\begin{tabular}{ccccccc}
\hline & \multicolumn{3}{c}{ ARD (\%) } & \multicolumn{3}{c}{ BIAS (\%) } \\
\hline CEoS & $\mathbf{P}$ & $\boldsymbol{\rho}^{\mathbf{L}}$ & $\boldsymbol{\rho}^{\mathbf{V}}$ & $\mathbf{P}$ & $\boldsymbol{\rho}^{\mathbf{L}}$ & $\boldsymbol{\rho}^{\mathbf{V}}$ \\
\hline NEoS & 0.4 & 1.9 & 2.0 & -0.2 & 0.2 & -1.5 \\
\hline PT-EoS & 0.5 & 4.3 & 0.9 & -0.3 & 0.5 & 0.1 \\
\hline PR-EoS & 0.9 & 3.9 & 0.8 & -0.5 & 3.3 & 0.2 \\
\hline
\end{tabular}


Table 8.a - ARD and BIAS for the pure compounds R-1234yf, R-1216, CO2, R-134a, the binary mixtures R-421A, R-508A, and the ternary mixture R-404A, using the calculated parameters for EoSs.

\begin{tabular}{|c|c|c|c|c|c|c|c|}
\hline \multirow[b]{2}{*}{ Compounds } & \multirow[b]{2}{*}{ CEOS } & \multicolumn{3}{|c|}{ ARD (\%) } & \multicolumn{3}{|c|}{ BIAS (\%) } \\
\hline & & $\mathbf{P}$ & $\rho^{\mathbf{L}}$ & $\rho^{v}$ & $\mathbf{P}$ & $\rho^{\mathbf{L}}$ & $\rho^{\mathrm{V}}$ \\
\hline \multirow{3}{*}{ R-1234yf } & NEoS & 1.4 & 2.2 & 2.9 & -1.4 & -0.6 & -2.8 \\
\hline & PT-EoS & 2.2 & 3.9 & 2.0 & -2.2 & 1.9 & -1.8 \\
\hline & PR-EoS & 1.9 & 3.9 & 1.6 & -1.9 & 3.4 & -1.3 \\
\hline \multirow{3}{*}{ R-1216 } & NEoS & 0.5 & 5.2 & 6.2 & -0.5 & 4.0 & -4.9 \\
\hline & PT-EoS & 0.9 & 9.9 & 3.2 & -0.9 & 9.4 & -0.8 \\
\hline & PR-EoS & 0.6 & 9.5 & 3.5 & -0.6 & 8.4 & -0.8 \\
\hline \multirow{3}{*}{$\mathrm{CO}_{2}$} & NEoS & 2.7 & 2.3 & 5.9 & -2.7 & -0.2 & -5.6 \\
\hline & PT-EoS & 3.0 & 4.4 & 3.9 & -3.0 & 3.7 & -3.2 \\
\hline & PR-EoS & 1.4 & 4.3 & 2.1 & -1.3 & 1.5 & -1.5 \\
\hline \multirow{3}{*}{ R-134a } & NEoS & 4.4 & 2.8 & 5.5 & 4.4 & -0.1 & 4.1 \\
\hline & PT-EoS & 3.6 & 3.3 & 4.6 & 3.6 & 0.4 & 4.5 \\
\hline & PR-EoS & 1.7 & 4.6 & 1.0 & -1.0 & 4.6 & 0.0 \\
\hline \multirow{3}{*}{ R-421A } & NEoS & 1.1 & 2.4 & 23.2 & -0.4 & -1.8 & -23.2 \\
\hline & PT-EoS & 1.5 & 3.6 & 22.7 & -1.4 & 0.5 & -22.7 \\
\hline & PR-EoS & 1.4 & 3.3 & 22.2 & -1.3 & 2.5 & -22.2 \\
\hline \multirow{3}{*}{ R-508A } & NEoS & 1.0 & 1.7 & 1.7 & -0.4 & -1.1 & 1.0 \\
\hline & PT-EoS & 1.9 & 2.7 & 5.3 & 1.0 & 0.4 & 4.9 \\
\hline & PR-EoS & 2.9 & 2.8 & 8.6 & 2.9 & -0.4 & 8.6 \\
\hline \multirow{3}{*}{ R-404A } & NEoS & 1.6 & 2.3 & 5.8 & -1.6 & -1.1 & -5.8 \\
\hline & PT-EoS & 2.6 & 3.7 & 5.3 & -2.6 & 1.3 & -5.3 \\
\hline & PR-EoS & 4.7 & 5.4 & 6.6 & -4.7 & 5.4 & -6.6 \\
\hline
\end{tabular}


Table 4.b - ARD and BIAS of the pressure and vapor composition for the VLE calculation

\begin{tabular}{|c|c|c|c|c|c|c|}
\hline \multirow{2}{*}{ Systems } & \multirow{2}{*}{$\mathbf{T} / \mathbf{K}$} & \multirow{2}{*}{$\mathbf{k}_{\mathrm{ij}}$} & \multicolumn{2}{|c|}{$\operatorname{ARD}(\%)$} & \multicolumn{2}{|c|}{ BIAS (\%) } \\
\hline & & & $\mathbf{P}$ & $\mathbf{y}_{1}$ & $\mathbf{P}$ & $\mathbf{y}_{1}$ \\
\hline \multirow{5}{*}{$\mathrm{R}-125(1)+\mathrm{R}-134 \mathrm{a}(2)$} & 263.15 & \multirow{5}{*}{0} & 1.5 & 1.2 & 0.0 & -1.2 \\
\hline & 273.15 & & 1.2 & 1.1 & 0.1 & -1.0 \\
\hline & 283.15 & & 1.1 & 1.1 & 0.3 & -0.2 \\
\hline & 293.15 & & 0.9 & 1.4 & 0.2 & -0.4 \\
\hline & 303.15 & & 0.7 & 1.1 & 0.4 & -0.3 \\
\hline \multirow{4}{*}{$\mathrm{R}-143 \mathrm{a}(1)+\mathrm{R}-134 \mathrm{a}(2)$} & 273.15 & \multirow{4}{*}{0} & 4.6 & 1.2 & 4.6 & -0.8 \\
\hline & 293.15 & & 2.1 & 1.3 & 2.1 & -1.3 \\
\hline & 303.15 & & 1.3 & 1.3 & 1.3 & -1.3 \\
\hline & 313.15 & & 0.7 & 0.7 & 0.7 & -0.7 \\
\hline \multirow{3}{*}{$\mathrm{R}-125(1)+\mathrm{R}-143 \mathrm{a}(2)$} & 273.15 & \multirow{3}{*}{0} & 1.9 & 3.0 & 1.0 & -2.8 \\
\hline & 293.15 & & 1.1 & 1.6 & 0.5 & -1.6 \\
\hline & 313.15 & & 0.7 & 1.2 & 0.3 & -1.0 \\
\hline \multirow{4}{*}{ R-32 (1) + R-227ea (2) } & 283.20 & \multirow{4}{*}{0} & 4.7 & 1.6 & 4.6 & 1.6 \\
\hline & 303.21 & & 3.8 & 1.9 & 3.8 & 1.8 \\
\hline & 323.21 & & 3.5 & 2.0 & 3.5 & 2.0 \\
\hline & 343.38 & & 2.7 & 2.8 & 2.6 & 2.8 \\
\hline \multirow{7}{*}{$\mathrm{R}-32(1)+\mathrm{R}-134 \mathrm{a}(2)$} & 263.15 & \multirow{7}{*}{0} & 7.7 & 1.7 & 7.7 & 1.7 \\
\hline & 273.15 & & 6.2 & 0.9 & 6.2 & 0.9 \\
\hline & 283.15 & & 5.8 & 0.5 & 5.8 & 0.1 \\
\hline & 293.15 & & 4.5 & 1.0 & 4.5 & -0.4 \\
\hline & 303.15 & & 3.7 & 0.6 & 3.7 & 0.1 \\
\hline & 313.15 & & 2.9 & 0.6 & 2.9 & 0.3 \\
\hline & 323.15 & & 2.1 & 0.6 & 2.1 & 0.3 \\
\hline \multirow{5}{*}{ R-143a (1) + R-1234yf (2) } & 283.15 & \multirow{5}{*}{0} & 2.5 & 1.9 & 2.1 & 1.9 \\
\hline & 293.15 & & 2.2 & 1.9 & 1.8 & 1.9 \\
\hline & 303.15 & & 1.8 & 1.9 & 1.5 & 1.9 \\
\hline & 313.15 & & 1.4 & 1.6 & 1.1 & 1.6 \\
\hline & 323.15 & & 1.1 & 1.4 & 0.9 & 1.4 \\
\hline \multirow{10}{*}{$\mathrm{SO}_{2}(1)+\mathrm{R}-32(2)$} & 288.07 & \multirow{8}{*}{0} & 3.8 & 1.3 & 2.6 & 1.3 \\
\hline & 303.16 & & 3.2 & 1.2 & 2.3 & 1.2 \\
\hline & 323.15 & & 1.8 & 0.8 & 0.8 & 0.8 \\
\hline & 343.15 & & 1.0 & 0.4 & -0.5 & 0.1 \\
\hline & 353.15 & & 1.1 & 0.7 & -1.1 & 0.3 \\
\hline & 363.15 & & 4.8 & 2.6 & 2.2 & 2.0 \\
\hline & 383.18 & & 4.3 & 3.3 & 0.7 & 3.3 \\
\hline & 403.16 & & 4.5 & 8.3 & 1.9 & 8.3 \\
\hline & 288.07 & \multirow{2}{*}{$\begin{array}{l}\text { Adjusted (cf } \\
\text { Table C. } 1 \text { in }\end{array}$} & 3.6 & 1.3 & 1.8 & 0.9 \\
\hline & 303.16 & & 3.0 & 0.8 & 1.3 & 0.7 \\
\hline
\end{tabular}




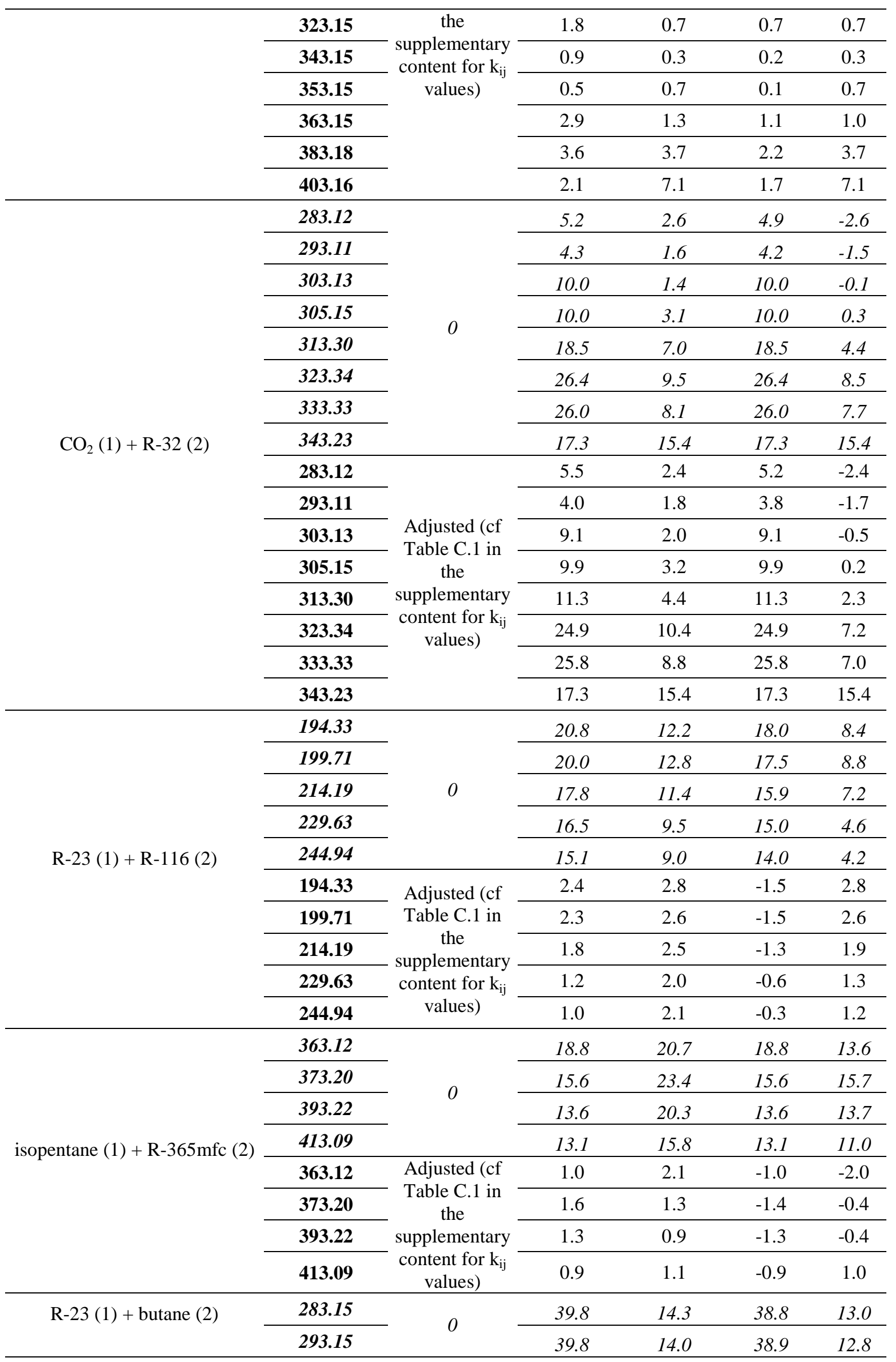




\begin{tabular}{|c|c|c|c|c|c|c|}
\hline & 303.15 & & 40.7 & 15.1 & 39.7 & 13.8 \\
\hline & 313.15 & & 38.6 & 19.9 & 37.7 & 18.4 \\
\hline & 283.15 & \multirow{4}{*}{$\begin{array}{c}\text { Adjusted (cf } \\
\text { Table C. } 1 \text { in } \\
\text { the } \\
\text { supplementary } \\
\text { content for } \mathrm{k}_{\mathrm{ij}} \\
\text { values) }\end{array}$} & 3.2 & 0.5 & -0.8 & 0.5 \\
\hline & 293.15 & & 4.3 & 0.9 & 0.2 & 0.9 \\
\hline & 303.15 & & 3.2 & 1.3 & -0.8 & 1.3 \\
\hline & 313.15 & & 2.8 & 2.1 & -0.6 & 2.1 \\
\hline \multirow{8}{*}{ isopentane (1) + R-245fa (2) } & 362.94 & \multirow{4}{*}{0} & 24.1 & 27.3 & 24.1 & -2.3 \\
\hline & 373.17 & & 18.3 & 18.2 & 18.3 & -0.2 \\
\hline & 392.87 & & 16.8 & 27.0 & 16.8 & 7.9 \\
\hline & 412.91 & & 16.3 & 15.1 & 16.3 & 6.3 \\
\hline & 362.94 & \multirow{4}{*}{$\begin{array}{l}\text { Adjusted (cf } \\
\text { Table C. } 1 \text { in } \\
\text { the } \\
\text { supplementary } \\
\text { content for } \mathrm{k}_{\mathrm{ij}} \\
\text { values) }\end{array}$} & 2.1 & 5.7 & -1.6 & -5.7 \\
\hline & 373.17 & & 3.3 & 6.6 & -2.9 & -6.6 \\
\hline & 392.87 & & 3.3 & 4.4 & -3.0 & -4.4 \\
\hline & 412.91 & & 4.1 & 3.5 & 0.9 & -2.6 \\
\hline
\end{tabular}


Table A.1 - Experimental and PT-EoS adjusted parameters for several refrigerant families $\left(\right.$ with $\mathbf{m}_{2}=$ 0.01 and $\left.m_{3}=0.4\right) . \omega$ is the acentric factor, $m_{1}$ the alpha function parameter, and $Z_{c, o p t}$ and $Z_{c}$ the optimized and the experimental critical compressibility factors, respectively.

\begin{tabular}{|c|c|c|c|c|c|}
\hline Families & Compounds & $\omega$ & $\mathbf{m}_{1}$ & $\mathbf{Z}_{\mathrm{c}, \mathrm{opt}}$ & $\mathrm{Z}_{\mathrm{c}}$ \\
\hline \multirow{4}{*}{ PFC } & R-C318 & 0.35530 & 0.90709 & 0.31295 & 0.27751 \\
\hline & $\mathrm{R}-14$ & 0.17850 & 0.67555 & 0.31954 & 0.27883 \\
\hline & $\mathrm{R}-116$ & 0.25660 & 0.77577 & 0.31510 & 0.28151 \\
\hline & $\mathrm{R}-218$ & 0.31720 & 0.84300 & 0.31391 & 0.27553 \\
\hline \multirow{10}{*}{ CFC } & $\mathrm{R}-11$ & 0.18875 & 0.65407 & 0.31346 & 0.27901 \\
\hline & $\mathrm{R}-12$ & 0.17948 & 0.63489 & 0.31310 & 0.27643 \\
\hline & $\mathrm{R}-13$ & 0.17230 & 0.63476 & 0.31484 & 0.27685 \\
\hline & $\mathrm{R}-113$ & 0.25253 & 0.74834 & 0.31080 & 0.28019 \\
\hline & $\mathrm{R}-114$ & 0.25230 & 0.74764 & 0.30981 & 0.27563 \\
\hline & $\mathrm{R}-115$ & 0.25000 & 0.75177 & 0.31374 & 0.26779 \\
\hline & $\mathrm{R}-22$ & 0.22082 & 0.66722 & 0.30519 & 0.26825 \\
\hline & $\mathrm{R}-123$ & 0.28192 & 0.76770 & 0.30627 & 0.26806 \\
\hline & $\mathrm{R}-124$ & 0.28810 & 0.77740 & 0.30741 & 0.26865 \\
\hline & $\mathrm{R}-141 \mathrm{~b}$ & 0.21950 & 0.69075 & 0.30842 & 0.27057 \\
\hline \multirow{14}{*}{ HFC } & $\mathrm{R}-125$ & 0.30520 & 0.80551 & 0.30706 & 0.26844 \\
\hline & $\mathrm{R}-134 \mathrm{a}$ & 0.32684 & 0.79532 & 0.29871 & 0.26004 \\
\hline & R-143a & 0.26150 & 0.67484 & 0.29264 & 0.25502 \\
\hline & $\mathrm{R}-152 \mathrm{a}$ & 0.27521 & 0.67453 & 0.28916 & 0.25233 \\
\hline & R-161 & 0.21700 & 0.62261 & 0.29548 & 0.25979 \\
\hline & R-227ea & 0.35700 & 0.88229 & 0.30851 & 0.26849 \\
\hline & $\mathrm{R}-23$ & 0.26300 & 0.67957 & 0.29438 & 0.25821 \\
\hline & R-236ea & 0.37940 & 0.92944 & 0.31120 & 0.27578 \\
\hline & R-236fa & 0.37721 & 0.90641 & 0.30662 & 0.26664 \\
\hline & $\mathrm{R}-245 \mathrm{ca}$ & 0.35360 & 0.87946 & 0.30986 & 0.27003 \\
\hline & $\mathrm{R}-245 \mathrm{fa}$ & 0.37760 & 0.90658 & 0.30630 & 0.26702 \\
\hline & $\mathrm{R}-32$ & 0.27690 & 0.61931 & 0.27683 & 0.24291 \\
\hline & $\mathrm{R}-365 \mathrm{mfc}$ & 0.38000 & 0.90970 & 0.30914 & 0.26686 \\
\hline & $\mathrm{R}-41$ & 0.20040 & 0.52412 & 0.27968 & 0.24036 \\
\hline \multirow{2}{*}{ HFO } & R-1234yf & 0.27600 & 0.74045 & 0.30169 & 0.26519 \\
\hline & R-1234ze(E) & 0.31300 & 0.80128 & 0.30522 & 0.26651 \\
\hline HCFO & R-1233zd(E) & 0.34137 & 0.82034 & 0.30811 & 0.27884 \\
\hline
\end{tabular}


Table B.1 - Experimental and PR-EoS adjusted parameters for several refrigerant families $\left(\right.$ with $\mathbf{m}_{2}=0$ and $\left.m_{3}=0.49\right)$. $\omega$ is the acentric factor, $m_{1}$ the alpha function parameter, and $Z_{c, o p t}$ and $Z_{c}$ the optimized and the experimental critical compressibility factors, respectively.

\begin{tabular}{|c|c|c|c|}
\hline Families & Compounds & $\omega$ & $\mathbf{m}_{1}$ \\
\hline \multirow{4}{*}{ PFC } & R-C318 & 0.35530 & 0.87504 \\
\hline & $\mathrm{R}-14$ & 0.17850 & 0.61886 \\
\hline & $\mathrm{R}-116$ & 0.25660 & 0.73579 \\
\hline & R-218 & 0.31720 & 0.80385 \\
\hline \multirow{6}{*}{ CFC } & $\mathrm{R}-11$ & 0.18875 & 0.61810 \\
\hline & $\mathrm{R}-12$ & 0.17948 & 0.59947 \\
\hline & $\mathrm{R}-13$ & 0.17230 & 0.59317 \\
\hline & $\mathrm{R}-113$ & 0.25253 & 0.72610 \\
\hline & $\mathrm{R}-114$ & 0.25230 & 0.73275 \\
\hline & $\mathrm{R}-115$ & 0.25000 & 0.71730 \\
\hline \multirow{6}{*}{ HCFC } & R-21 & 0.20610 & 0.65949 \\
\hline & $\mathrm{R}-22$ & 0.22082 & 0.66061 \\
\hline & $\mathrm{R}-123$ & 0.28192 & 0.75902 \\
\hline & $\mathrm{R}-124$ & 0.28810 & 0.76343 \\
\hline & $\mathrm{R}-141 \mathrm{~b}$ & 0.21950 & 0.67316 \\
\hline & $\mathrm{R}-142 \mathrm{~b}$ & 0.23210 & 0.68115 \\
\hline \multirow{14}{*}{ HFC } & $\mathrm{R}-125$ & 0.30520 & 0.79991 \\
\hline & R-134a & 0.32684 & 0.82270 \\
\hline & $\mathrm{R}-143 \mathrm{a}$ & 0.26150 & 0.72686 \\
\hline & $\mathrm{R}-152 \mathrm{a}$ & 0.27521 & 0.73535 \\
\hline & $\mathrm{R}-161$ & 0.21700 & 0.65300 \\
\hline & R-227ea & 0.35700 & 0.86570 \\
\hline & $\mathrm{R}-23$ & 0.26300 & 0.71889 \\
\hline & R-236ea & 0.37940 & 0.90565 \\
\hline & R-236fa & 0.37721 & 0.90003 \\
\hline & $\mathrm{R}-245 \mathrm{ca}$ & 0.35360 & 0.85944 \\
\hline & R-245fa & 0.37760 & 0.89974 \\
\hline & R-32 & 0.27690 & 0.72710 \\
\hline & $\mathrm{R}-365 \mathrm{mfc}$ & 0.38000 & 0.89465 \\
\hline & $\mathrm{R}-41$ & 0.20040 & 0.61788 \\
\hline \multirow{2}{*}{ HFO } & R-1234yf & 0.27600 & 0.76202 \\
\hline & $\mathrm{R}-1234 \mathrm{ze}(\mathrm{E})$ & 0.31300 & 0.80066 \\
\hline HCFO & R-1233zd(E) & 0.34137 & 0.80854 \\
\hline NATURAL FLUIDS & $\mathrm{CO}_{2}$ & 0.22394 & 0.69219 \\
\hline
\end{tabular}




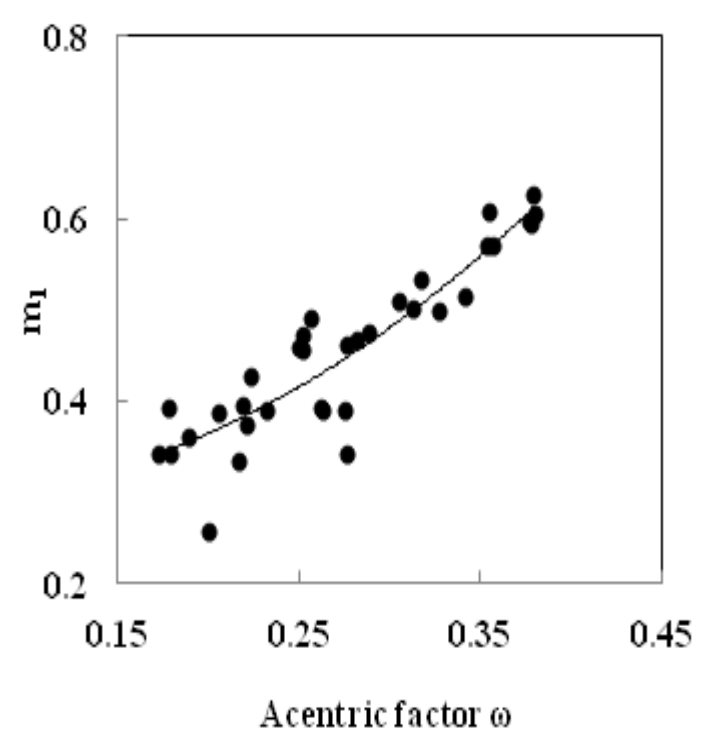

(a)

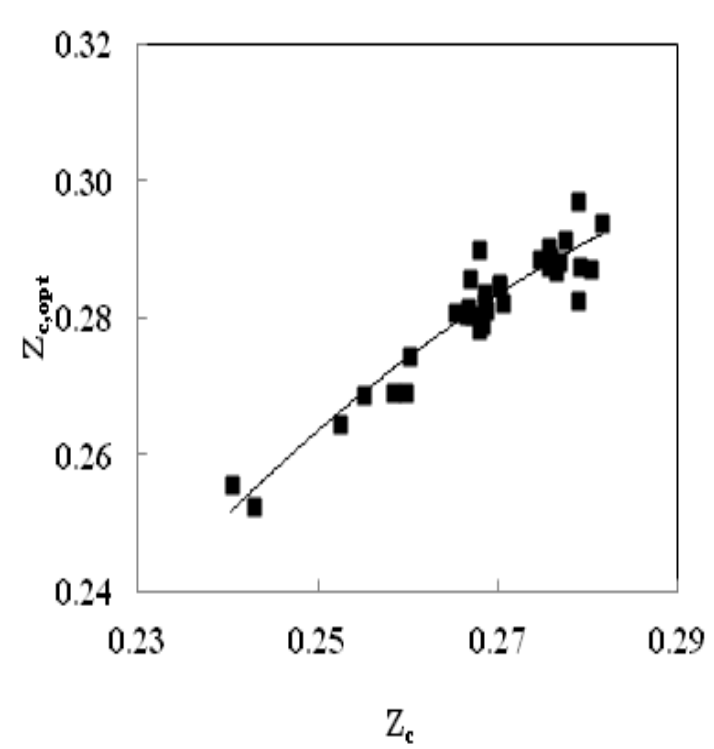

(b)

Fig. 22 - Correlations obtained with the NEoS. (a): the $m_{1}$ parameter as a function of the acentric factor $\omega$ (coefficient of determination $R^{2}=0.82$ ); (b): the optimized critical compressibility factor $Z_{c, o p t}$ as a function of the experimental critical compressibility factor $Z_{c}\left(\right.$ coefficient of determination $\left.R^{2}=0.89\right)$. 


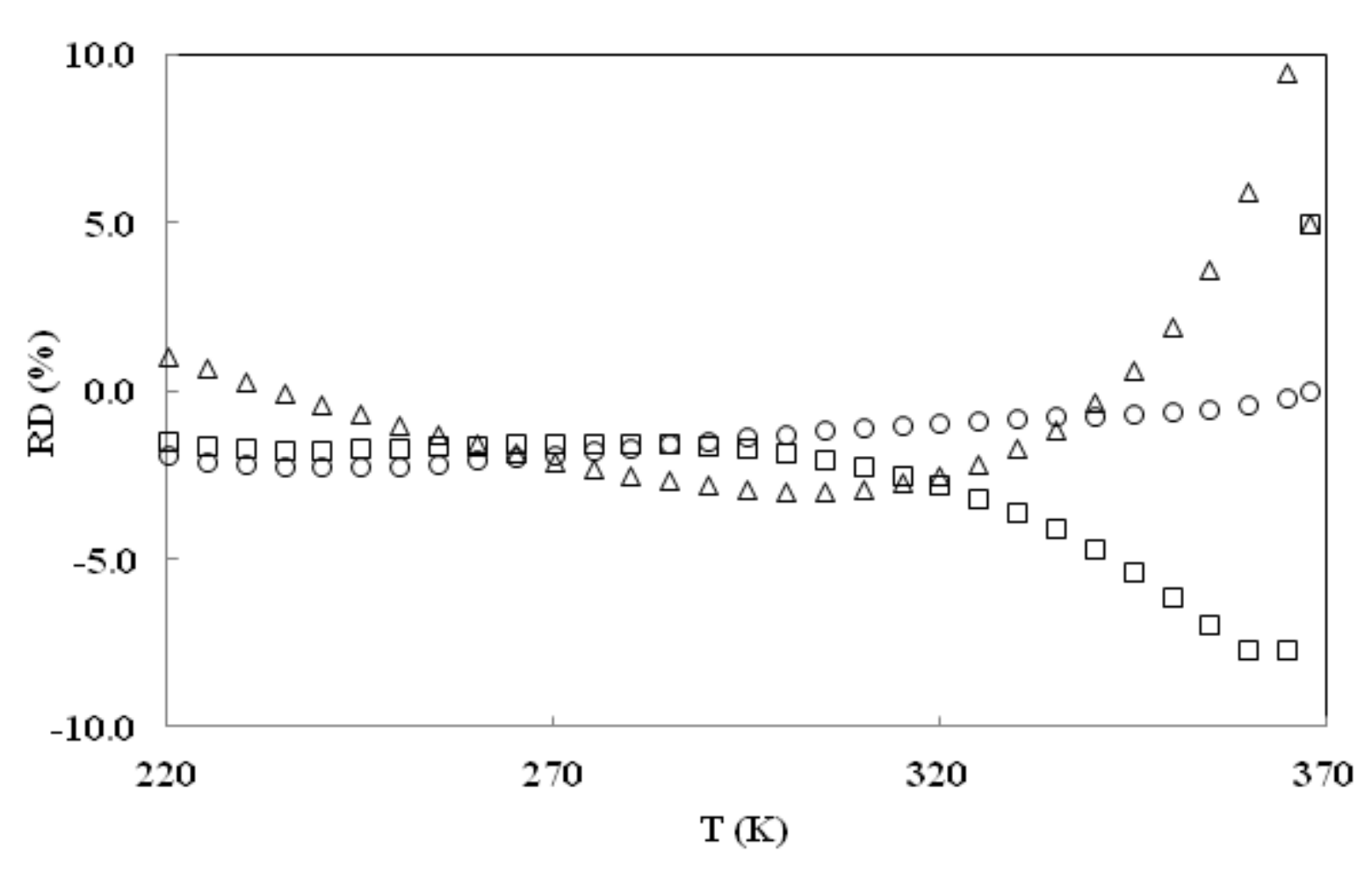

Fig. 23 - Relative deviation (RD) as a function of the temperature for R-1234yf with NEoS, using the calculated parameters.

( $\circ$ ) RD of vapor pressure; $(\Delta)$ RD of saturated liquid density;

( $\square$ ) RD of saturated vapor density. 


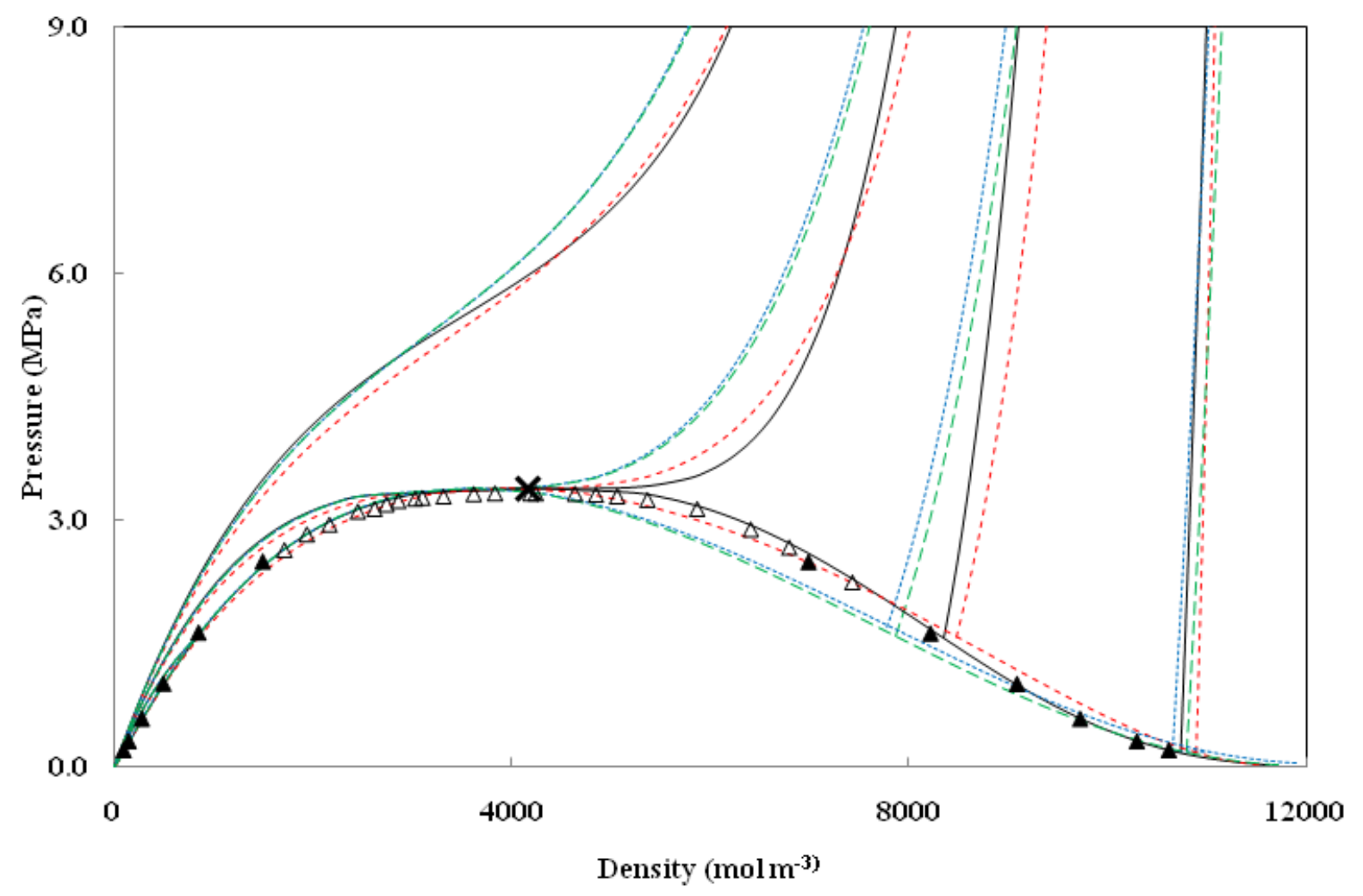

Fig. 24 - P- $\rho$ diagram for R-1234yf.

( $\triangle$ ) Experimental data [24]; ( $\Delta$ ) Confidential Experimental data [23]; (-) REFPROP; $(\times)$ Critical Point: REFPROP $\left(T_{c}=367.85 K\right)$; (- - - ) NEoS; (.....) PT-EoS; $(---)$ PR-EoS. Out of saturation: $T_{r}=0.7,0.9$, 1.0, 1.1. 


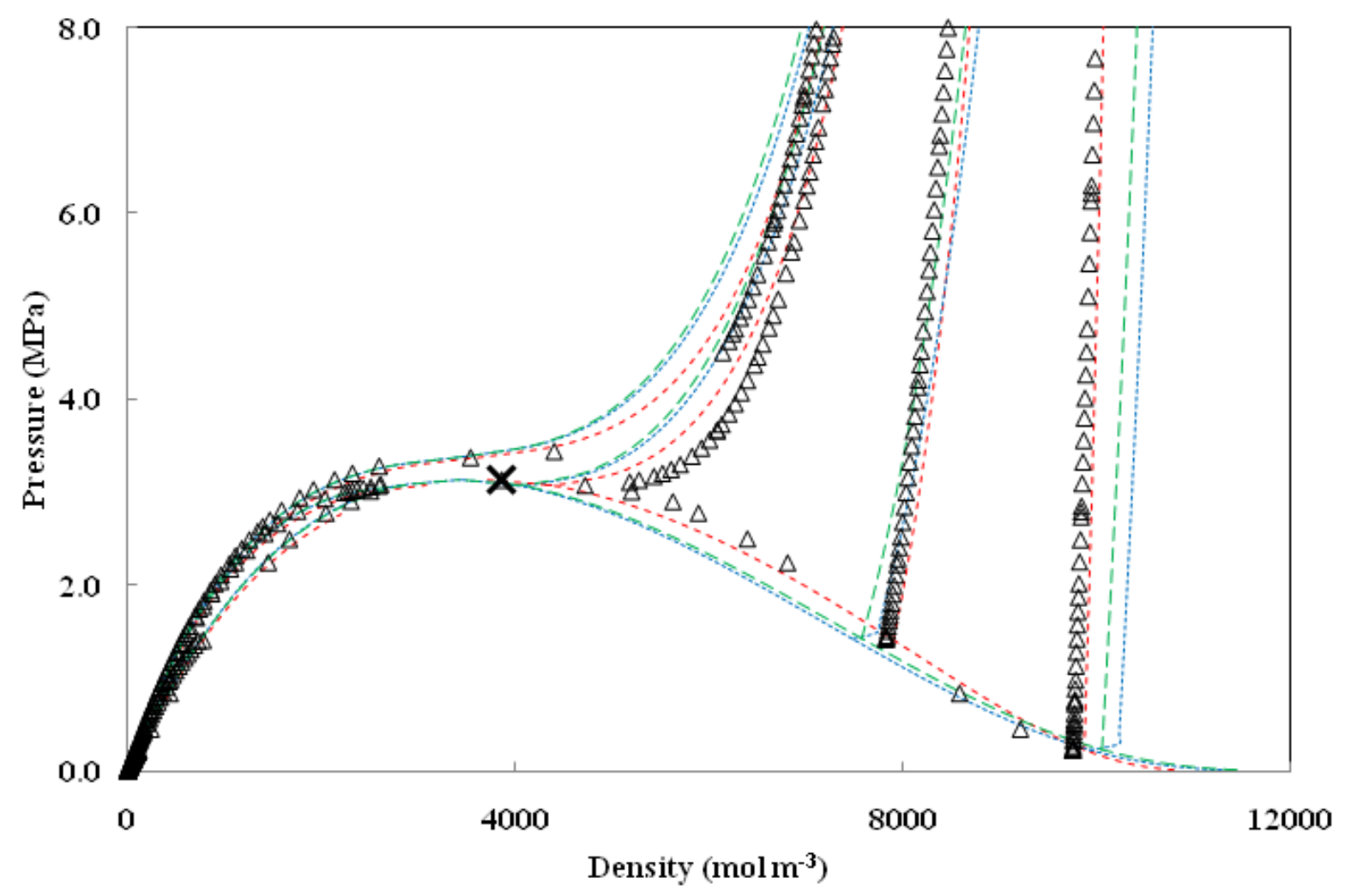

Fig. 25 - P-p diagram for R-1216.

( $\Delta$ ) Experimental data [25]; ( $\times$ ) Critical Point: Experimental $\left(\mathbf{T}_{\mathrm{c}}=358.9\right.$ K) [25]; (- - - -) NEoS; (......) PTEoS; $(---)$ PR-EoS. Out of saturation: $T_{r}=0.73,0.9,1.0$, and 1.01. 


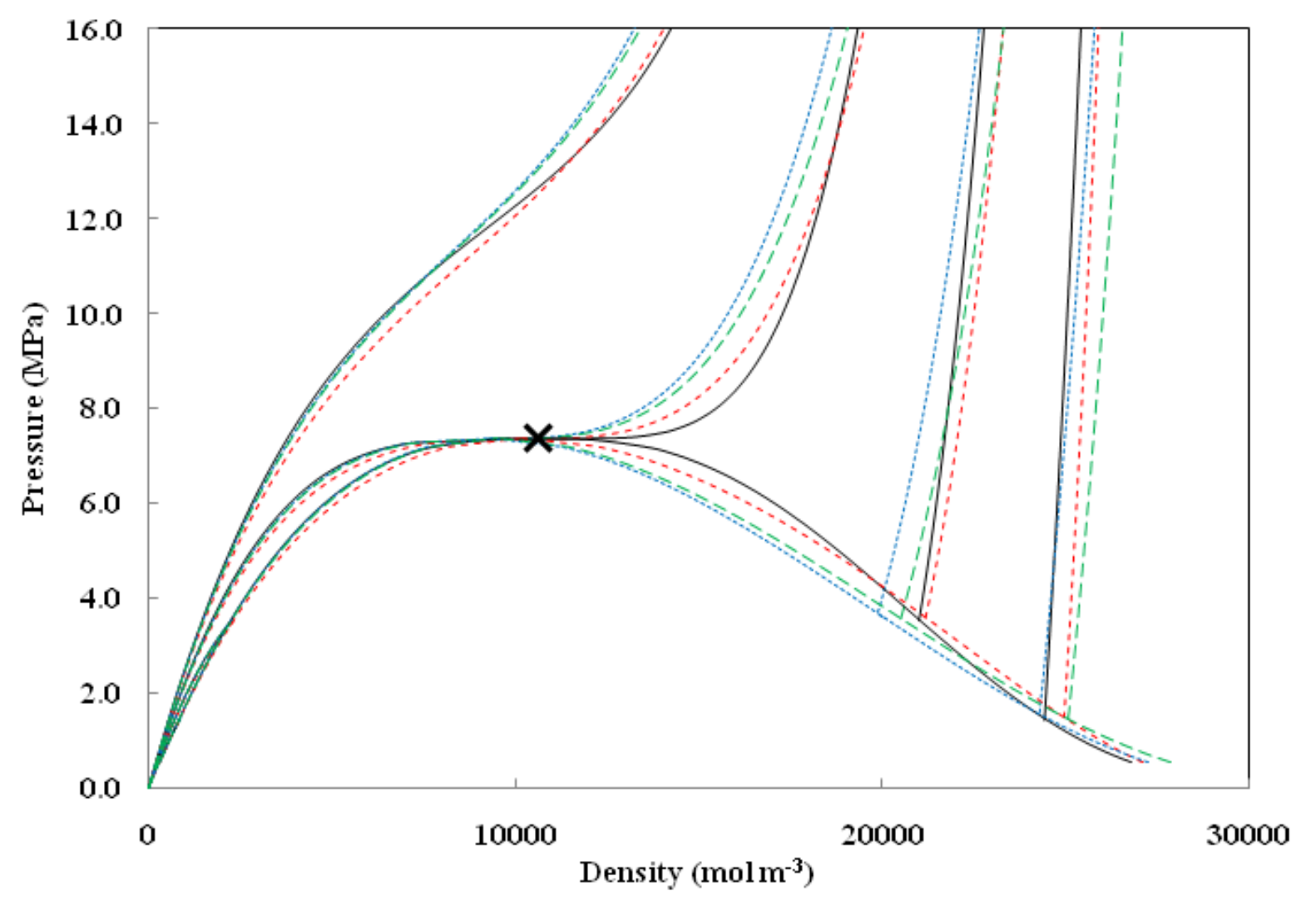

Fig. 26 - P-p diagram for $\mathrm{CO}_{2}$.

(一) REFPROP; $(\times)$ Critical Point: REFPROP $\left(T_{c}=304.13 K\right)$; (- - - -) NEoS; (......) PT-EoS; $(---)$ PR-EoS. Out of saturation: $T_{r}=0.8,0.9,1.0$, and 1.1. 


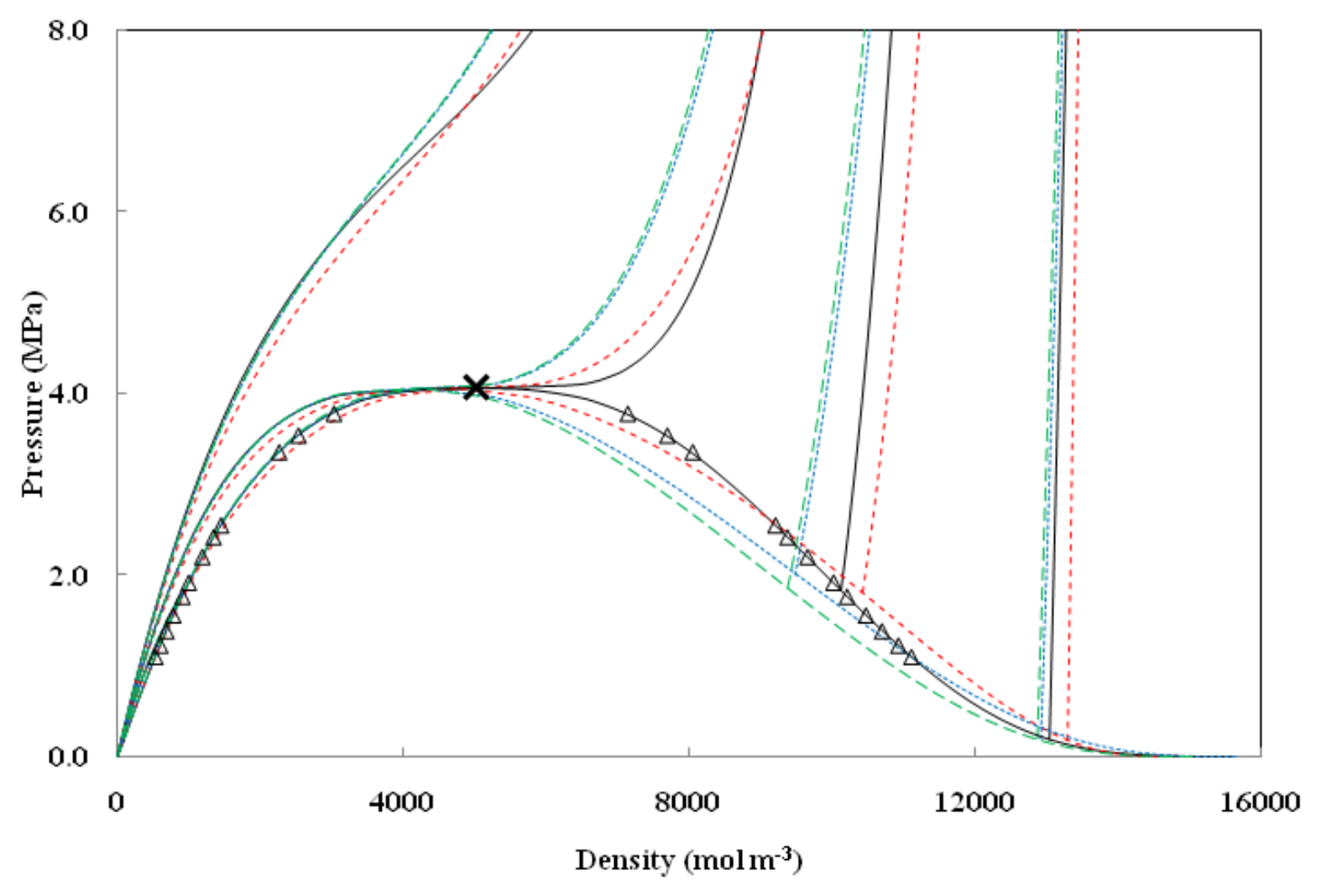

Fig. 27 - P-p diagram for R-134a.

$(\triangle)$ Experimental data [26]; (-) REFPROP; $(x)$ Critical Point: $\operatorname{REFPROP}\left(\mathrm{T}_{\mathrm{c}}=374.21 \mathrm{~K}\right)$; (- - -) NEoS; (.....) PT-EoS; (-- -) PR-EoS. Out of saturation: $T_{r}=0.7,0.9,1.0$, and 1. 


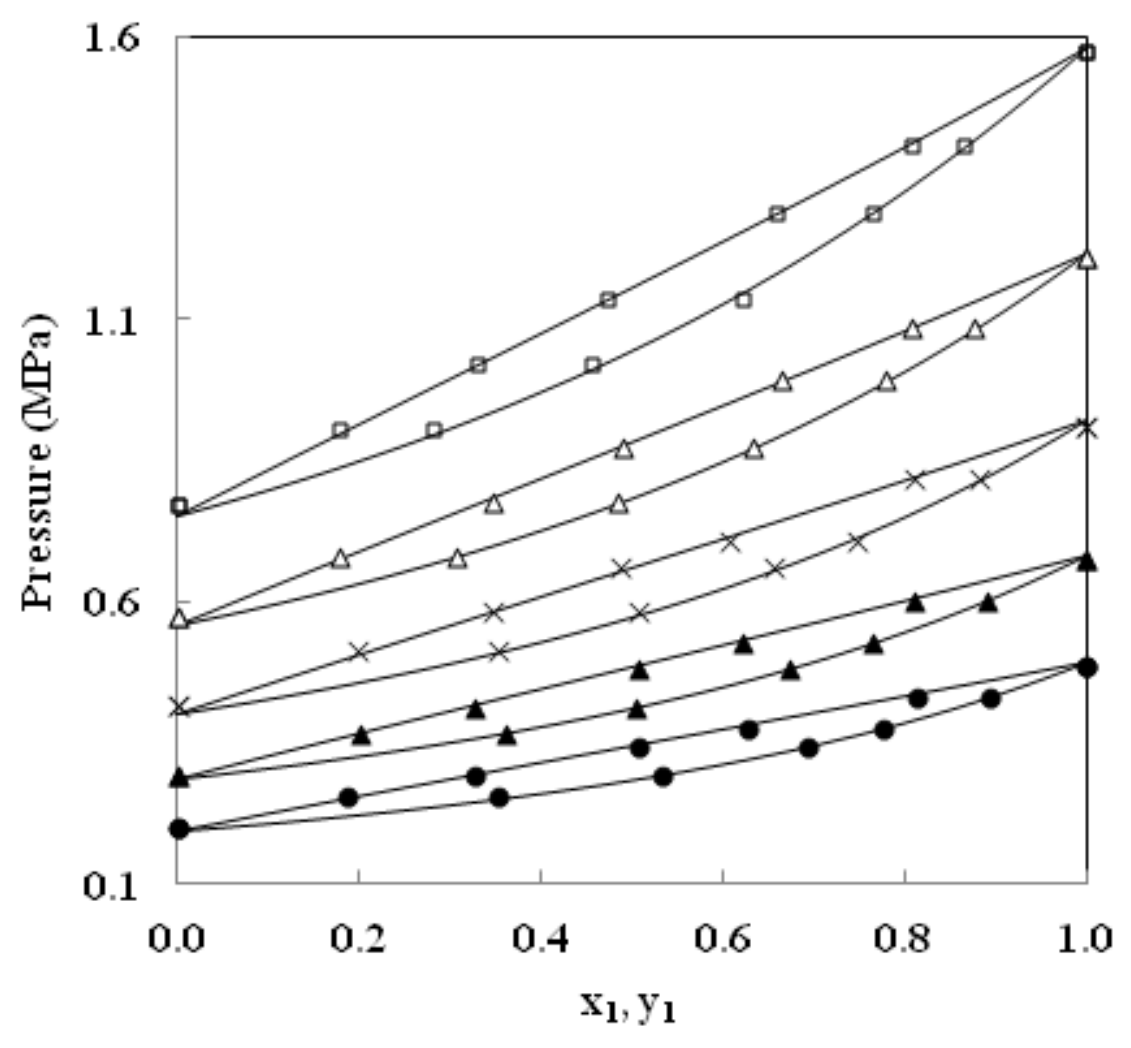

Fig. 28 - VLE prediction for R-125 (1) + R-134a (2).

Experimental data [28]: (•) 263.15 K; ( $\Delta$ ) $273.15 \mathrm{~K}$;

(×) 283.15 K; ( $\Delta)$ 293.15 K; ( $\square)$ 303.15 K.

NEoS: $(-) \mathbf{k}_{\mathrm{ij}}=\mathbf{0}$. 


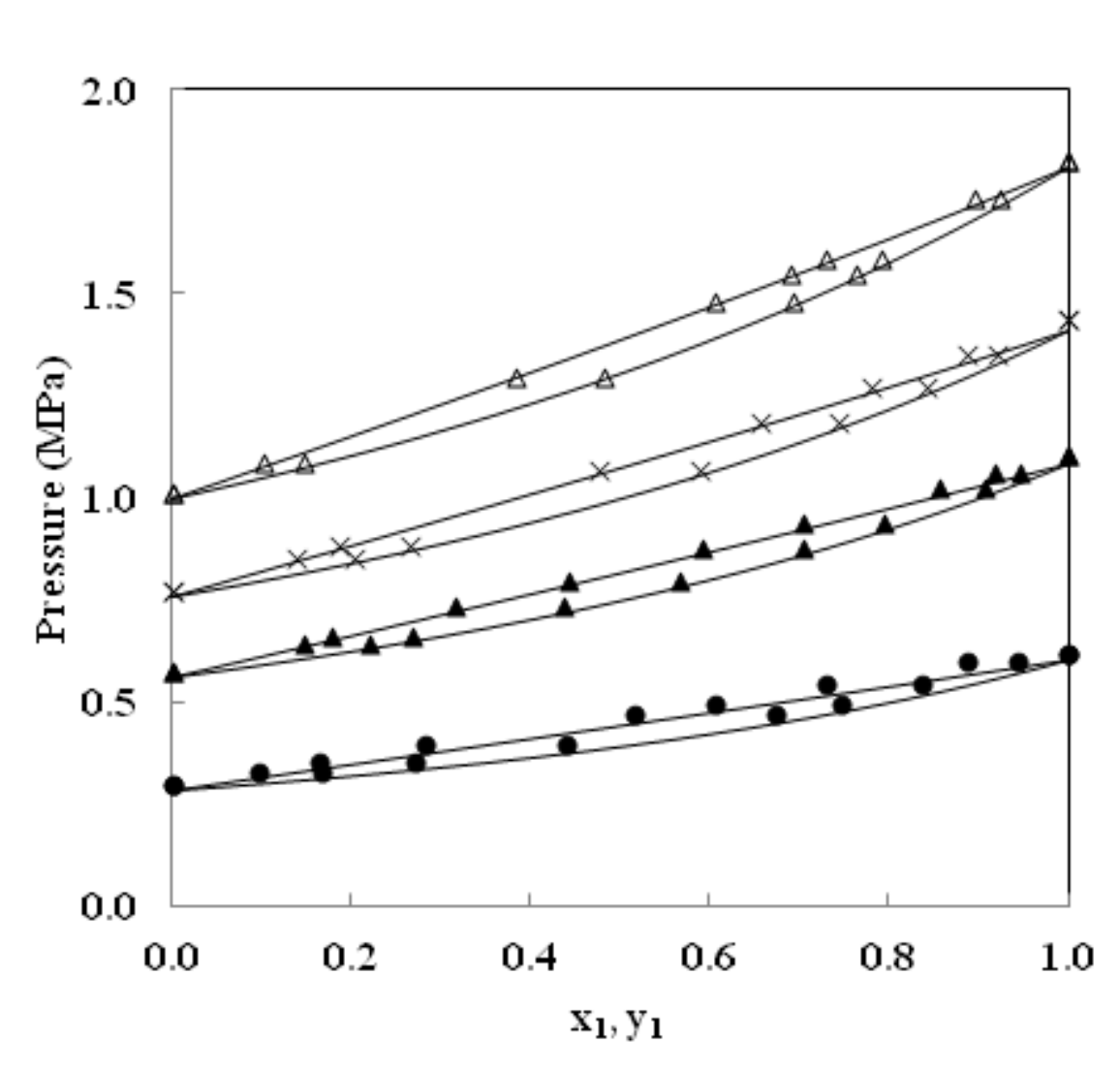

Fig. 29 - VLE prediction for R-143a (1) + R-134a (2). Experimental data [29]: (•) 273.15K; ( $\Delta$ ) 293.15K;

(×) 303.15 K; ( $\Delta)$ 313.15 K.

NEoS: $(-) \mathbf{k}_{\mathrm{ij}}=0$. 


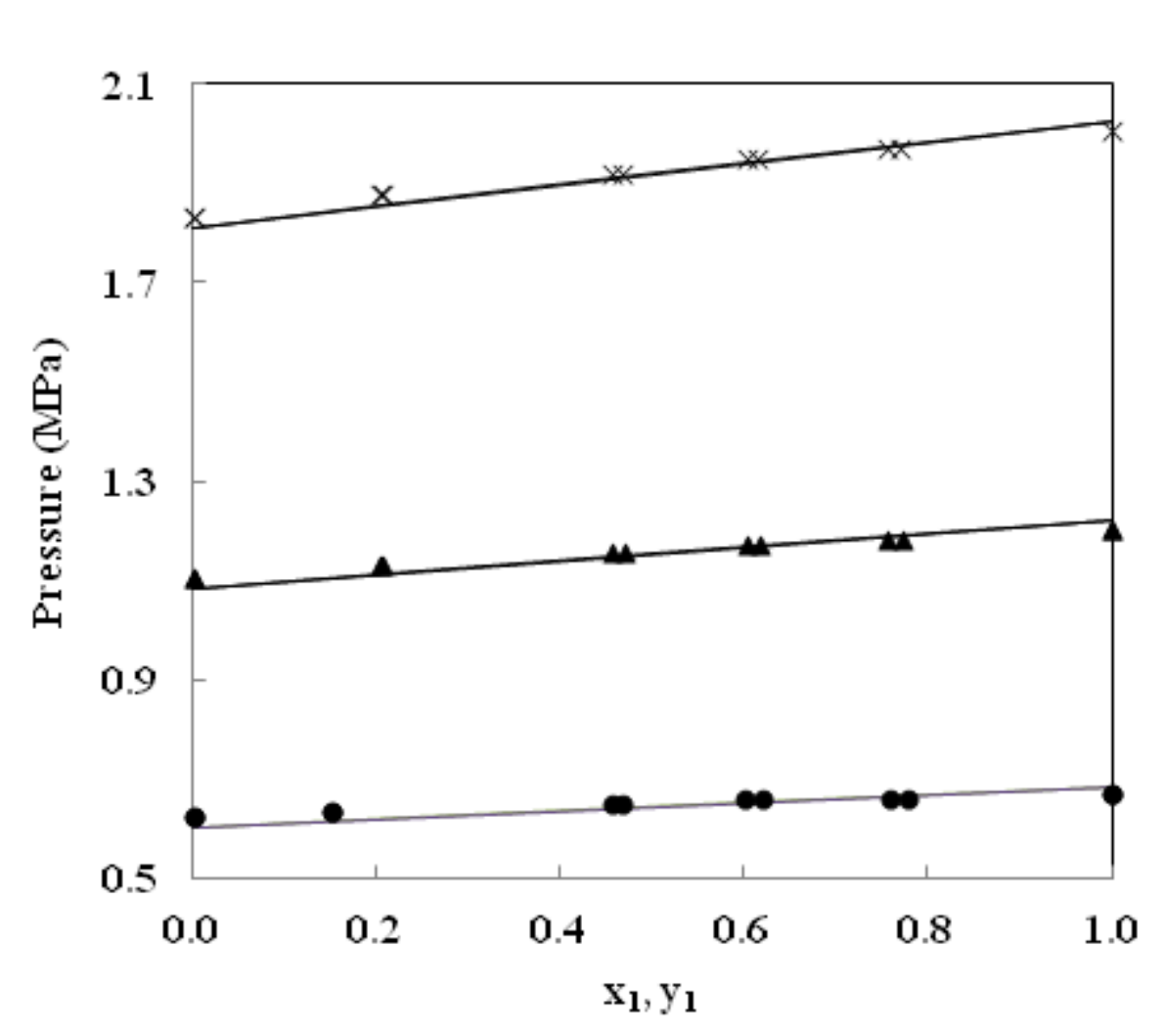

Fig. 30 - VLE prediction for R-125 (1) + R-143a (2).

Experimental data [30]: (•) 273.15 K; ( $\Delta$ ) 293.15 K;

(x) $313.15 \mathrm{~K}$.

NEoS: $(-) \mathbf{k}_{\mathrm{ij}}=\mathbf{0}$. 


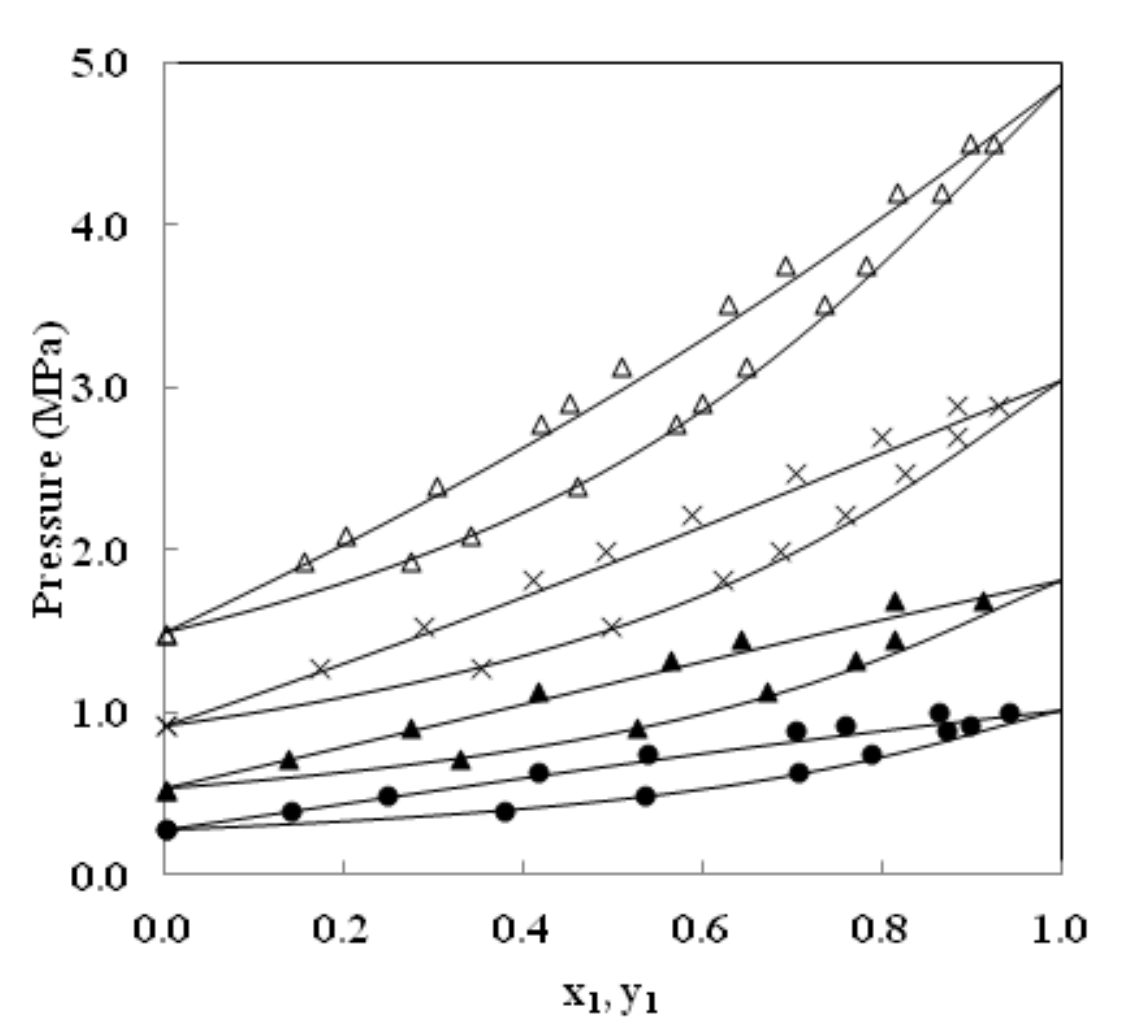

Fig. 31 - VLE prediction for R-32 (1) + R-227ea (2).

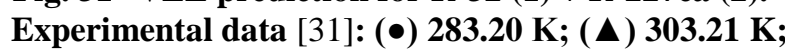
(×) 323.21 K; $(\Delta) 343.38 \mathrm{~K}$.

NEoS: $(-) \mathbf{k}_{\mathrm{ij}}=\mathbf{0}$. 


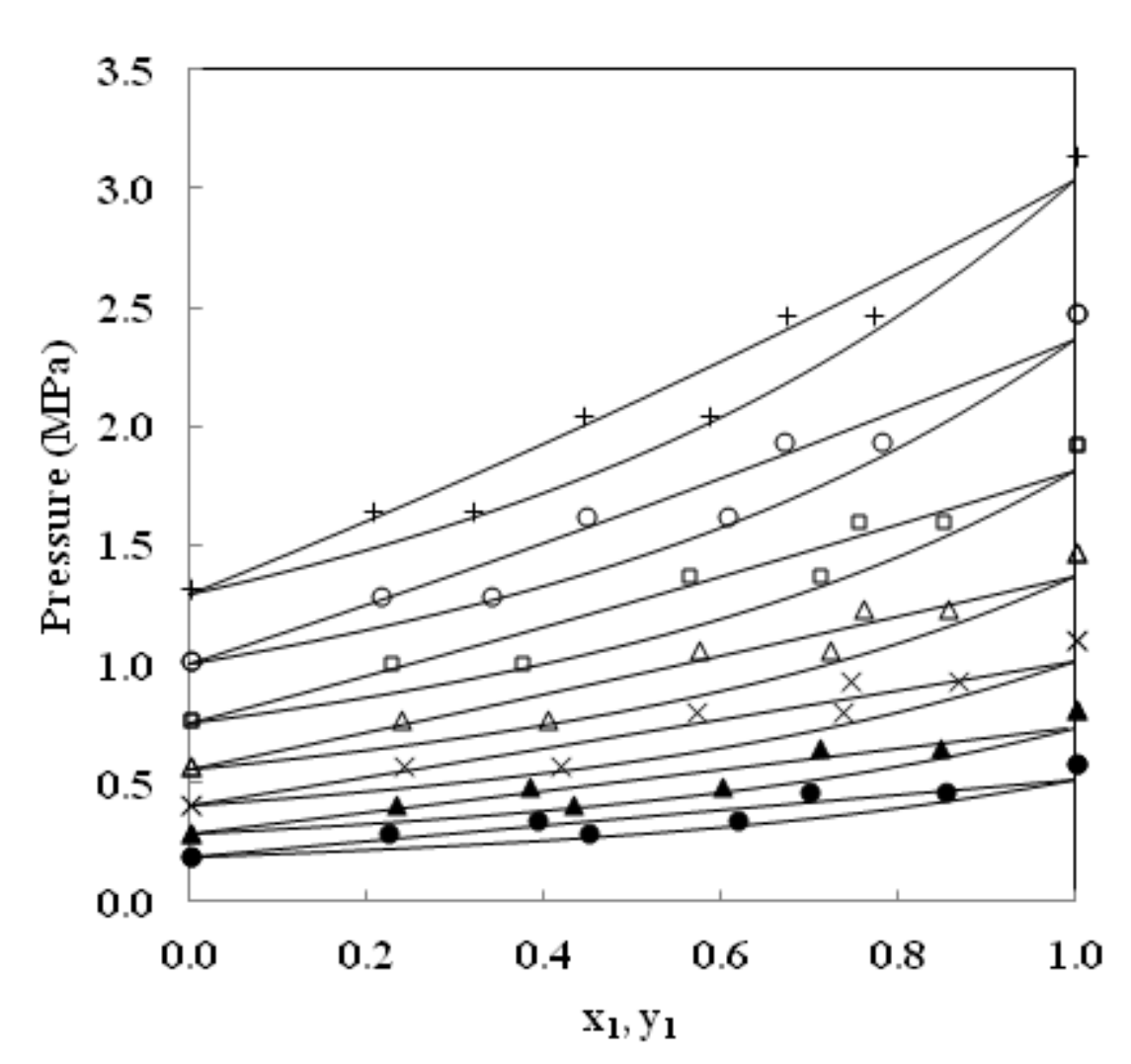

Fig. 32 - VLE prediction for R-32 (1) + R-134a (2).

Experimental data [32]: (•) 263.15 K; ( $\Delta$ ) 273.15 K;

(×) 283.15 K; ( $\triangle$ ) 293.15 K; ( $\square)$ 303.15 K; ( $)$ 313.15 K;

(+) 323.15 K. NEoS: $(-) k_{i j}=0$. 


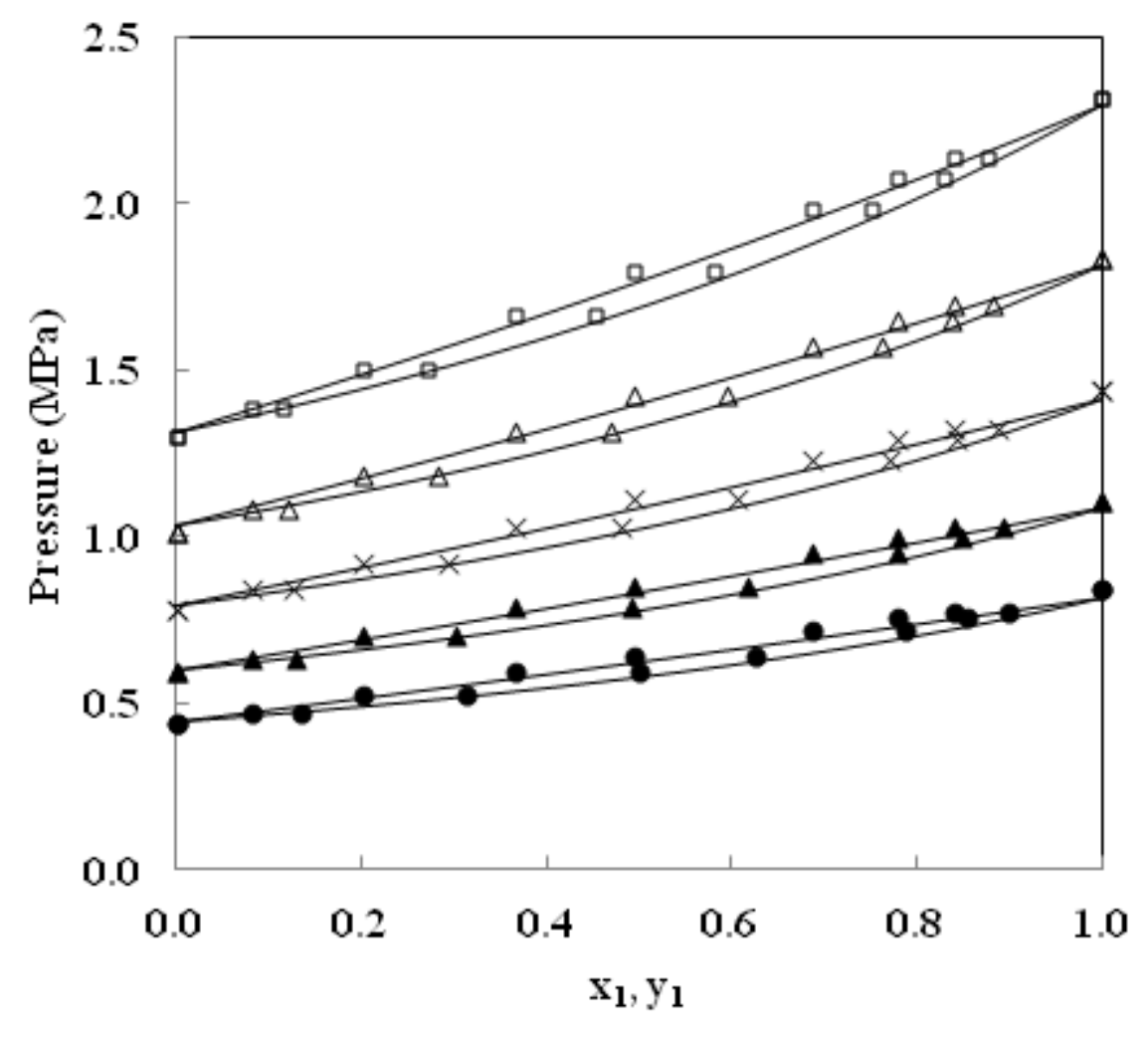

Fig. 33 - VLE prediction for R-143a (1) + R-1234yf (2).

Experimental data [33]: (•) 283.15 K; ( $\Delta$ ) 293.15 K;

(×) 303.15 K; ( $\Delta)$ 313.15 K; ( $\square) 323.15 \mathrm{~K}$.

NEoS: $(-) \mathbf{k}_{\mathrm{ij}}=\mathbf{0}$. 


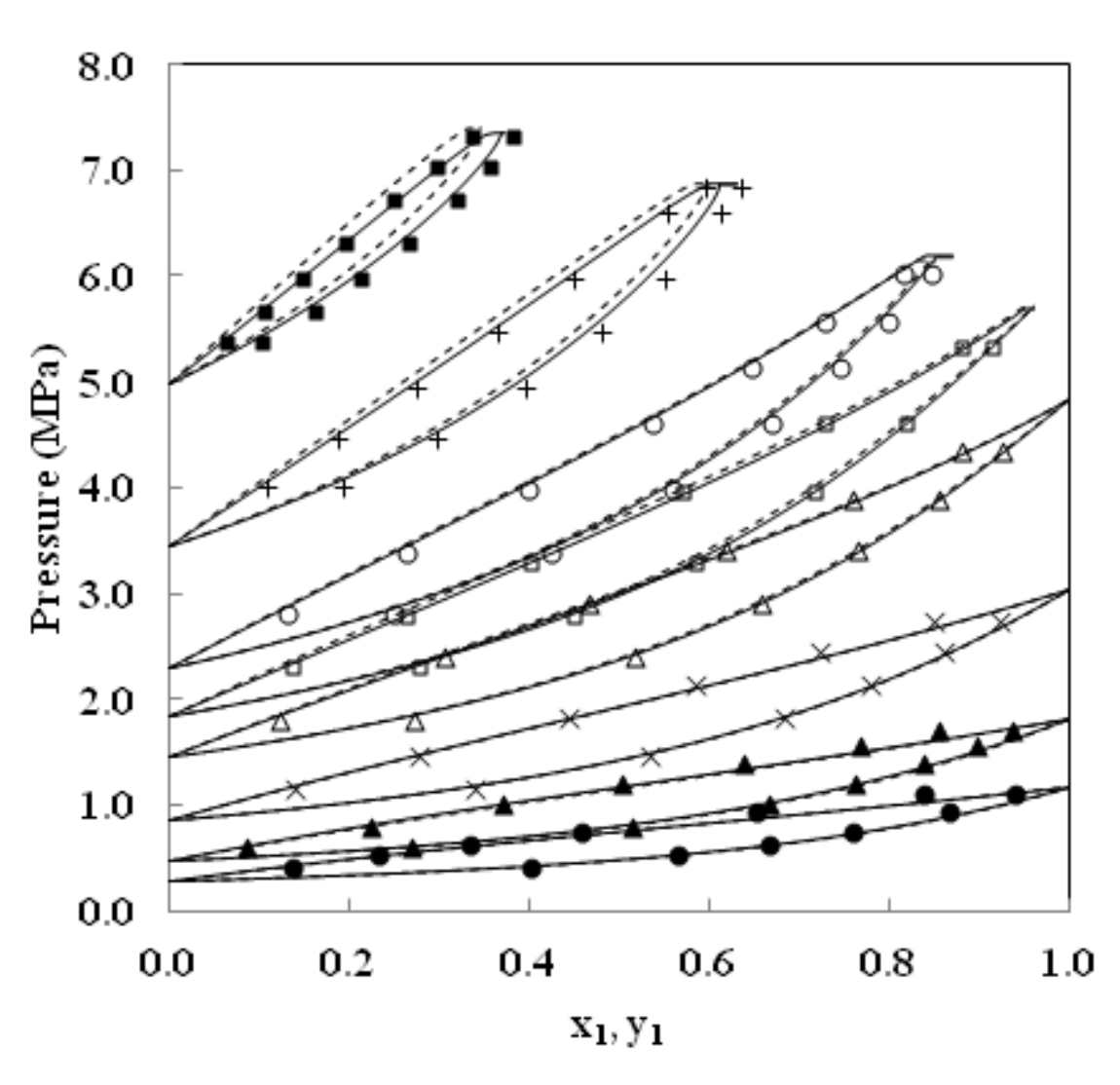

Fig. 34 - VLE prediction for $\mathrm{SO}_{2}(1)+\mathrm{R}-32$ (2).

Experimental data [34]: (•) 288.07 K; ( $\Delta$ ) 303.16 K;

(×) 323.15 K; ( $\Delta$ ) 343.15 K; ( $\square$ ) 353.15 K; (○) 363.15 K;

(+) $383.18 \mathrm{~K}$; (घ) 403.16 K.

NEoS: $(-) k_{i j}=0$; (- - - ) $k_{i j}$ adjusted. 


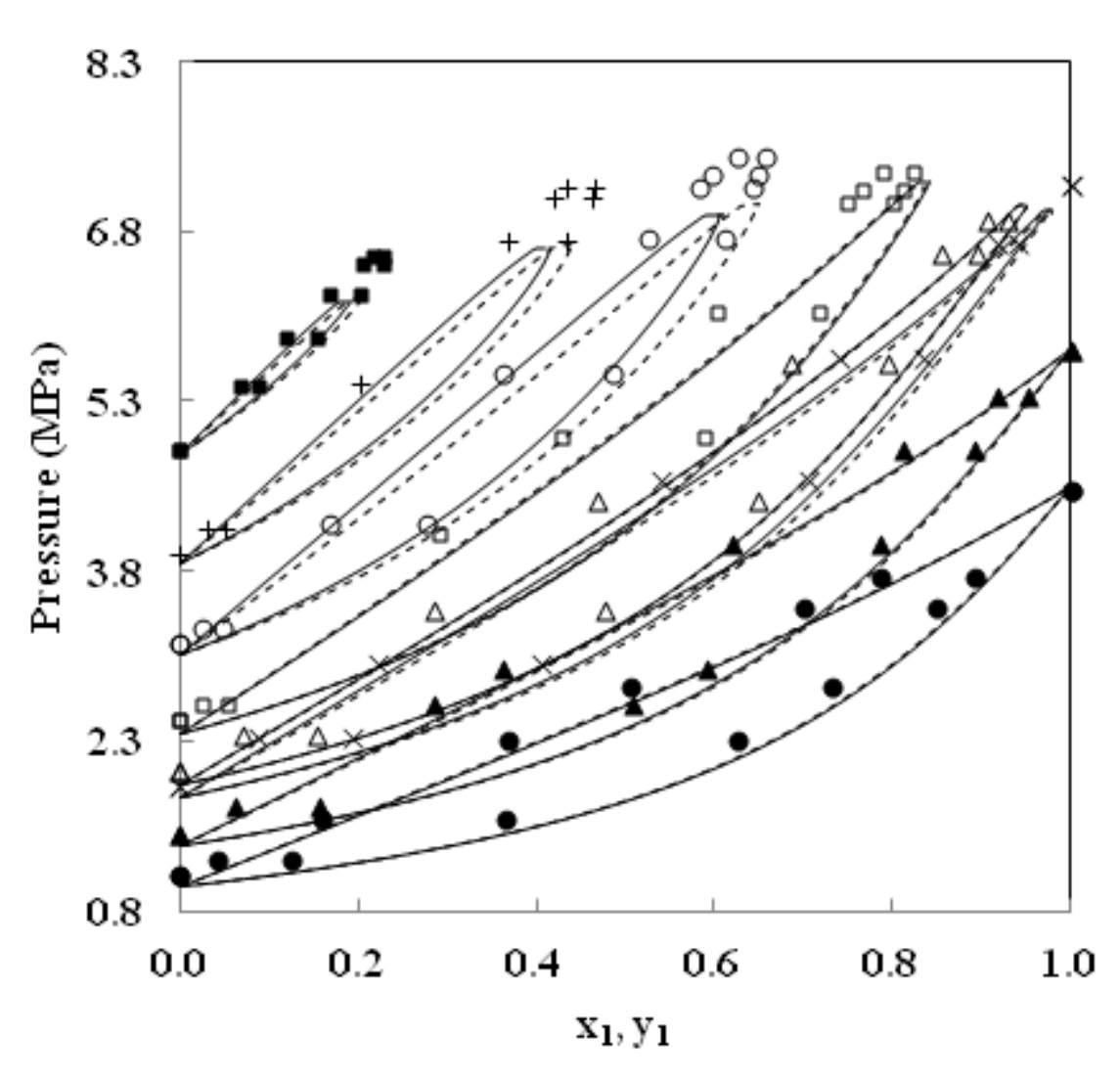

Fig. 35 - VLE prediction for $\mathrm{CO}_{2}(1)+\mathrm{R}-32$ (2).

Experimental data [35]: (•) 283.12 K; ( $\Delta$ ) $293.11 \mathrm{~K}$;

(×) 303.13 K; ( $\Delta$ ) 305.15 K; ( () $313.30 \mathrm{~K}$; ( ( ) 323.34 K;

(+) $333.33 \mathrm{~K}$; (口) $343.23 \mathrm{~K}$.

NEoS: (-) $k_{i j}=0$; (- - -) $k_{i j}$ adjusted. 


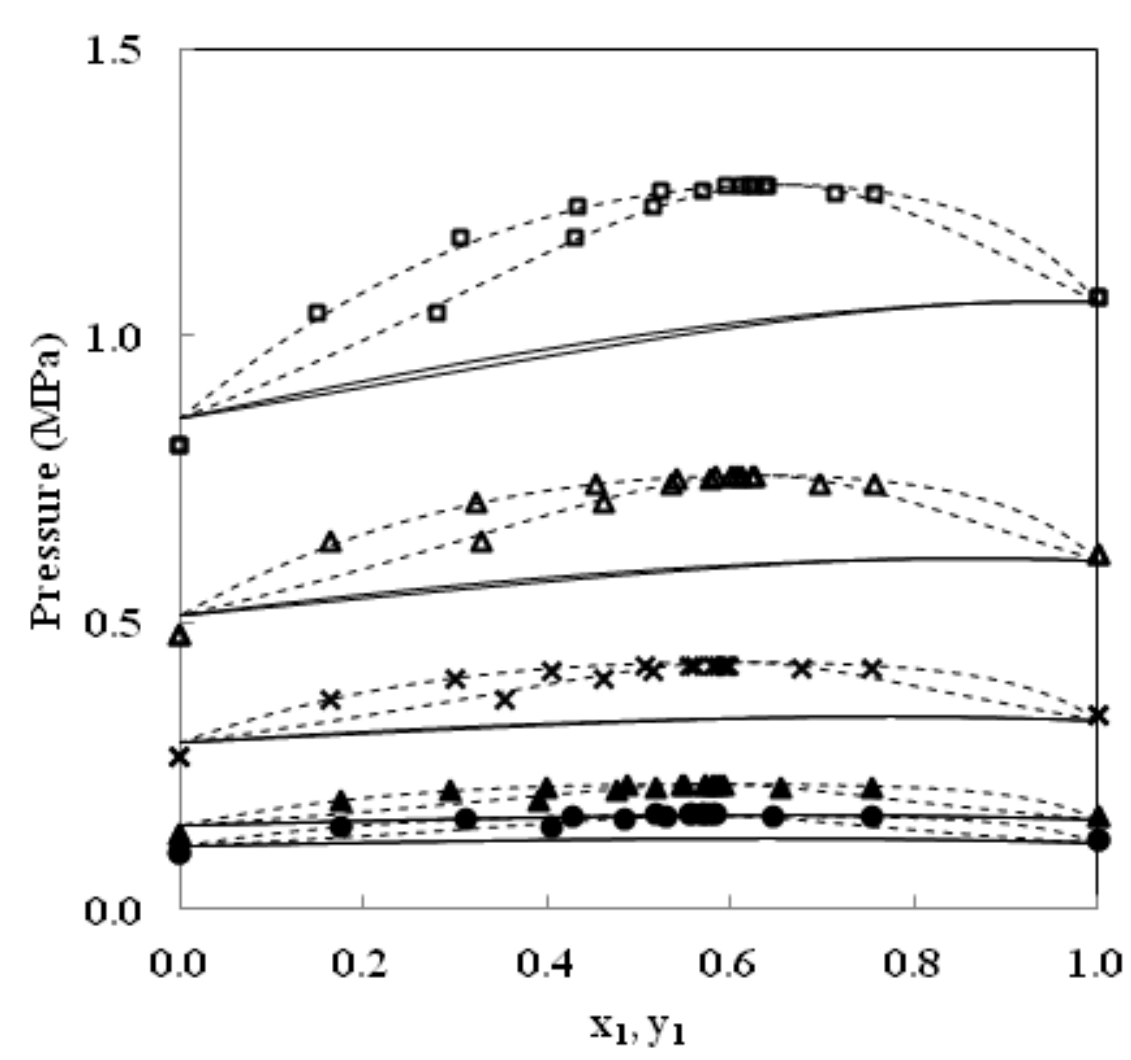

Fig. 36 - VLE prediction for R-23 (1) + R-116 (2).

Experimental data [36]: (•) $194.33 \mathrm{~K}$;

( А ) 199.71 K; (×) 214.19 K; ( $\Delta$ ) 229.63 K;

() $244.94 \mathrm{~K}$.

NEoS: (—) $\mathbf{k}_{\mathrm{ij}}=0$; (- - -) $\mathbf{k}_{\mathrm{ij}}$ adjusted. 


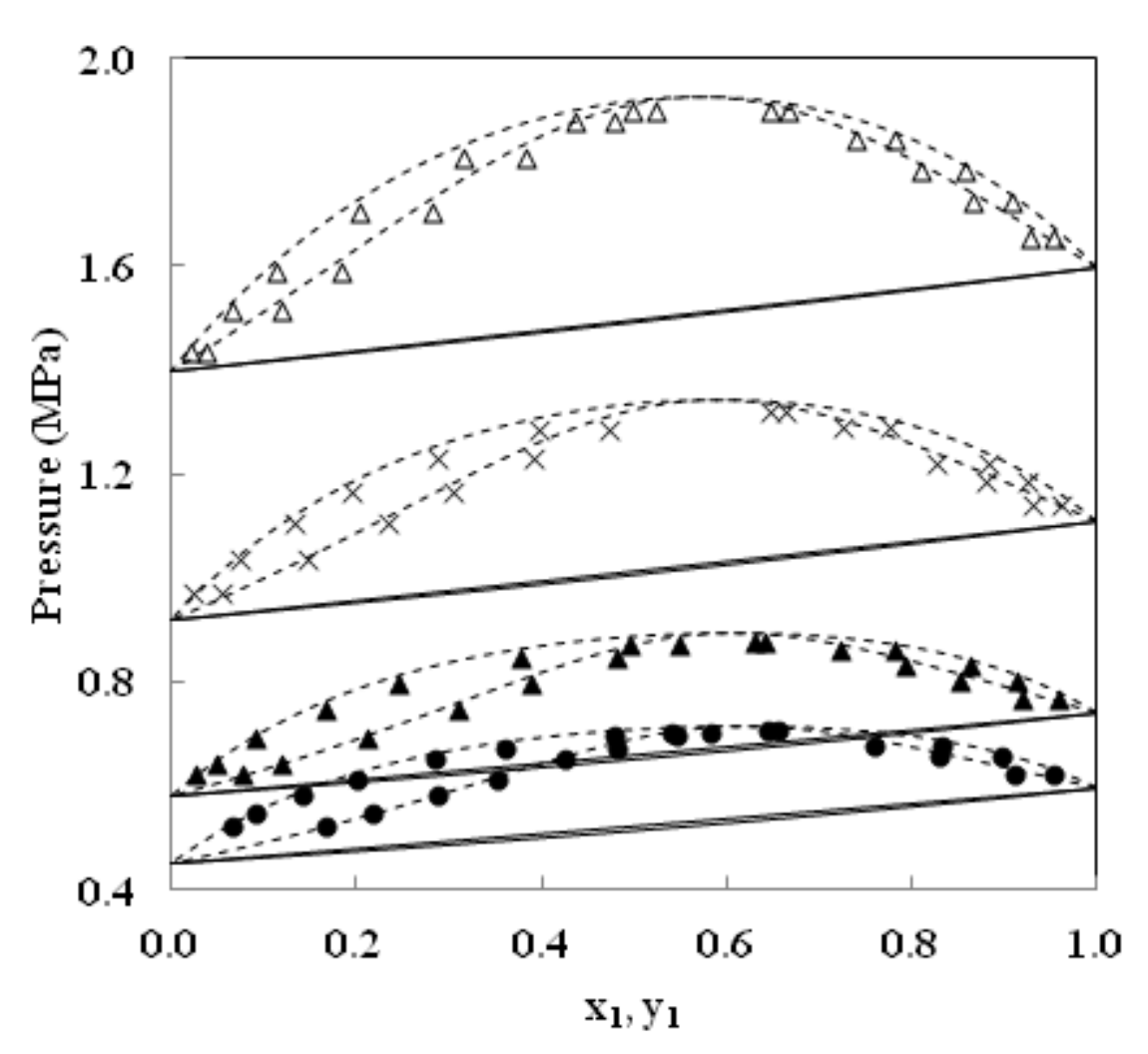

Fig. 37 - VLE prediction for isopentane (1) + R-365mfc (2).

Experimental data [37]: (•) 363.12 K;

( $\Delta$ ) 373.20 K; (x) 393.22 K; ( $\Delta$ ) 413.09 K.

NEoS: $(-) k_{i j}=0$; (- - - ) $k_{i j}$ adjusted. 


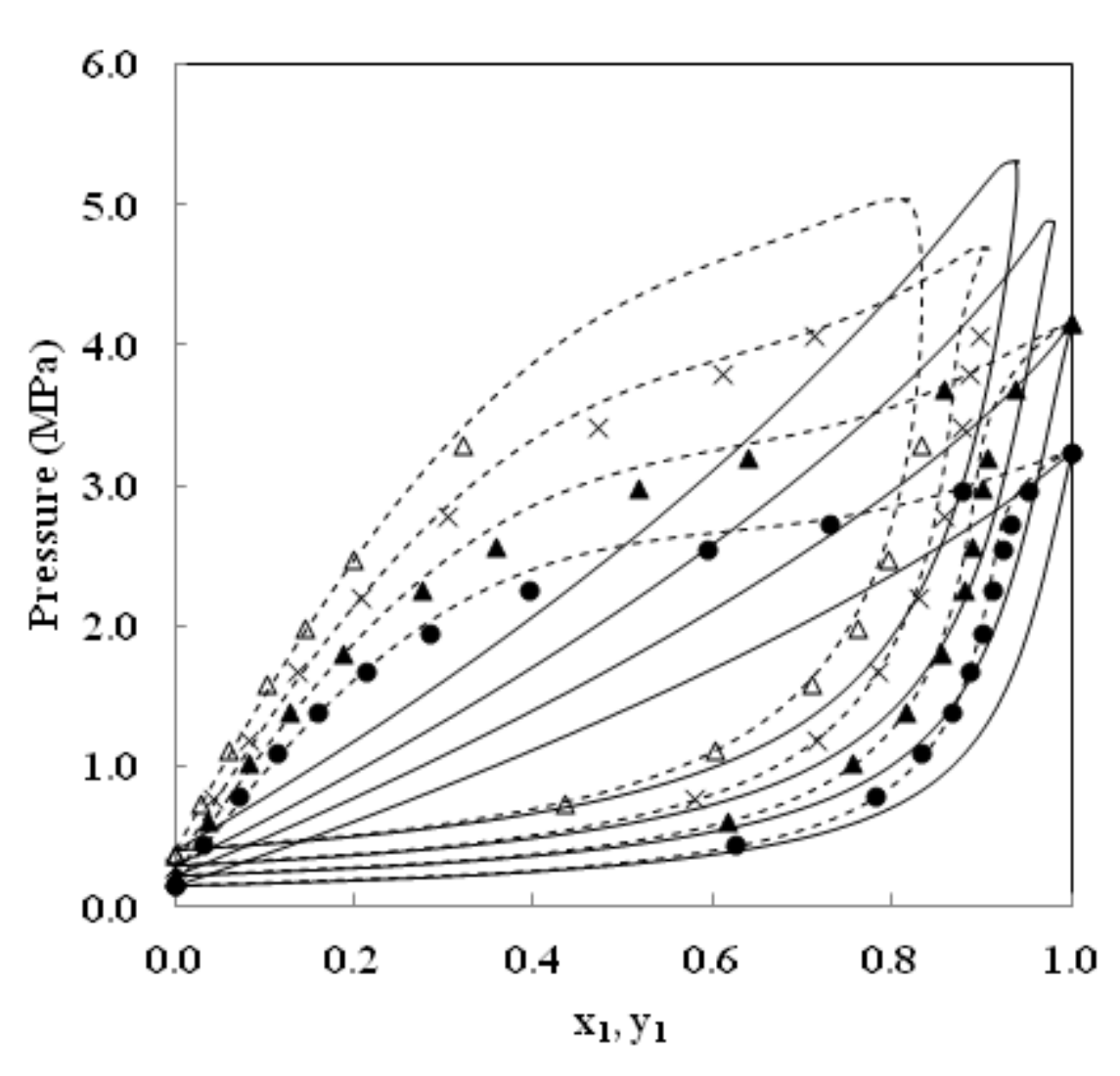

Fig. 38 - VLE prediction for R-23 (1) + butane (2).

Experimental data [38]: (•) 283.15 K; ( $\Delta$ ) 293.15 K;

(x) 303.15 K; ( $\Delta) 313.15 \mathrm{~K}$.

NEoS: $(-) k_{\mathrm{ij}}=0$; (- - -) $\mathbf{k}_{\mathrm{ij}}$ adjusted. 


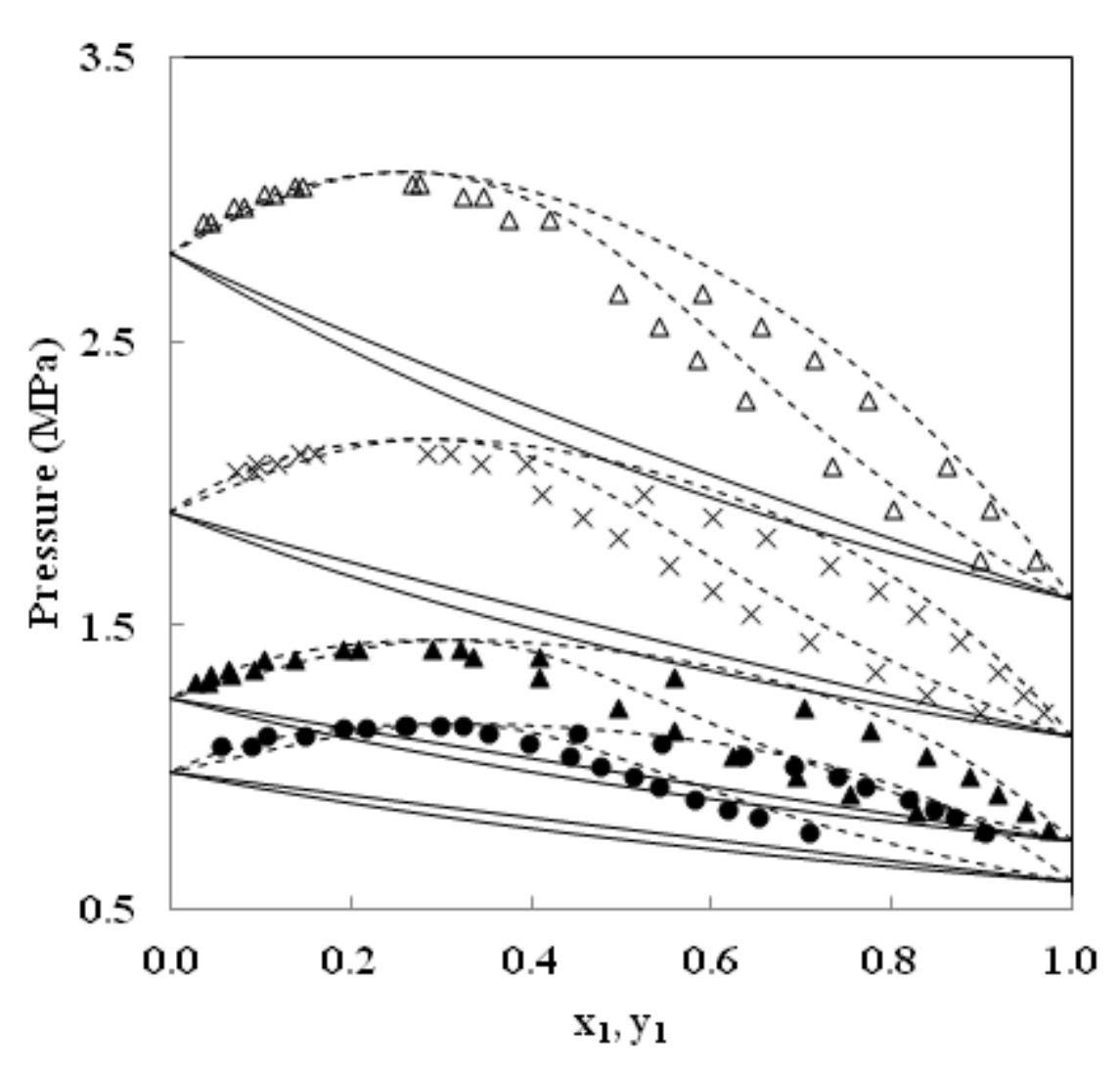

Fig. 39 - VLE prediction for isopentane (1) + R-245fa (2).

Experimental data [37]: (•) $362.94 \mathrm{~K}$; ( $\Delta$ ) $373.17 \mathrm{~K}$;

(x) 392.87 K; ( $\Delta)$ 412.91 K.

NEoS: $(-) k_{i j}=0$; (- - -) $k_{i j}$ adjusted. 


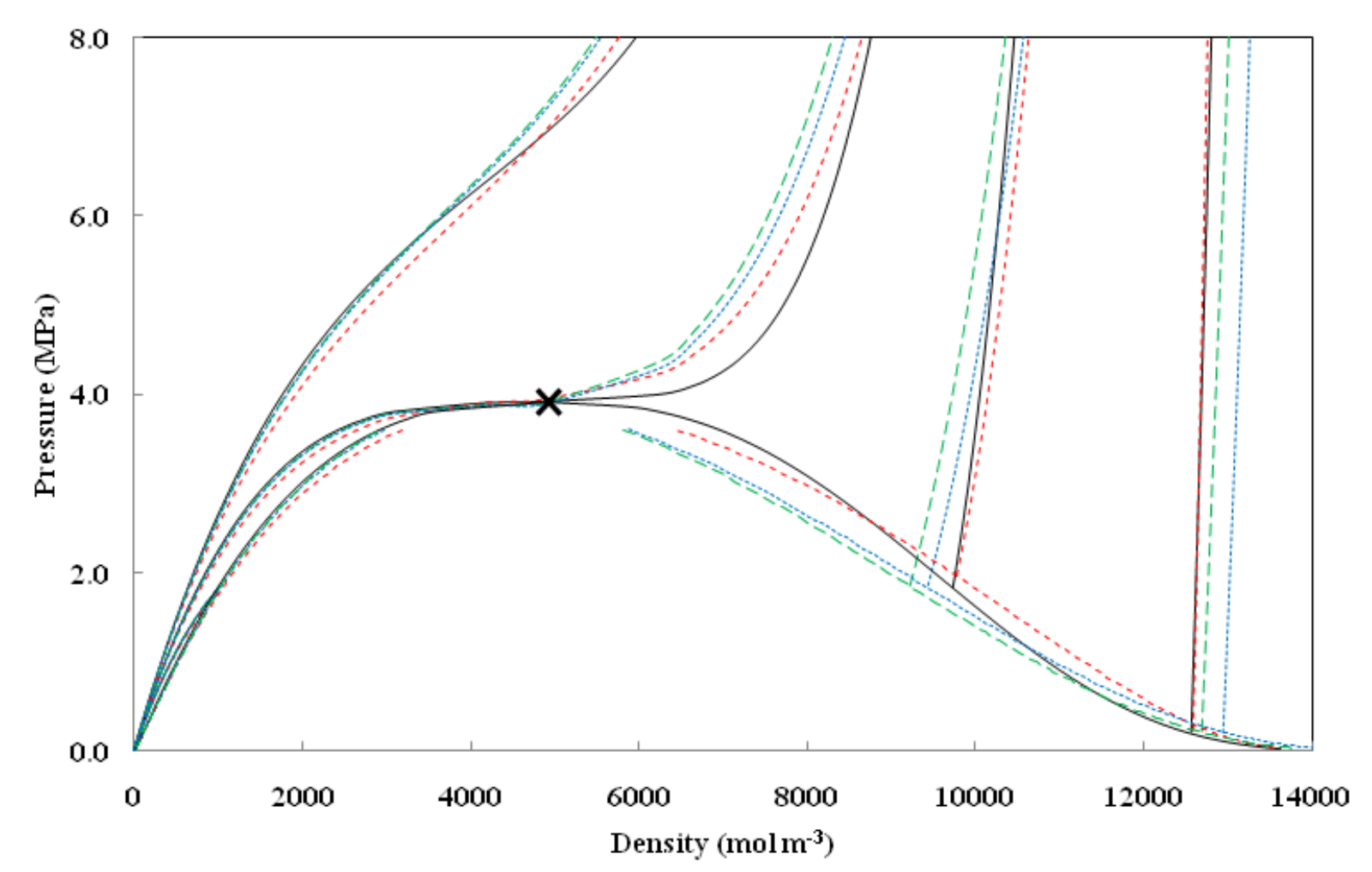

Fig. 40 - P- $\rho$ diagram for R-421A.

(-) REFPROP; $(\times)$ Critical Point: REFPROP $\left(T_{c}=355.93\right.$ K); (- - - -) NEoS; (......) PT-EoS; $(---)$ PR-EoS. Out of saturation: $T_{r}=0.7,0.9,1.0,1.1$. 


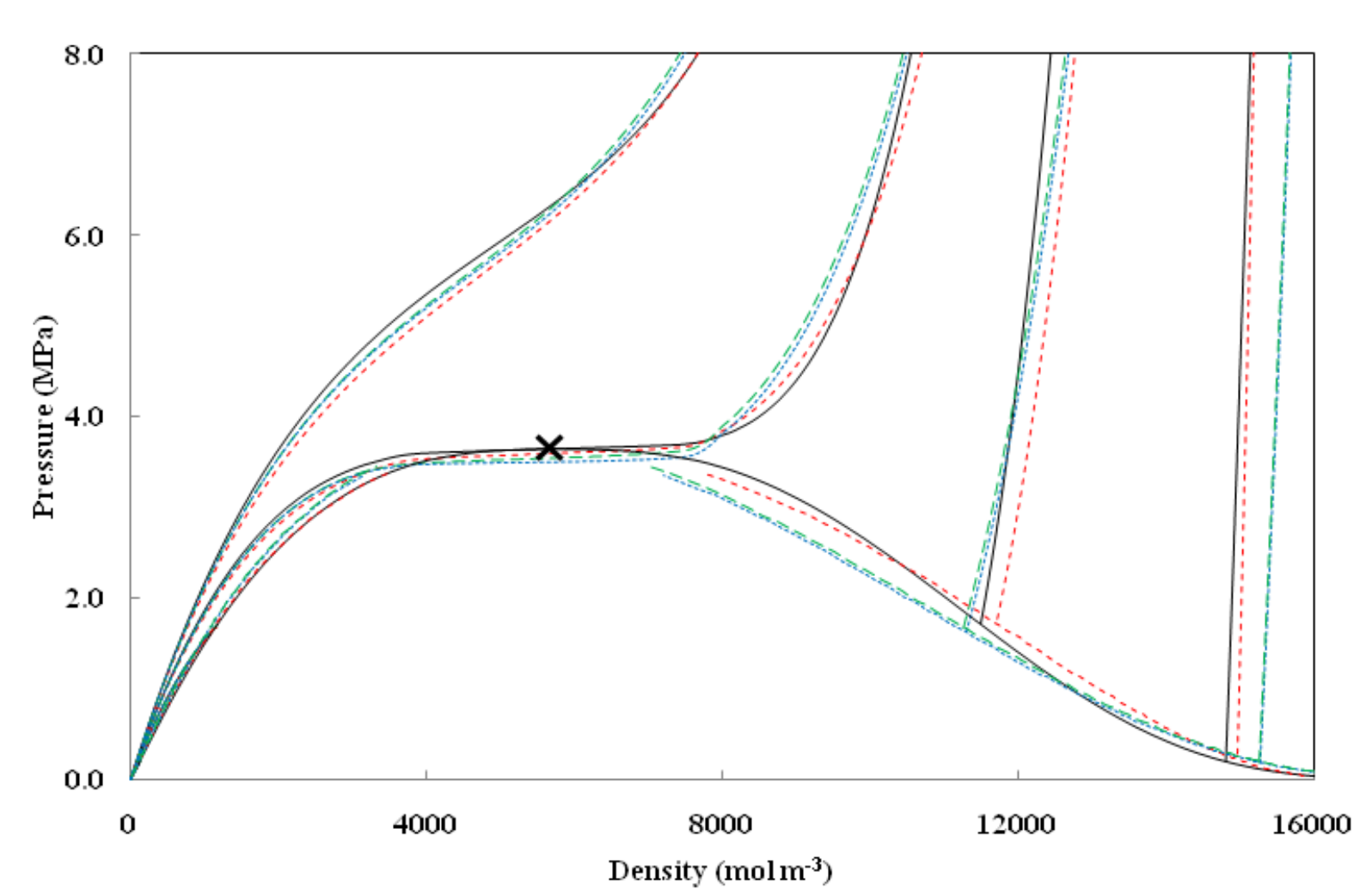

Fig. 41 - P- $\rho$ diagram for R-508A.

(一) REFPROP; $(\times)$ Critical Point: REFPROP $\left(T_{c}=283.34 K\right)$; (- - - ) NEoS; (.....) PT-EoS; $(---)$ PR-EoS. Out of saturation: $T_{r}=0.7,0.9,1.0,1.1$. 


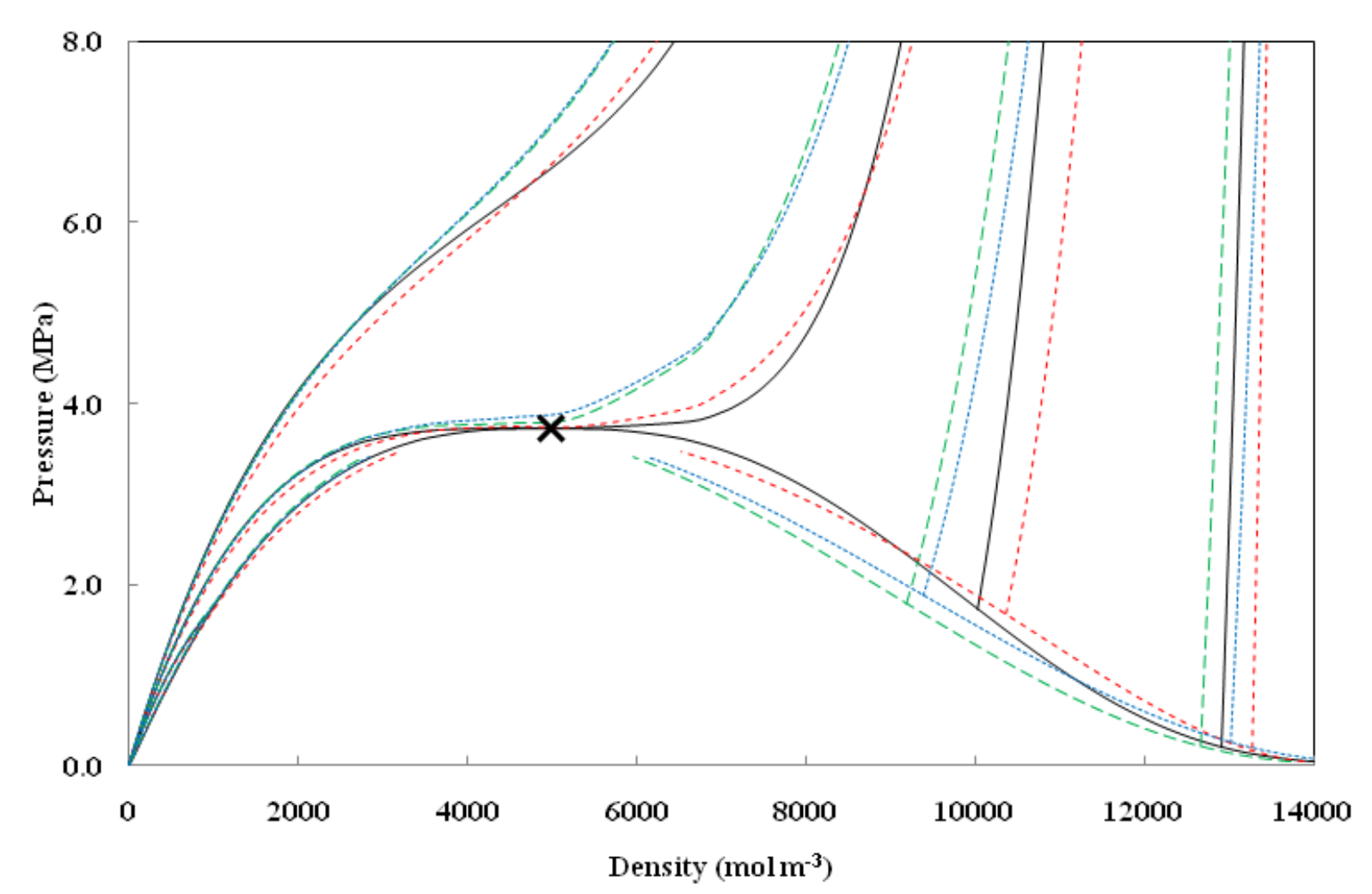

Fig. 42 - P- $\rho$ diagram for R-404A.

(-) REFPROP; $(\times)$ Critical Point: REFPROP $\left(\mathrm{T}_{\mathrm{c}}=345.2 \mathrm{~K}\right)$; (- - - -) NEoS; (......) PT-EoS; $(---)$ PR-EoS. Out of saturation: $T_{r}=0.7,0.9,1.0,1.1$. 


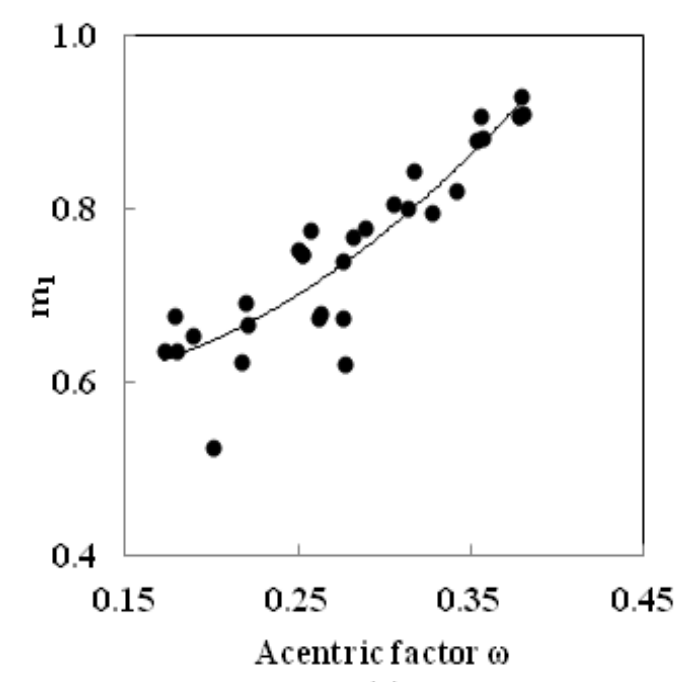

(a)

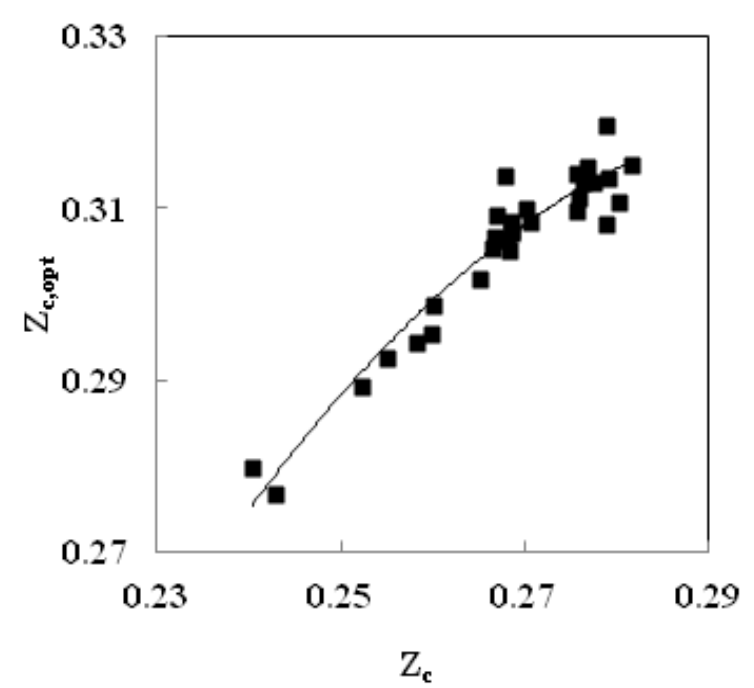

(b)

Fig. A.1 - Correlations obtained with the PT-EoS. (a): the $m_{1}$ parameter as a function of the acentric factor $\omega$ (coefficient of determination $R^{2}=0.83$ ). (b): the optimized critical compressibility factor $Z_{c, o p t}$ as a function of the experimental critical compressibility factor $Z_{c}\left(\right.$ coefficient of determination $\left.R^{2}=0.92\right)$. 


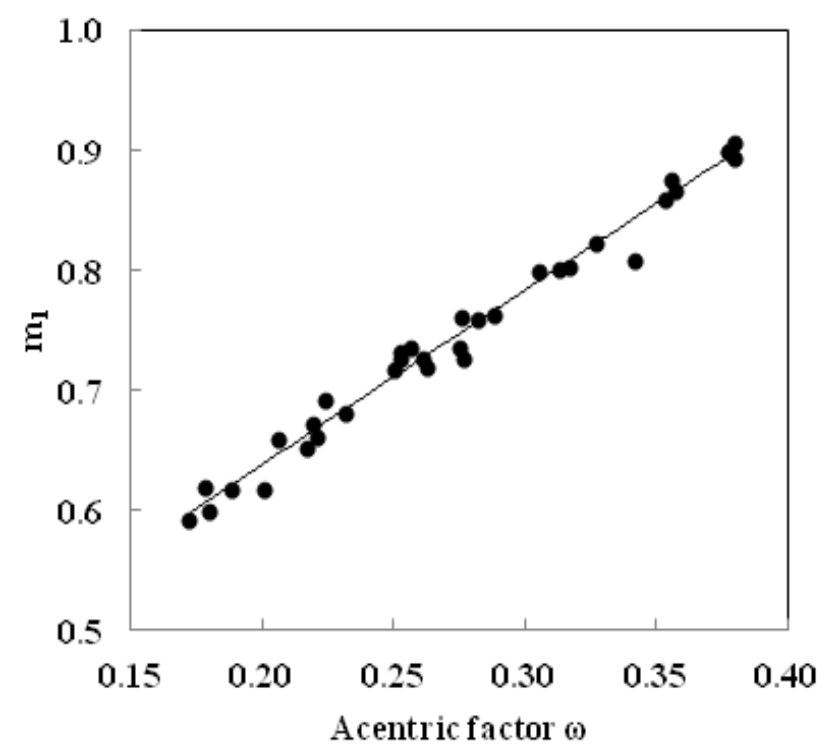

Fig. B.1 - Correlation obtained with the PR-EoS: $m_{1}$ parameter as a function of the acentric factor $\omega$ (coefficient of determination $R^{2}=0.98$ ). 
Prediction of thermodynamic properties of refrigerant fluids with a new threeparameter cubic equation of state

Prédiction des propriétés thermodynamiques des fluides frigorigènes avec une nouvelle équation d'état cubique à trois paramètres

\section{Christophe Coquelet, Jamal El Abbadi, Céline Houriez}

Mines ParisTech, PSL Research University, CTP - Centre Thermodynamique des Procédés, 35 rue Saint Honoré, 77305 Fontainebleau Cedex, France

Table A.9 - $\mathrm{k}_{\mathrm{ij}}$ values used with the NEoS and PR-EoS, for the azeotropic and supercritical systems.

\begin{tabular}{|c|c|c|c|}
\hline & \multicolumn{3}{|c|}{ Binary interaction parameter $k_{i j}$} \\
\hline Systems & $\mathbf{T}(\mathbf{K})$ & NEoS & PR-EoS \\
\hline \multirow{8}{*}{$\mathrm{SO}_{2}+\mathrm{R}-32$} & 288.07 & 0.0030 & -0.0189 \\
\hline & 303.16 & 0.0044 & -0.0152 \\
\hline & 323.15 & 0.0008 & -0.0183 \\
\hline & 343.15 & -0.0035 & -0.0191 \\
\hline & 353.15 & -0.0067 & -0.0205 \\
\hline & 363.15 & -0.0031 & -0.0188 \\
\hline & 383.18 & -0.0082 & -0.0036 \\
\hline & 403.16 & -0.0165 & -0.0133 \\
\hline \multirow{8}{*}{$\mathrm{CO}_{2}+\mathrm{R}-32$} & 283.12 & -0.0023 & 0.0196 \\
\hline & 293.11 & 0.0030 & 0.0212 \\
\hline & 303.13 & 0.0068 & 0.0373 \\
\hline & 305.15 & 0.0008 & 0.0167 \\
\hline & 313.30 & -0.0028 & 0.0174 \\
\hline & 323.34 & 0.0189 & 0.0276 \\
\hline & 333.33 & 0.0119 & 0.0363 \\
\hline & 343.23 & 0.0129 & 0.0600 \\
\hline \multirow{5}{*}{ R-23 + R-116 } & 194.33 & 0.0890 & 0.1025 \\
\hline & 199.71 & 0.0901 & 0.1033 \\
\hline & 214.90 & 0.0907 & 0.1043 \\
\hline & 229.63 & - & 0.1068 \\
\hline & 244.94 & - & - \\
\hline \multirow{4}{*}{ Isopentane + R-365mfc } & 363.12 & 0.1168 & 0.1233 \\
\hline & 393.22 & 0.1161 & 0.1250 \\
\hline & 373.20 & 0.1189 & 0.1261 \\
\hline & 413.09 & 0.1111 & 0.1218 \\
\hline \multirow{4}{*}{ R-23 + butane } & 283.15 & 0.1915 & 0.2012 \\
\hline & 293.15 & 0.1904 & 0.2007 \\
\hline & 303.15 & 0.1885 & 0.1993 \\
\hline & 313.15 & 0.1905 & 0.2023 \\
\hline
\end{tabular}




\begin{tabular}{llll}
\hline & 363.12 & 0.1168 & 0.1233 \\
Isopentane + R-245fa & 393.22 & 0.1161 & 0.1250 \\
& 373.20 & 0.1189 & 0.1261 \\
& 413.09 & 0.1111 & 0.1218 \\
\hline
\end{tabular}




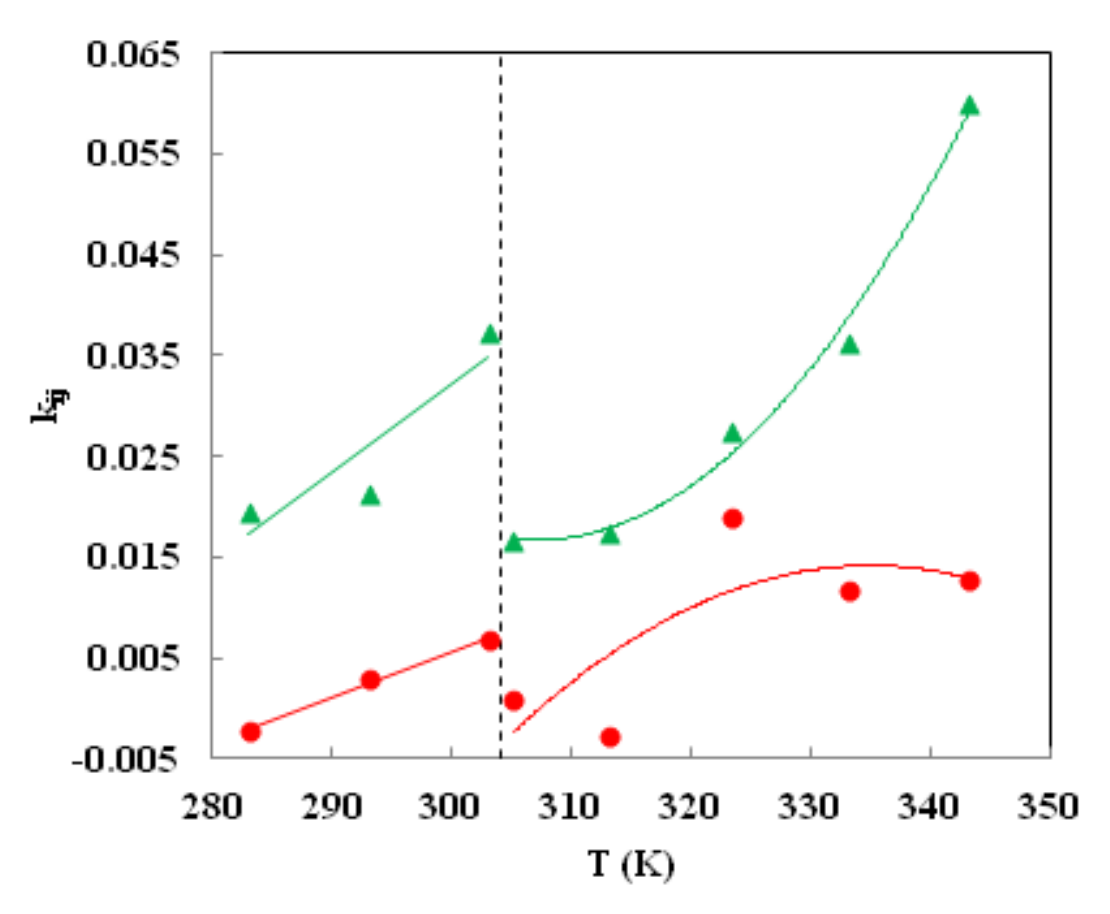

Fig. A.43 - $\mathrm{k}_{\mathrm{ij}}$ as a function of temperature: $\mathrm{CO}_{2}+\mathrm{R}-32$.

(•) NEoS; ( $\triangle$ ) PR-EoS;

$\left.(--)^{-}\right) \mathrm{CO}_{2}$ critical temperature $\left(\mathrm{T}_{\mathrm{c}}=304.13 \mathrm{~K}\right)$. 


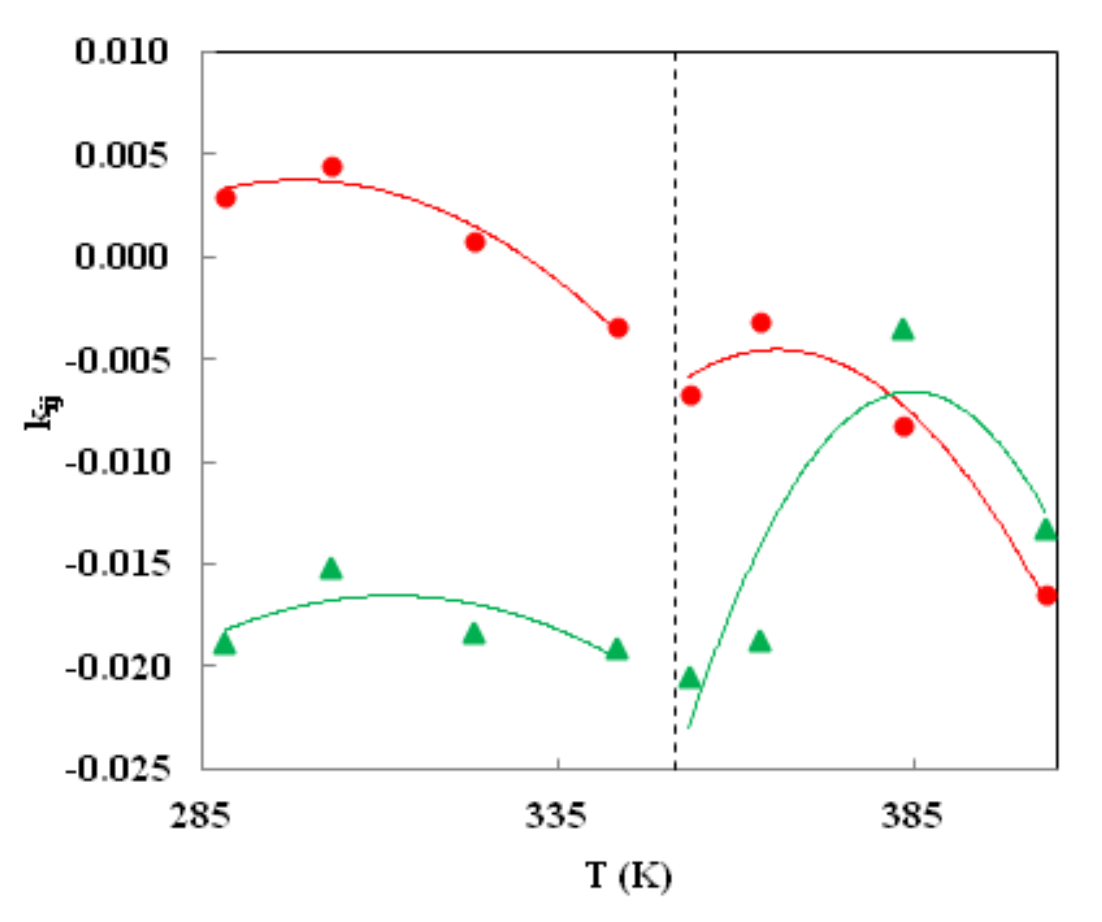

Fig. A.44 $-\mathrm{k}_{\mathrm{ij}}$ as a function of temperature: $\mathrm{SO}_{2}+\mathrm{R}-32$.

(•) NEoS; ( $\triangle$ ) PR-EoS;

$\left(--\right.$ - ) $R$-32 critical temperature $\left(T_{c}=351.26 \mathrm{~K}\right)$. 


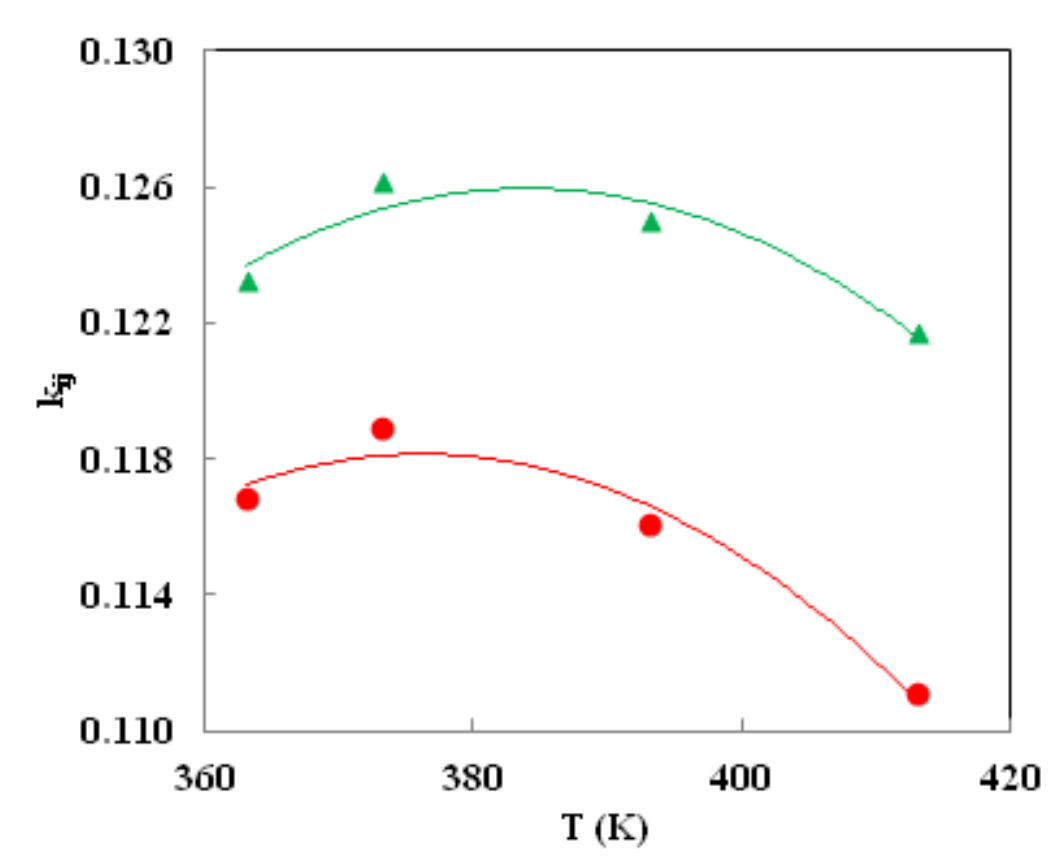

Fig. A.45 - $k_{i j}$ as a function of temperature: isopentane + R-365mfc. (•) NEoS; ( $\triangle$ ) PR-EoS. 


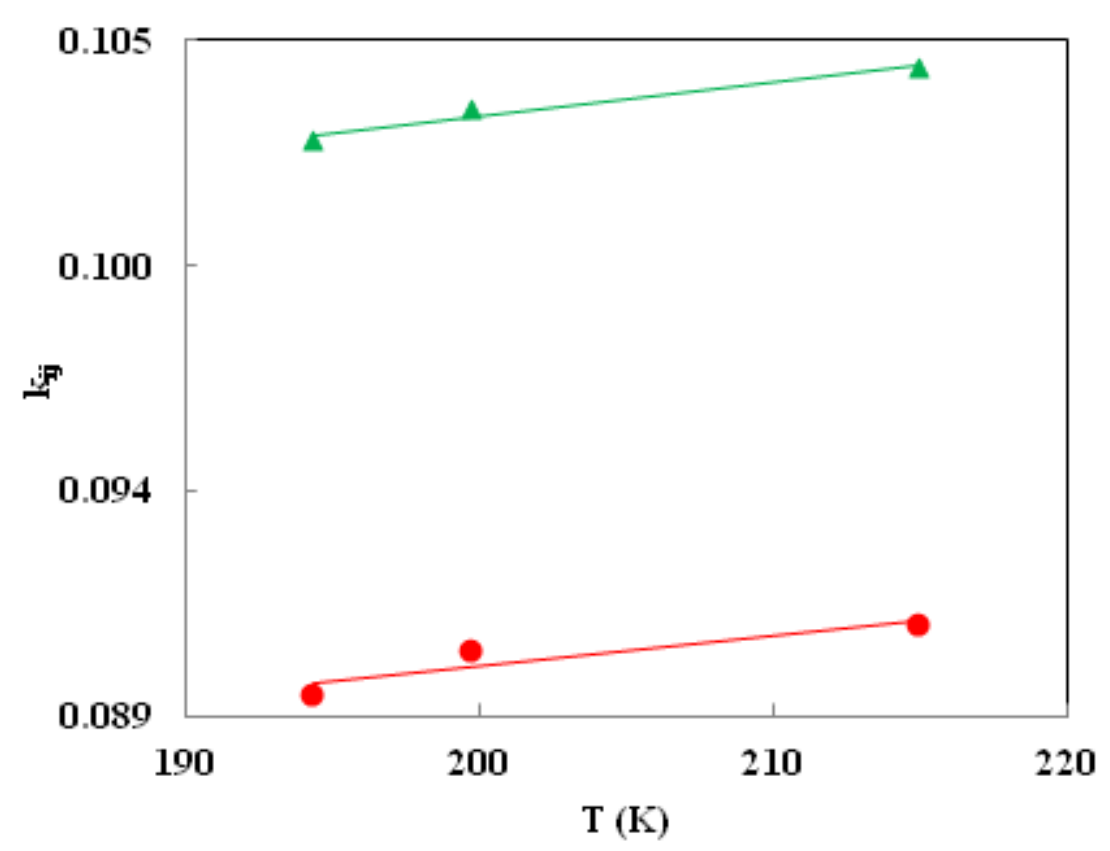

Fig. A.46 - $k_{\mathrm{ij}}$ as a function of temperature:

$$
\text { R-23 + R-116. }
$$

(•) NEoS; ( $\triangle$ ) PR-EoS. 


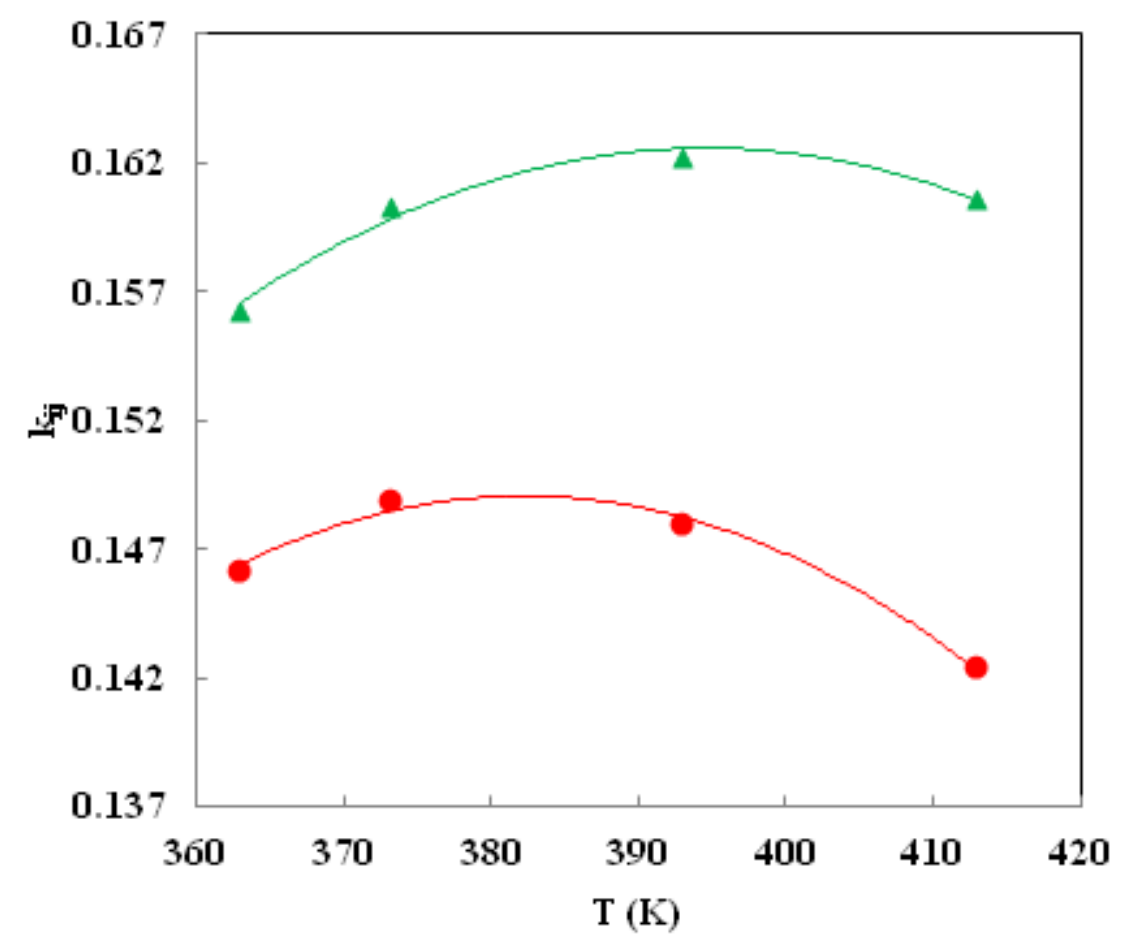

Fig. A.47 - $k_{\mathrm{ij}}$ as a function of temperature: isopentane + R-245fa.

(•) NEoS; ( $\triangle$ ) PR-EoS. 


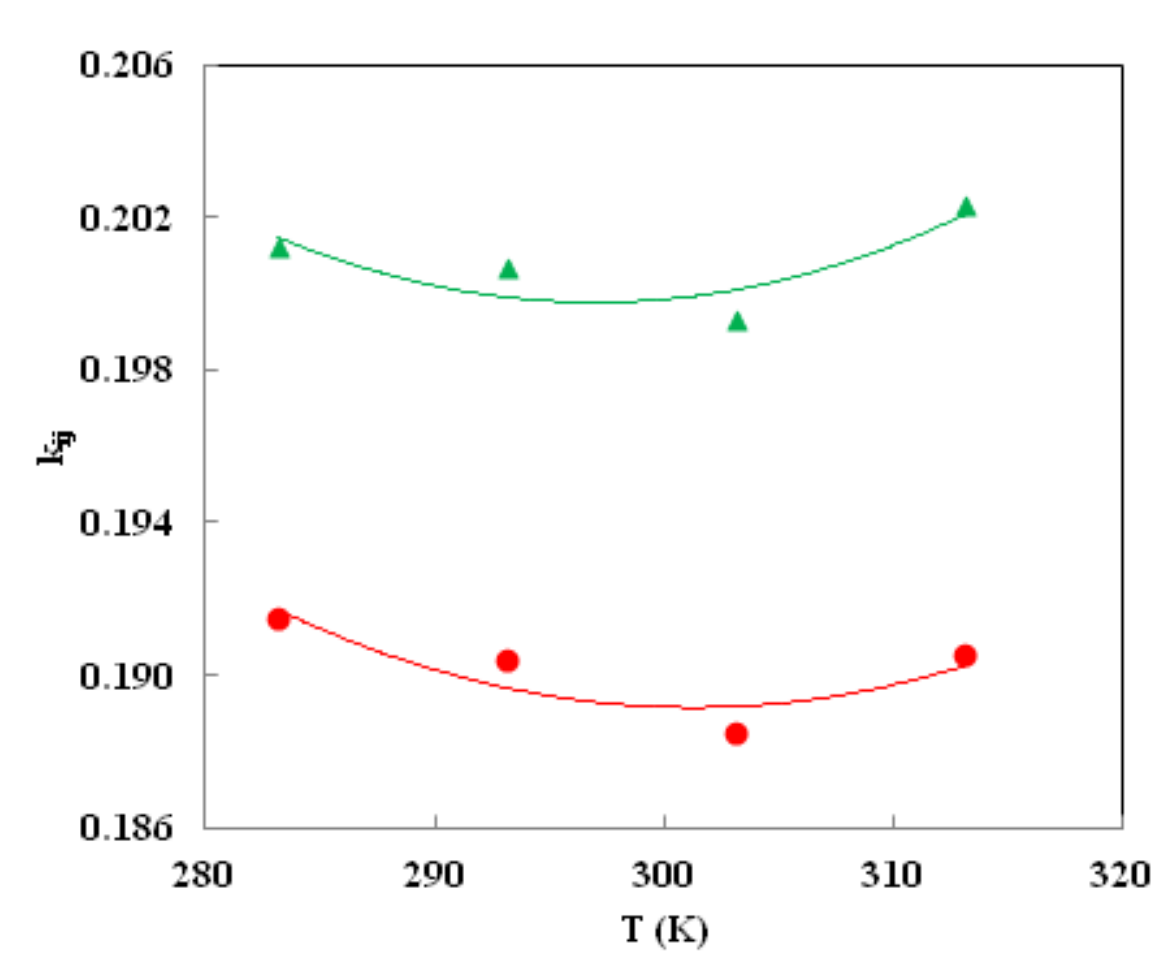

Fig. A.48 - $k_{i j}$ as a function of temperature: R-23 + butane.

(•) NEoS; ( $\triangle$ ) PR-EoS. 


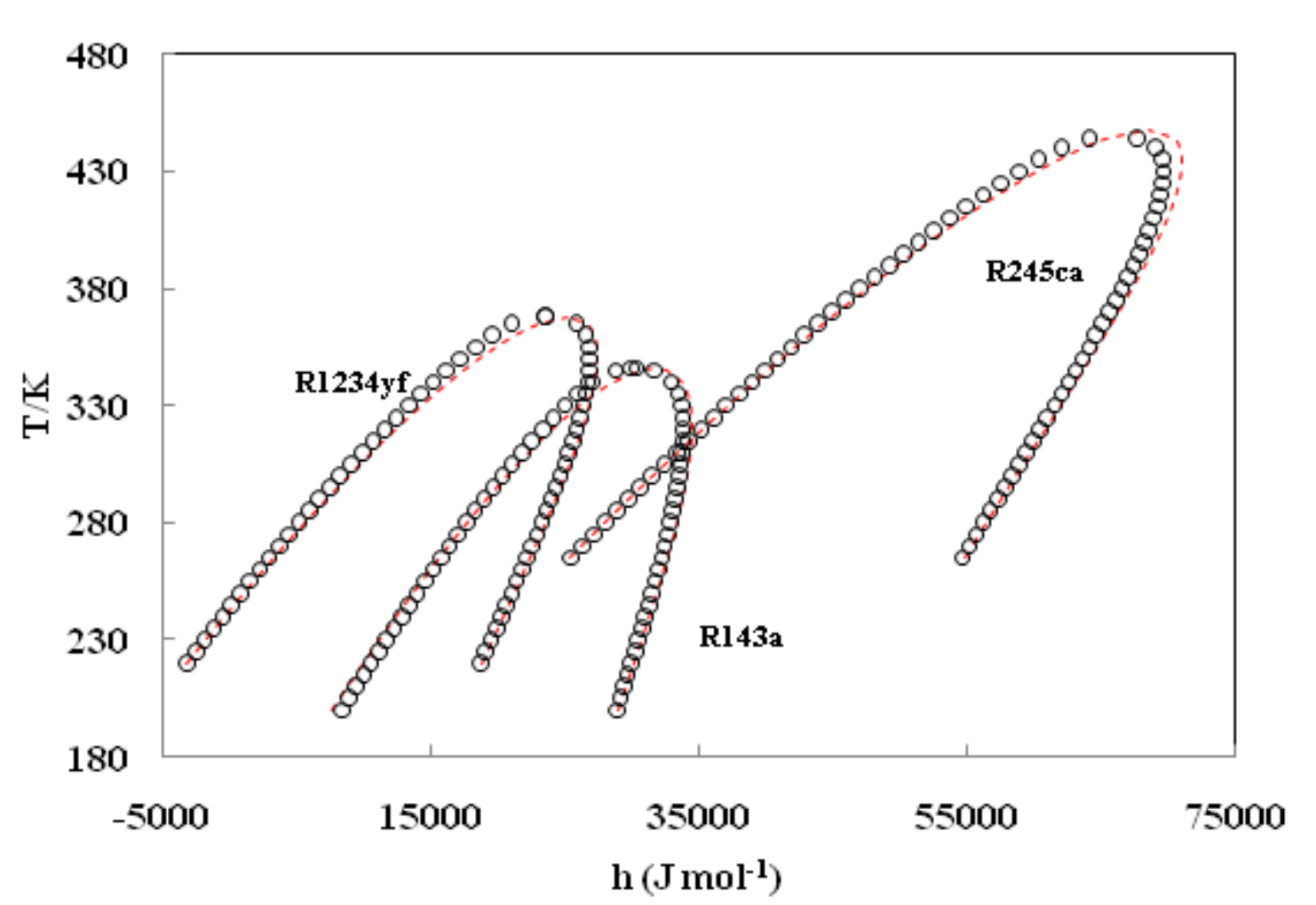

Fig. A.49 - Enthalpies of saturated phases. (०) REFPROP. (- - - -) NEoS. 


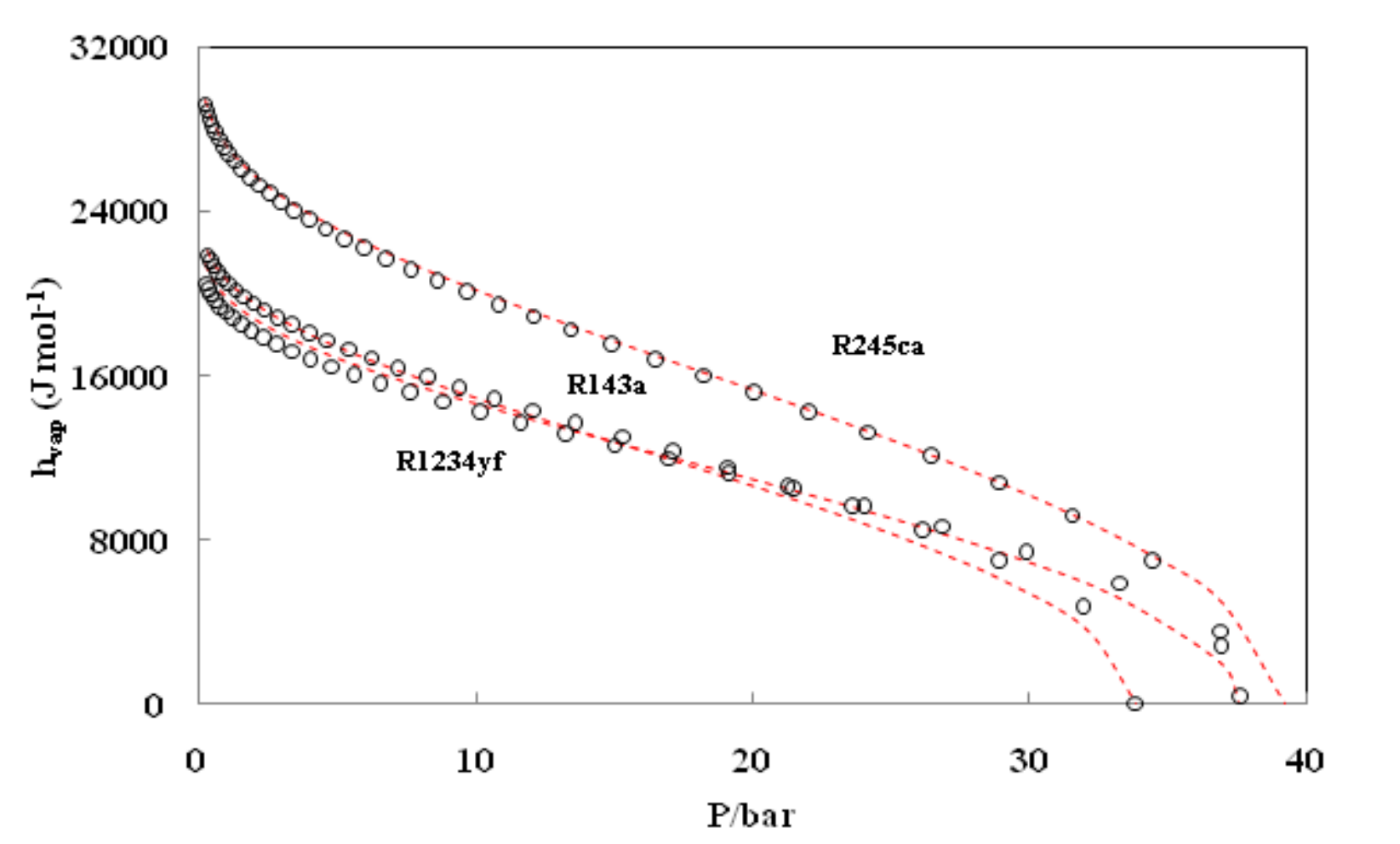

Fig. A.50 - Enthalpies of vaporization. (०) REFPROP; (- - - ) NEoS. 


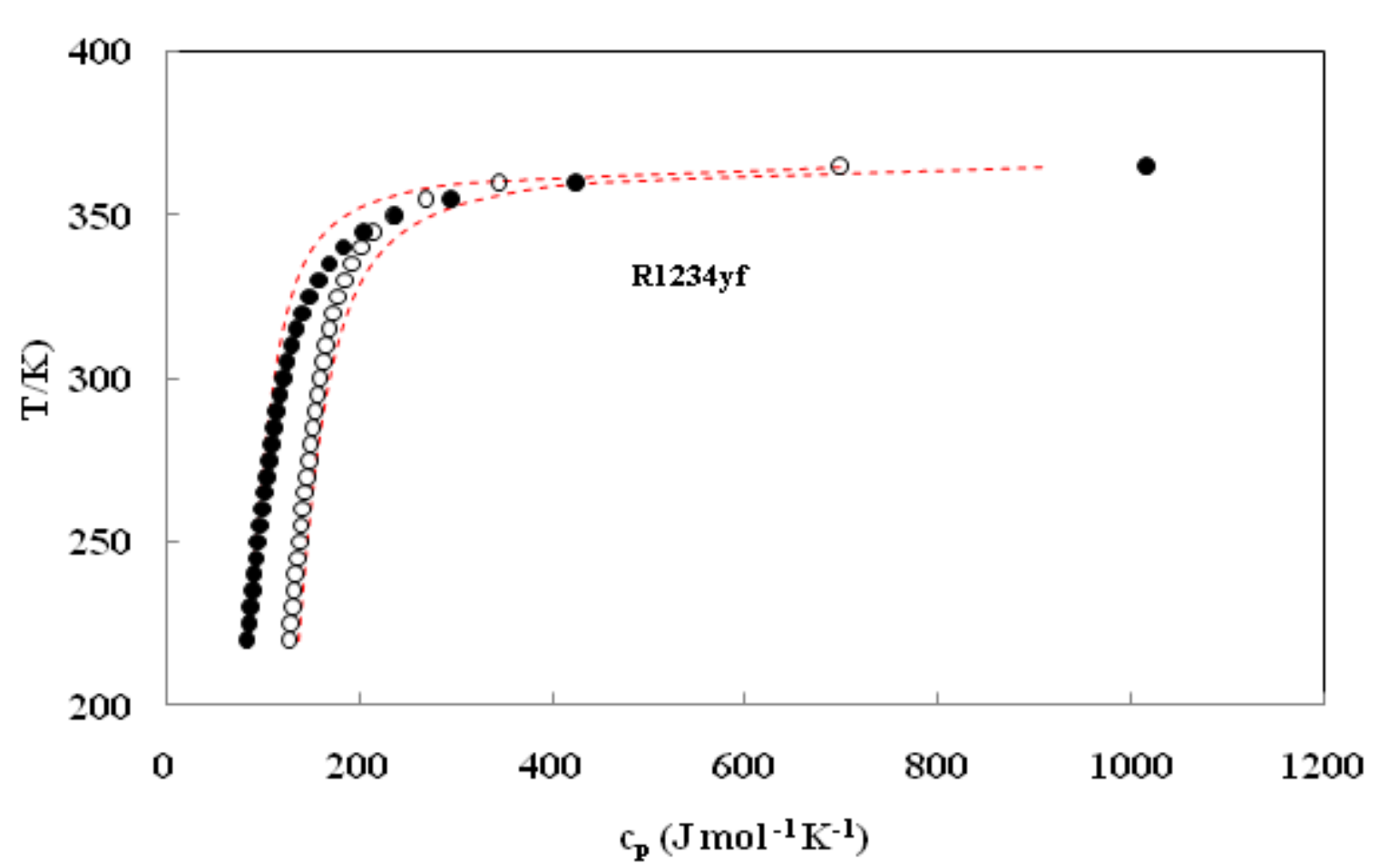

Fig. A.51 - Isobaric heat capacities of saturated phases. ( $\bigcirc)$ Liquid, (•) Vapor - REFPROP; (- - - -) NEoS. 


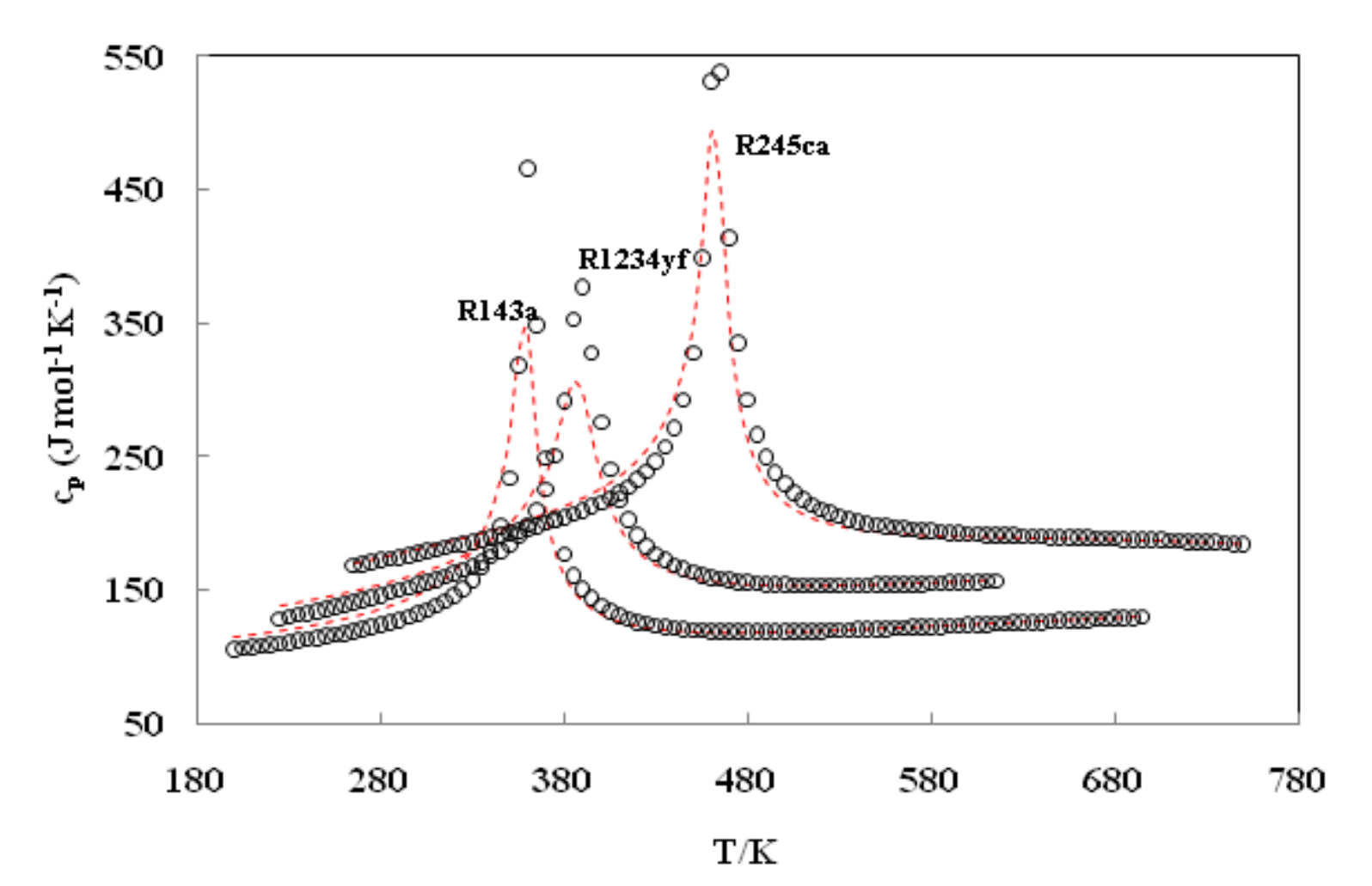

Fig. A.52 - Isobaric heat capacities at P = 5 MPa. ( () REFPROP; (- - - -) NEoS. 